\title{
Greenhouse gas emissions from international aviation - Nordic perspectives
}

\section{Part I and Part II}

By COWI Consultancy within Engineering, Environvent and Economics

TemaNord 2004:533 


\section{Greenhouse gas emissions from international aviation - Nordic perspectives}

TemaNord 2004:533

(C) Nordic Council of Ministers, Copenhagen 2004

ISBN 92-893-1026-X

ISSN 0908-6692

Print: Ekspressen Tryk \& Kopicenter

Coverphoto: Lars Johansson

Copies: 300

Printed on paper approved by the Nordic Environmental Labelling.

This publication may be purchased from any of the sales agents listed on the last page.

\author{
Nordic Council of Ministers \\ Store Strandstræde 18 \\ DK-1255 Copenhagen K \\ Phone $(+45) 33960200$ \\ Fax $\quad(+45) 33960202$
}

\author{
Nordic Council \\ Store Strandstræde 18 \\ DK-1255 Copenhagen K \\ Phone (+45) 33960400 \\ Fax $\quad(+45) 33111870$
}

\section{www.norden.org}

\section{Nordic co-operation in the transport sector}

The overall, general objective of co-operation is to foster a Nordic transport sector characterised by efficiency, competitiveness, safety, sustainability, and equality. In order to attain these objectives with the resources available, co-operation will be focussed on four areas: Sustainable Mobility, The Baltic Sea, Intelligent Transport Systems and Transport Safety.

\section{The Nordic Council of Ministers}

was established in 1971. It submits proposals on co-operation between the governments of the five Nordic countries to the Nordic Council, implements the Council's recommendations and reports on results, while directing the work carried out in the targeted areas. The Prime Ministers of the five Nordic countries assume overall responsibility for the co-operation measures, which are co-ordinated by the ministers for co-operation and the Nordic Co-operation committee. The composition of the Council of Ministers varies, depending on the nature of the issue to be treated.

\section{The Nordic Council}

was formed in 1952 to promote co-operation between the parliaments and governments of Denmark, Iceland, Norway and Sweden. Finland joined in 1955. At the sessions held by the Council, representatives from the Faroe Islands and Greenland form part of the Danish delegation, while Åland is represented on the Finnish delegation. The Council consists of 87 elected members - all of whom are members of parliament. The Nordic Council takes initiatives, acts in a consultative capacity and monitors co-operation measures. The Council operates via its institutions: the Plenary Assembly, the Presidium and standing committees. 
Part I:

Data availability, emission calculation methodologies and allocation methods 



\section{Table of Contents}

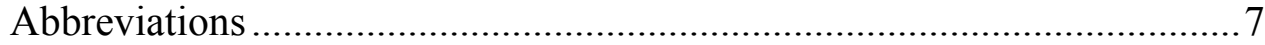

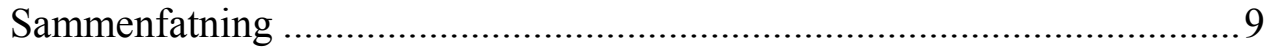

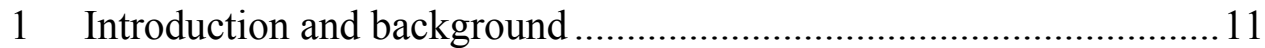

2 Objective and methodology .............................................................. 13

3 IPCC/UNFCCC reporting guidelines and associated

methodologies and data sources...................................................... 15

3.1 UNFCCC/IPCC reporting requirements ...................................... 15

3.2 Methodologies and data sources ............................................... 15

3.3 Annex I country reporting performance .................................... 20

4 International methodological frameworks and data sources

for emissions calculation and reporting .............................................2. 23

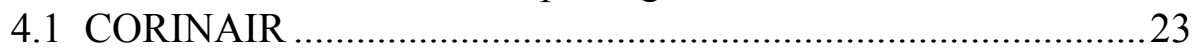

4.2 The TRENDS project.............................................................. 24

4.3 Eurostat support for harmonization of data reported to

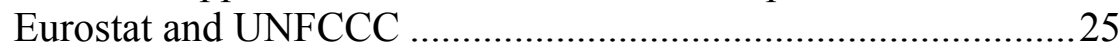

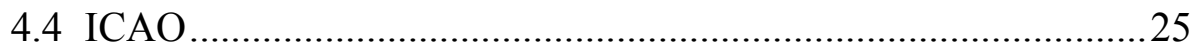

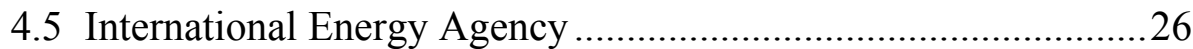

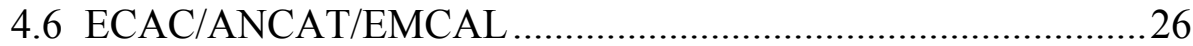

4.7 UNECE Long Range Transboundary Air Pollution Convention. 26

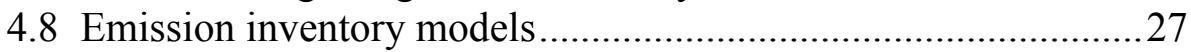

4.9 Airline companies ....................................................................2 27

4.10 Other methodological frameworks and data sources .................27

5 Major issues in relation to data and methodologies...........................29

5.1 Separation of national and international bunker fuels ................29

5.2 The importance of cruising altitude and non-CO2 emissions...... 31

5.3 Separation of fuel consumed by military aircraft from fuel

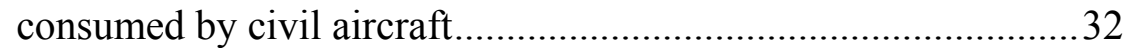

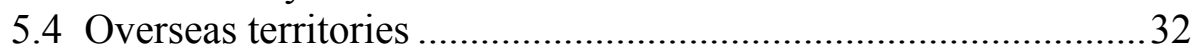

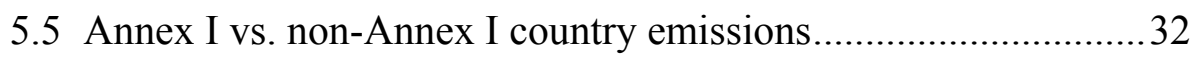

5.6 Passenger/freight loads and their origin/destination.....................33

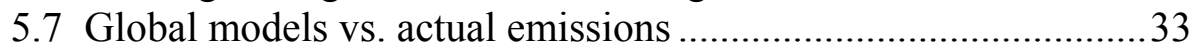

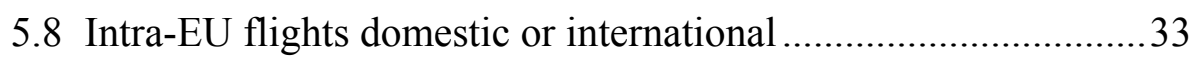

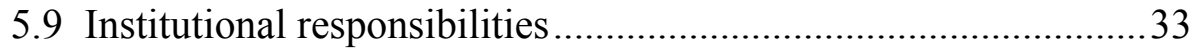

6 Methodologies and data for the Nordic countries............................... 35

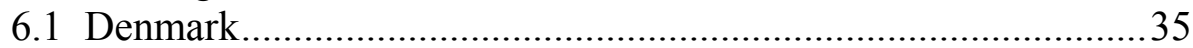

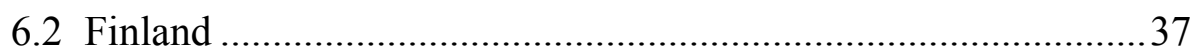

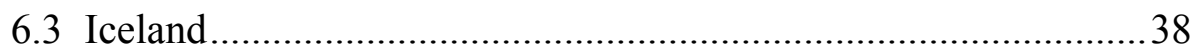

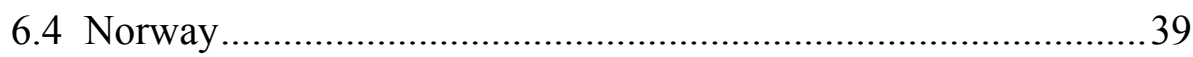

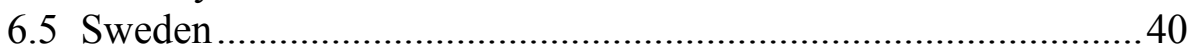


7 Methods for allocating emissions to parties ................................... 43

7.1 No allocation to Parties ............................................................... 43

7.2 Allocation to Parties according to the country where the bunker fuel is sold ............................................................. 45

7.3 Allocation to Parties according to the nationality of the airline .. 45

7.4 Allocation to parties according to the country of destination or departure of the aircraft

7.5 Allocation to Parties according to the country of destination or departure of passengers and cargo ............................................ 46

7.6 Status of international discussions about allocation methods...... 47

8 Principles and criteria for assessing allocation methods .................. 49

8.1 Allocation should be in accordance with the "Polluter Pays Principle"

8.2 Allocation should lead to minimum trade distortion among companies

8.3 Allocation should reflect that only Annex I countries have

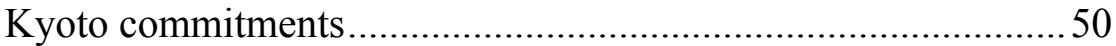

8.4 Allocation should be comprehensive in terms of relevant greenhouse gases and radiative forcing ....................................50

8.5 Allocation should enable regulation of emissions by responsible authorities ............................................................. 51

8.6 Allocation should not encourage strategic behaviour.................53

8.7 Allocation should be administratively feasible............................53

8.8 Overview of allocation methods and evaluation criteria .............53

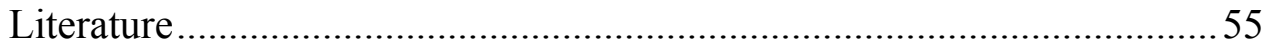


Abbreviations

$\begin{array}{ll}\text { ANCAT } & \begin{array}{l}\text { Group of Experts on the Abatement of Nuisances Caused by } \\ \text { Air Transport (under ECAC) }\end{array} \\ \begin{array}{l}\text { Annex I coun- } \\ \text { tries }\end{array} & \begin{array}{l}\text { Industrialised countries under the UNFCCC (and for simplicity } \\ \text { assumed to be identical to Annex B countries under the Kyoto }\end{array} \\ \text { Protocol) } \\ \text { CAEP } & \text { Committee on Aviation Environmental Protection } \\ \text { COP } & \text { Conference of the Parties (of UNFCCC) } \\ \text { CORINAIR } & \text { CORe INventory of AIR emissions } \\ \text { ECAC } & \text { European Civil Aviation Conference } \\ \text { EEA } & \text { European Environment Agency } \\ \text { EMCAL } & \text { ANCAT Subgroup on Emissions Calculations } \\ \text { EMEP } & \text { European Union Emission Inventory Programme } \\ \text { IATA } & \text { International Air Transport Association } \\ \text { ICAO } & \text { International Civil Aviation Organization } \\ \text { IEA } & \text { International Energy Agency } \\ \text { IPCC } & \text { Intergovernmental Panel on Climate Change } \\ \text { LTO } & \text { Landing and Take Off } \\ \text { NIR } & \text { National Inventory Report } \\ \text { SBSTA } & \text { Subsidiary Body for Scientific and Technological Advice } \\ \text { TRENDS } & \text { Transport and Environment Database System Project } \\ \text { UNECE } & \text { United Nations Economic Commission for Europe } \\ \text { UNFCCC } & \text { United Nations Framework Convention on Climate Change }\end{array}$




\section{Sammenfatning}

Resumé og konklusioner

Denne rapport er udarbejdet for Arbejdsgruppen om Bæredygtig Mobilitet under Nordisk Ministerråd.

Rapporten giver et overblik over og en vurdering af data og metoder til beregning og afrapportering af energiforbrug og drivhusgasudslip fra international luftfart. Endvidere diskuteres mulighederne for allokeringen af disse udslip til de nordiske lande. Der er lagt vægt på evalueringen af muligheder, fordele og ulemper ved de forskellige metoder og principper for allokering til de nordiske lande.

$\mathrm{CO}_{2}$-udslip fra international luftfart er ikke dækket af reduceringsforpligtigelserne i Kyotoprotokollen. Udslippene fra international luftfart er i kraftig vækst, og hvis de skal indarbejdes i Protokollens Anneks 1-landes reduktionsforpligtigelser, er det vigtigt at de allokeres til parter, som er eller bliver ansvarlige for protokollens reduktionskrav.

De nordiske lande lægger stor vægt på at øge viden om og allokeringen af drivhusgasudslippene fra international luftfart, og Arbejdsgruppen om Bæredygtig Mobilitet har derfor bestilt denne rapport fra konsulentfirmaet COWI.

\section{Konklusioner}

Med udgangspunkt i både en kvalitativ og en kvantitativ vurdering af forskellige metoder til allokering af drivhusgasser fra international luftfart kan der drages følgende generelle konklusioner:

Emission af drivhusgasser fra luftfart består af en række gasser, herunder $\mathrm{CO}_{2}, \mathrm{~N}_{2} \mathrm{O}$, metan og damp. Samlet bidrager disse gasser sandsynligvis 2-4 gange mere til klimaændringer end $\mathrm{CO}_{2}$-udslippet alene. Dette er vigtig at holde sig for øje, da det samlede udslip af drivhusgasser og effekten heraf kan påvirkes af flyadfærden. Flyselskaberne har således forskellige muligheder for at reducere udslippet og/eller effekten heraf. Denne rapport omhandler dog udelukkende CO2-udslippet.

Allokering, forpligtelser og regulering kan ikke adskilles. Det er reduktionsforpligtelserne, der gør allokeringen vigtig. Om allokeringen til en part (f.eks. et land) er en fordel eller en ulempe afhænger naturligvis af den pågældende parts forpligtigelser og af, at der er realistiske reguleringsmuligheder.

Der eksisterer en række forskellige allokeringsmetoder, som enten allokerer $\mathrm{CO}_{2}$-udslip til landene eller til selve luftfartindustrien. Nogle metoder er mindre attraktive fordi de kræver store datamængder, andre kan være problematiske for landene mangler tilstrækkelige muligheder for regulering. Der er en risiko for, at det er svært at modsvare allokering til landene med tilstrækkelige nationale muligheder for regulering. Industrien er meget mobil og opererer globalt, hvilket vanskeliggør national regulering. F.eks. kan CO2-afgifter give luftfartselskaberne incitament til at ændre ruter og optankningsvaner for at undgå beskatning. 
Unilateral regulering øger risikoen for at luftfartmarkedet forvrides og er derfor svær at indføre. Risikoen for forvridninger er mindre ved multilateral regulering, f.eks. på EUniveau, eller i tilfælde af branchemæssige forpligtelser og regulering.

Meget taler for et branchemæssigt allokerings- og forpligtelsessystem, især pga. branchernes adgang til relevant data og bedre muligheder for at regulere udslippene uden at forvride luftfartsmarkedet. Den er en stigende interesse i den europæiske luftfartsbranche for at etablere et kvotehandelssystem, eventuelt i forbindelse med det kommende EU $\mathrm{CO}_{2}$ kvotemarked.

Samlet set er allokeringen af $\mathrm{CO}_{2}$ til de nordiske lande 7 \% højere, når der allokeres efter de nordiske flyselskabers brændstofforbrug, end når der allokeres efter salget af bunker brændstof i hvert enkelt land. Der er dog væsentlige forskelle mellem de nordiske lande. Således er allokeringen større til Finland og Island, når der allokeres efter flyselskabets nationalitet, hvorimod der er større allokering til Danmark, når der allokeres efter salg af bunker brændstof.

Et allokeringssystem der baseres på flyvninger til og fra lande i Anneks 1 i Kyotoprotokollen omfatter $85 \%$ af $\mathrm{CO}_{2}$-udslippet fra de nordiske flyselskabers internationale luftfart. De resterende $15 \%$ udgøres af flyvninger til lande, der ikke er Anneks 1-lande. 


\section{Introduction and background}

The present Report has been produced as part of a Study for the Working Group on Sustainable Mobility under the Nordic Council of Ministers.

The Study includes a review and assessment of the data and methodologies in relation to calculation and reporting of the energy consumption and greenhouse gas emissions from international aviation, as well as issues related to allocation of these emissions to countries. The emphasis is on the assessment of opportunities, advantages and disadvantages of the different methodologies and principles for allocation to the Nordic countries.

$\mathrm{CO}_{2}$ emissions from international aviation are not covered by the reduction and limitation commitments under the Kyoto Protocol. However, the emissions from international aviation are growing rapidly, and if they are to be included in the reduction efforts by Annex I countries, they will have to be allocated to parties who are or will become responsible in relation to the reduction commitments of the Protocol.

The issue has been dealt with on a continuous basis in the UNFCCC negotiations, and will be dealt with at SBSTA (the UNFCCC Subsidiary Body for Scientific and Technological Advice) 20 in the summer of 2004. On behalf of the Community, the European Commission has expressed the wish that bunker fuels be included in the Kyoto Protocol from the second commitment period starting in 2013.

The Nordic governments similarly support the inclusion of emissions from international aviation in the KP, and therefore are interested in an analysis and assessment of the options for quantifying and allocating the emissions from international aviation to the Nordic countries.

Article 2, Paragraph 2 of the Kyoto Protocol states that "The Parties included in Annex I shall pursue limitation or reduction of emissions of greenhouse gases not controlled by the Montreal Protocol from aviation and marine bunker fuels, working through the International Civil Aviation Organization (ICAO) and the International Maritime Organization, respectively". ICAO has subsequently agreed upon a working programme in this area, implemented through its Committee on Aviation Environmental Protection (CAEP). 


\section{$\underline{2}$ Objective and methodology}

The overall objective of the Study is to contribute to a common understanding among the Nordic countries regarding the inclusion of greenhouse gases from international aviation in the UNFCCC and its Kyoto Protocol.

The immediate objective is to:

- Identify the availability and quality of data reported to UNFCCC by the Nordic countries on emissions from international aviation

- Identify and assess different opportunities, advantages and disadvantages of different methods to allocate emissions to countries, seen from a Nordic perspective. The assessment of alternative methods will be based on principles and criteria that are of relevance to the Nordic countries.

The methodological approach of the Study has been to focus on three elements, the first two of which are reported in Part I of the Report, while the second is reported in Part II:

\section{Part I:}

\section{Data availability and emission calculation methodologies}

The existing data available to the Nordic countries for their assessment of energy consumption and GHG emissions have been described along with the methodologies applied to the calculation of emissions from domestic and international aviation.

According to the IPCC/UNFCCC guidelines, the Annex I countries should include emissions from international aviation in their inventories. However, SBSTA has noted that the quality of reporting by Annex I Parties on bunker fuel emissions needs to be improved. In particular, issues related to the calculation of domestic vs. international emissions are a cause of concern.

\section{Allocation of emissions to countries}

SBSTA has considered various methods for allocating emissions and has selected a number of these for further consideration. These include:

A. No allocation

B. Allocation to the country where the fuel is sold

C. Allocation to the nationality of airlines

D. Allocation to the country of destination or departure of aircraft

E. Allocation to Parties according to the country of departure or destination of passenger or cargo.

An important activity is to establish a number of principles and criteria against which the above methodologies can be assessed. These principles and criteria are defined on the basis of existing considerations among the Nordic countries, within UNFCCC and within the international aviation community, e.g. ICAO and CAEP. 


\section{Part II:}

\section{Assessment of allocation methodologies}

The assessment of allocation methods includes two main activities:

- An evaluation of the proposed allocation methods against the principles and criteria identified.

The purpose of this exercise has been to get a picture of how the individual methods perform in relation to the established criteria. The assessment is primarily qualitative.

- A quantitative assessment of the consequences of the most relevant methodologies.

Based on existing data, an initial assessment of how the different allocation methods are likely to affect the Nordic countries has been made. For practical reasons, a number of assumptions are made, and the quantitative assessment aims at estimating the order of magnitude of differences in allocation resulting from the selected methods rather than attempting to calculate total emissions for the Nordic countries.

The consultant has consulted key persons and available literature regarding the data and methodological issues. 


\section{$3 \quad$ IPCC/UNFCCC reporting guidelines and associated methodologies and data sources}

\subsection{UNFCCC/IPCC reporting requirements}

All Parties to the Convention shall report national inventories of anthropogenic emissions by sources and removals by sinks of all greenhouse gases not covered by the Montreal Protocol. Parties must report on CO2, CH4, N2O, PFCs, HFCs and SF6. They should also provide information on emissions of CO, NOx and NMVOCs, and are encouraged to provide information on emissions of SO2. The inventory guidelines include definitions, emission estimation methodologies and reporting procedures.

The IPCC guidelines specify that "Parties should also report emissions from international aviation and marine bunker fuels as two separate entries in their inventories". These emissions are reported separately in a table of the Common Reporting Format (CRF) designed for this purpose (table 1.C).

Parties are also asked to explain how they distinguish between domestic and international fuel consumption and emissions in their national inventory reports (NIRs) in the CRF table 1.C. SBSTA has noted that the quality of reporting by Annex I Parties on bunker fuel emissions needs to be improved and has invited the International Civil Aviation Organization (ICAO) to explore opportunities for examining and improving the quality of data reporting and comparability under the relevant provisions of the Convention and the Kyoto Protocol, and under ICAO.

\subsection{Methodologies and data sources}

According to decision 9/CP.2, Annex I Parties are to follow the "Revised 1996 IPCC Guidelines for National Greenhouse Gas Inventories". Furthermore, IPCC has developed additional reporting guidelines that are described in the guidance document "Good Practice Guidance and Uncertainty Management in National Greenhouse Gas Inventories".

According to the IPCC guidelines, fuel use data distinguished between domestic and international aviation may be obtained in different ways. Both bottom-up and top-down data sources should be evaluated.

Bottom-up data can be obtained from:

- surveys of airline companies for fuel used

- aircraft movement data and tables of fuel consumed 
Top-down data can be obtained from:

- national energy statistics

- surveys of airports for data covering the delivery of aviation kerosene and aviation gasoline

- delivery by fuel suppliers of aviation fuel

- production by refineries (production of aviation fuels), corrected for import and export

The calculation of $\mathrm{CO}_{2}$ emissions from fuel combustion may be done at three different levels referred to as Tiers $1,2 \mathrm{a}$ and $2 \mathrm{~b}$ in the IPCC Guidelines. The three methods differ in terms of accuracy, detail and complexity. This is similar to the CORINAIR and

ANCAT/EMCAL reporting guidelines, which are dealt with in subsequent Sections. All methods are based on distinguishing between domestic fuel use and international fuel use.

\section{Tier 1 method}

The Tier I method is a top-down methodology which enables rough estimations of $\mathrm{CO} 2$, $\mathrm{CH} 4, \mathrm{~N} 2 \mathrm{O}, \mathrm{NOx}, \mathrm{CO}$ and NMVOV. Similarly, the method allows the estimation of SOx by the use of assumptions on the sulphur quantities of the fuel. The Tier 1 method concentrates on estimating the emissions from the carbon content of fuels supplied to the country as a whole (the reference approach) or to the main fuel combustion activities (source categories).

The Reference Approach assumes that carbon brought into an economy is either saved or released to the atmosphere. Carbon released is estimated without knowledge on processes undertaken through the transformation. This top-down approach provides only aggregate estimates of emissions by fuel type supplied to the country and does not break down the emissions by sector nor distinguishes between stationary combustion emissions and mobile combustion emissions.

A sectoral breakdown of national $\mathrm{CO}_{2}$ emissions using the defined IPCC source categories is needed for abatement measures and monitoring. Estimates of emissions based on the Reference Approach will not be exactly the same as estimates based on the Sectoral Approach, as emissions are measured at different points.

The Tier 1 method is based on aggregate figures for fuel consumption for civil aviation multiplied by average emissions factors. Only data on fuel consumption are needed, and the resulting emissions are estimated on the basis of fuel consumed and average emission factors based on fleet average values. These emission factors are calculated on the basis of the assumption that $10 \%$ of the fuel is used in the Landing and Take Off (LTO) phase of the flight.

Emissions $=$ Fuel Consumption $\mathrm{x}$ Emission Factor 
The IPCC Good Practice Guidelines provide the following activity data decision tree:

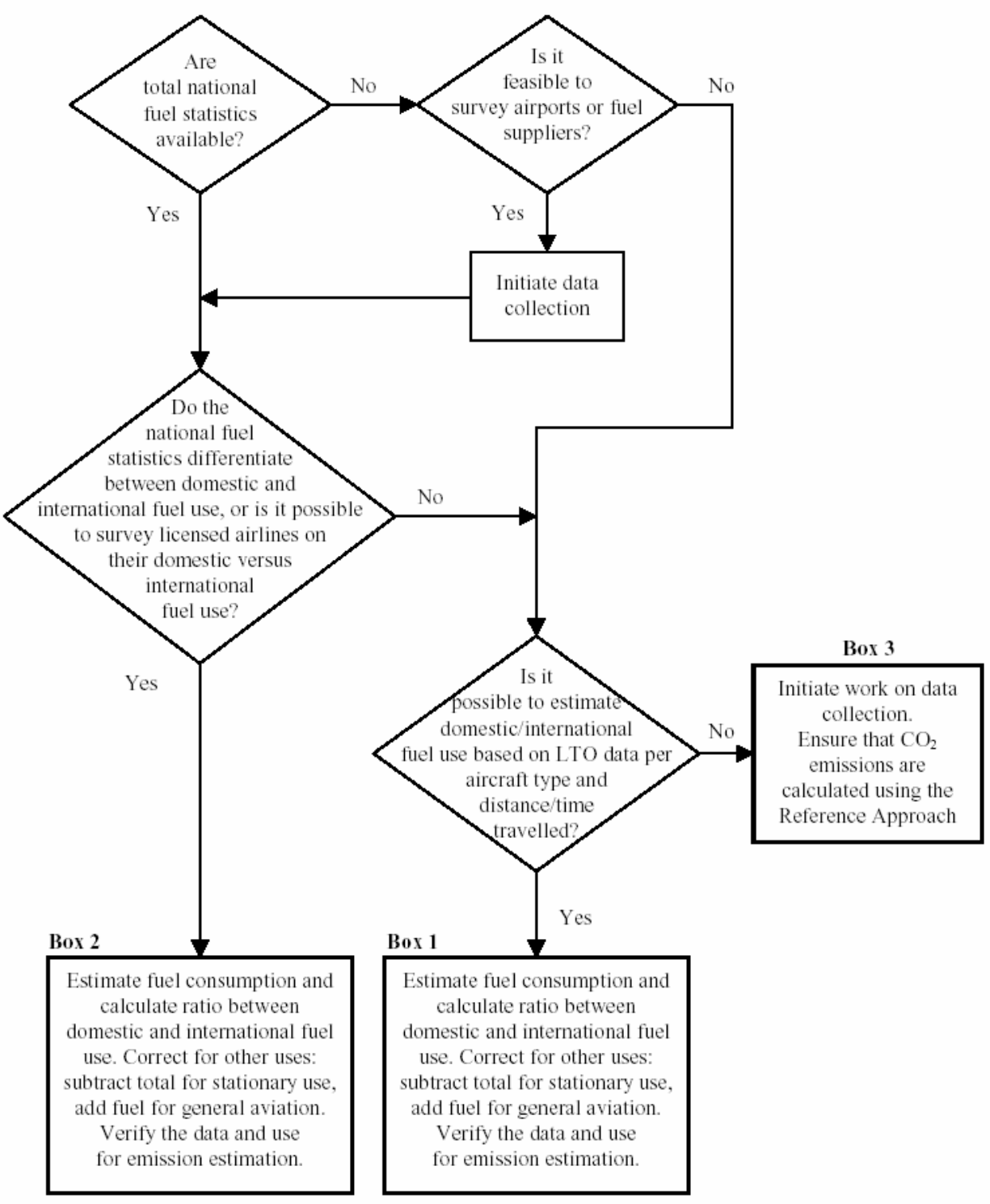

\section{Tier 2 methods}

The detailed Tier 2 methodologies accounts also for the process of combustion. Tier 1 method is purely fuel based, whereas Tier 2 methods are based on actual activity data, including the number of LTO cycles and related fuel use. Tier 2 also base emission estimates on the composition of the aircraft fleet.

In the IPCC Guidelines, the Tier 2 Method consists of a number of four steps:

1) Estimate the total fuel

2) Split into domestic and international

3) Split each into LTO fuel use and cruise fuel use

4) Apply emissions factors for the gas concerned. 
The Tier 2 methods distinguish between emissions below and above 3000 feet (914 m). This improves the accuracy of emission estimates because emission factors depend on the phases of the flight. The emissions in the two flying phases are estimated separately. The method is applied at either the aggregated level of all aircraft (Tier 2a) or at the level of individual aircraft types (Tier $2 b$ )

Emissions and fuel used in the LTO phase are estimated based on the number of LTOs (aggregate or per aircraft type, depending on data available) and default emission factors or fuel use factors per LTO cycle (average or per aircraft type). Cruise emissions depend on the length of the flight and other factors. In the Tier 2 method, the fuel used in the cruise phase is estimated as total fuel use minus fuel used in the LTO phase of the flight.

The estimated fuel use is multiplied by aggregate emission factors (again, average or per aircraft type) in order to estimate the emissions.

For the Tier $2 b$ approach, the estimate should include all aircraft types frequently used for domestic and international aviation. For the Tier 2a approach, the IPCC Guidelines provide aggregate emission factors per LTO. The aggregated emission factors are proposed for national and international aviation separately, and for an old and average fleet.

Both Tier 2 approaches use the following equations to estimate emissions:

Emissions $=$ LTO Emissions + Cruise Emissions

where

LTO Emissions $=$ Number of LTOs x Emission Factor ${ }_{\text {LTO, }}$

LTO Fuel Consumption $=$ Number of LTOs $x$ Fuel Consumption per LTO

Cruise Emissions $=($ Total Fuel Consumption - LTO Fuel Consumption $) \mathrm{x}$ Emission

FactorcRUISE

Tier $2 a$ corresponds to the CORINAIR Simple Methodology (see later Section) while Tier $2 b$ resembles the CORINAIR Detailed Methodology (see later Section), but is less detailed in the number of aircraft categories and emission factors than CORINAIR. 
The IPCC Good Practice Guidance provides the following decision tree for deciding upon the choice of methodology.

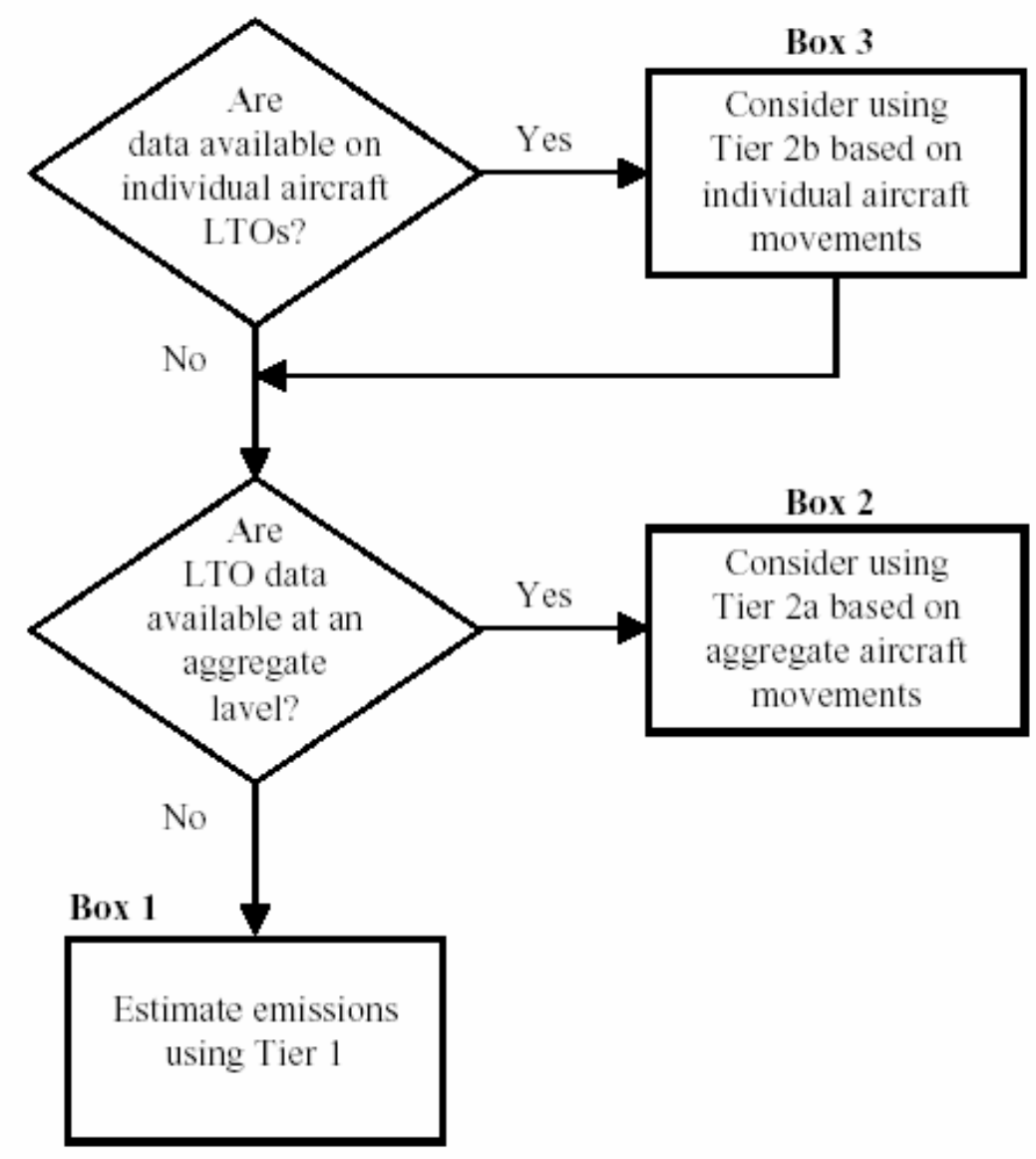

The IPCC guidelines allow Parties to use national approaches if they are well documented and have been peer reviewed. The choice of method depends on national circumstances, particularly the availability of data.

A few important observations can be made regarding the various Tiers:

- The results of a bottom-up approach and a top-down fuel-based approach for aircraft.

- Inventory quality will only improve by moving from Tier 1 to Tier 2 if activity data are complete.

- All three methods capture changes in technology that influence fuel consumption, but only the detailed Tier $2 \mathrm{~b}$ captures the effects on $\mathrm{CH} 4$ and $\mathrm{N} 2 \mathrm{O}$ emissions of changing emission factors.

- Tier 1 and Tier 2a, which are based on aggregate LTO data, should not require considerable resources, but Tier $2 \mathrm{~b}$, based on individual aircraft, may be very timeconsuming. 


\section{Emission factors}

As a general rule, gas emissions resulting from the combustion of fossil fuels depend upon fuel type and quality, combustion technology, operating conditions, age, and maintenance routines and practices of the combustion source in question. Obtaining quality data required for estimating such emissions can therefore be quite a challenge.

According to the study conducted by DNV (Det Norske Veritas), the use of national emission factors and other associated parameters reflect the level of work carried out on the topic by individual Parties. The origin, validity and comparability of national emission factors and associated parameters (as opposed to those referred to in the IPCC Guidelines) are in most cases not discussed. Emission estimate methodologies are often a combination of a national approach and that of the IPCC. A number of Parties refer to the CORINAIR approach in their reporting.

The ICAO Engine Exhaust Emission Data Bank is referred to in the IPCC Guidelines as a source of information for GHG inventories. It includes data on all emissions certified engines and many older engines as well. The data bank holds detailed information for an LTO cycle, including fuel use and emissions of hydrocarbons, CO and NOX. The fuel data cannot be used to determine cruise fuel consumption or emission factors, however, which can be obtained from performance codes.

\subsection{Annex I country reporting performance}

Most Annex I Parties (including all Nordic countries) are complying with the IPCC and UNFCCC guidelines in terms of providing the required data on fuel consumption and emissions in the CRF. 
Table 1: Emissions data reported by Annex I Parties in their 2002 GHG inventory submissions (CRF table 1.c)

\begin{tabular}{|c|c|c|c|c|c|c|c|c|c|c|}
\hline \multirow{3}{*}{ Party } & \multirow{3}{*}{ Years } & \multicolumn{8}{|c|}{ International aviation } & \\
\hline & & \multirow{2}{*}{$\begin{array}{c}\text { Fuel } \\
\text { amount }\end{array}$} & \multicolumn{7}{|c|}{ Emissions dita far: } & \\
\hline & & & $\mathrm{CO}_{2}$ & $\mathrm{CH}_{4}$ & $\mathrm{~N}, 0$ & $\mathrm{CO}$ & \begin{tabular}{|l|}
$N_{x}$ \\
\end{tabular} & NMVOC & $\mathrm{SO}_{2}$ & a \\
\hline Australin & $1990-2000$ & $\nabla$ & \pm & $\sqrt{v}$ & $\sqrt{2}$ & $\sqrt{v}$ & $\sqrt{v}$ & \pm & 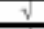 & \\
\hline Ausiris & $1990-2000$ & $\sqrt{2}$ & $\Delta$ & 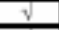 & $\nabla$ & $\checkmark$ & $\nabla$ & $\Delta$ & $\sqrt{v}$ & \\
\hline Belgium & $1990-2000$ & & $\sqrt{1}$ & $\nabla$ & $\nabla$ & $\nabla$ & $\nabla$ & \pm & $\nabla$ & \\
\hline Bulgaria & 1999 & $\sqrt{1}$ & 可 & $\sqrt{v}$ & $\checkmark$ & $\frac{v}{v}$ & $\bar{v}$ & $\sqrt{1}$ & $\checkmark$ & \\
\hline Canda & $1990-2000$ & $\sqrt{1}$ & $\sqrt{1}$ & $\sqrt{2}$ & $\sqrt{2}$ & 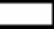 & & & & \\
\hline Casch Rapublic & 1990.2000 & 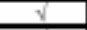 & 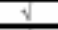 & $\nabla$ & $\checkmark$ & $\nabla$ & $\nabla$ & 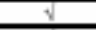 & $\nabla$ & \\
\hline Demmark & $1990-2000$ & $\sqrt{1}$ & $\checkmark$ & $\nabla$ & $\checkmark$ & $\sqrt{v}$ & $\sqrt{ }$ & $\checkmark$ & $\checkmark$ & \\
\hline Estonia & 2000 & & & & & $\sqrt{v}$ & $\sqrt{v}$ & $\sqrt{1}$ & & \\
\hline European Community & $1990-2000$ & & $\sqrt{1}$ & $\sqrt{ }$ & $\sqrt{v}$ & $\checkmark$ & $\sqrt{v}$ & $\sqrt{1}$ & $\checkmark$ & \\
\hline Finlind & $1990-2000$ & $\sqrt{1}$ & $\sqrt{1}$ & $\sqrt{ }$ & $\sqrt{v}$ & $\sqrt{ }$ & $\sqrt{ }$ & $\checkmark$ & $\nabla$ & \\
\hline France & $1990-2000$ & $\sqrt{1}$ & $\sqrt{1}$ & & & $\sqrt{v}$ & $\sqrt{v}$ & $\sqrt{1}$ & $\checkmark$ & \\
\hline Gemminy & $1990-2000$ & & $\sqrt{1}$ & $\sqrt{ }$ & $\sqrt{v}$ & $\sqrt{ }$ & $\sqrt{ }$ & $\sqrt{1}$ & $\sqrt{v}$ & \\
\hline Gresce & $1990-2000$ & $\sqrt{1}$ & $\sqrt{1}$ & $\sqrt{v}$ & $\sqrt{ }$ & $\sqrt{v}$ & $\sqrt{ }$ & $\sqrt{1}$ & $\sqrt{v}$ & \\
\hline Humpary ${ }^{3}$ & 2000 & $\sqrt{1}$ & $\sqrt{1}$ & & & $\sqrt{v}$ & & & & \\
\hline lodand & 2000 & $\sqrt{1}$ & $\sqrt{1}$ & $\sqrt{v}$ & $\sqrt{v}$ & $\sqrt{ }$ & $\sqrt{v}$ & $\sqrt{1}$ & $\sqrt{v}$ & \\
\hline Irelind & $1990-2000$ & $\sqrt{1}$ & $\sqrt{1}$ & & & $\sqrt{v}$ & $\sqrt{v}$ & $\sqrt{1}$ & $\sqrt{ }$ & \\
\hline laly ${ }^{2}$ & 2000 & $\sqrt{1}$ & $\sqrt{1}$ & $\sqrt{v}$ & $\sqrt{v}$ & $\sqrt{v}$ & $\sqrt{v}$ & $\sqrt{1}$ & $\sqrt{v}$ & \\
\hline Japain & $1990-1999$ & $\sqrt{2}$ & $\sqrt{1}$ & $\sqrt{ }$ & $\sqrt{ }$ & $\sqrt{ }$ & $\sqrt{ }$ & $\sqrt{ }$ & & \\
\hline Luxambours & 2000 & & $\sqrt{1}$ & & & $\sqrt{2}$ & $\sqrt{ }$ & $\sqrt{1}$ & $\sqrt{ }$ & \\
\hline Netherlands & $1990-2000$ & $\sqrt{2}$ & $\sqrt{1}$ & & & & & & & \\
\hline New Zealand ${ }^{2}$ & 2000 & $\sqrt{1}$ & $\sqrt{1}$ & $\sqrt{2}$ & $\sqrt{v}$ & $\bar{v}$ & $\bar{v}$ & $\sqrt{1}$ & $\sqrt{2}$ & \\
\hline Norwax & $1990,1958-2000$ & $\sqrt{1}$ & $\sqrt{2}$ & $\nabla$ & $\sqrt{ }$ & $\sqrt{v}$ & $\sqrt{v}$ & $\sqrt{2}$ & $\checkmark$ & \\
\hline Poland ${ }^{2}$ & 2000 & $\sqrt{1}$ & $\sqrt{1}$ & 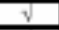 & $\sqrt{2}$ & - & & & & \\
\hline Poriugal & $1990-2000$ & $\sqrt{2}$ & \pm & $\sqrt{2}$ & $\sqrt{v}$ & $\sqrt{v}$ & 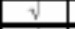 & 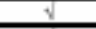 & 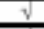 & \\
\hline Romania & $\begin{array}{c}1992,1994-1997, \\
1999\end{array}$ & & & & & $\sqrt{v}$ & $\sqrt{v}$ & $\sqrt{v}$ & $\sqrt{ }$ & \\
\hline Russian Fedatation & $1997-1999$ & & & & & & & & & \\
\hline Spain & $1990-2000$ & $\sqrt{2}$ & $\sqrt{1}$ & $\sqrt{ }$ & $\sqrt{ }$ & $\sqrt{ }$ & $\sqrt{ }$ & $\sqrt{2}$ & $\sqrt{ }$ & \\
\hline Swaden & $1990-2000$ & $\sqrt{1}$ & $\Delta$ & $\nabla$ & $\sqrt{v}$ & $\sqrt{ }$ & $\sqrt{v}$ & $\sqrt{1}$ & $\checkmark$ & \\
\hline Switzaland" & 2000 & $\sqrt{2}$ & \pm & $\sqrt{2}$ & $\sqrt{2}$ & $\sqrt{2}$ & $\sqrt{2}$ & \pm & $\nabla$ & \\
\hline Unitad Kingdam & $1990-2000$ & $\sqrt{2}$ & \pm & 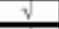 & $\sqrt{2}$ & $\sqrt{2}$ & $\sqrt{v}$ & \pm & $\sqrt{2}$ & \\
\hline Unitad Qates & $1990-2000$ & $\sqrt{2}$ & 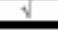 & $\sqrt{2}$ & $\sqrt{2}$ & $\sqrt{2}$ & $\sqrt{2}$ & $\sqrt{ }$ & & \\
\hline
\end{tabular}

Source: FCCC/SBSTA/2003/INF.3

Although the IPCC guidelines are intended to enhance consistency and comparability of national reporting, it has been recognised that uncertainties in emissions estimates are inevitable. The main sources of uncertainty are (Source: Velzen):

- varying interpretations of sector/source definitions, assumptions, emission factors, etc.

- $\quad$ erroneous data or data simplification through use of 'averaged' values

- uncertainties in the basic socio-economic data driving the calculations

- inherent uncertainties in the scientific understanding of the basic processes leading to emissions.

According to the 1999 study by DNV (UNFCCC 1999a), sources for international bunker fuel consumption are reported to be national energy balances, fuel sales statistics and consumers of international fuels. The methodologies and procedures used for collecting fuel data, is not sufficiently detailed to illustrate sources of error or assumptions made.

According to the DNV study, international bunker fuel emissions reported in the National Communications and those in international statistics (IEA, UN, ICAO, etc.) are not consistent in their interpretation of definitions and methodologies and also contain major gaps. Other sources of statistical data are often formatted for dedicated purposes and may require adaptation before they are suitable for preparing national inventories. 


\subsubsection{UNFCCC reporting via EU}

The European Community has a monitoring mechanism on $\mathrm{CO}_{2}$ and other greenhouse gas emissions. Member States must report to the Commission their national inventory data on emissions (and removal by sinks) of the Kyoto Greenhouse gases on an annual basis, and as a Party to the Convention, EU is obliged to report inventory data to UNFCCC.

The responses to a questionnaire submitted to EU governments regarding data, methodologies and allocation in late 2002 (Nielsen 2003a) revealed a number of issues:

- Several different methodologies of varying detail and complexity are used by Member States (IPCC 1, IPCC2a and IPCC 2b methodologies, CORINAIR very simple, detailed and improved detailed methodology and other country specific models. For example, some countries use country specific models for aviation based on seat-kilometres and available freight-tonne kilometres is in use).

- Some Member States have plans to begin using more detailed methodologies in the future than they currently do.

- Some Member States do not yet report emissions of CH4 and N2O.

- Some Member States report emissions of additional species (NMVOC, SO2, $\mathrm{CO}, \mathrm{NOx}$ ).

- There are differences in the data reported to the UNFCCC, Eurostat and the IEA.

- Some Member States are having difficulties in producing consistent time series.

In the EC inventory, total international bunker emissions are the sum of the international emissions of the Member States. The data basis for the EC IPCC reference approach is the Eurostat New Cronos database. Member states submit energy statistics to Eurostat using joint Eurostat/IEA/UNECE (United Nations Economic Commission for Europe) questionnaires. Based on this information, Eurostat compiles annual energy balances which are used for the estimation of $\mathrm{CO}_{2}$ emissions from fossil fuels by Member States and for the EU as a whole.

For international bunkers, data on international aviation are not estimated separately during the above process. This means that total Eurostat calculated $\mathrm{CO}_{2}$ emissions as estimated with the reference approach include $\mathrm{CO}_{2}$ emissions from international aviation. The IPCC default carbon emission factors adjusted for the fraction non-oxidised are used in the Eurostat New Cronos database. 


\section{International methodological frameworks and data sources for emissions calculation and reporting}

\subsection{CORINAIR}

CORINAIR (CORe INventory of AIR emissions) is a joint European system in function since 1995 managed by the European Topic Centre on Air Emissions for the European Environment Agency under the EMEP (European Union Emission Inventory Programme). The purpose is to manage a European air emission inventory and database system. All of the Nordic countries are covered by the CORINAIR project, which is not limited to emissions relevant to climate change.

The UNECE/EMEP Task Force on Emissions Inventories and Projections (TFEIP) publishes the "EMEP/CORINAIR Atmospheric Emission Inventory Guidebook". The CORINAIR Guidebook follows the same basic principles as the IPCC guidelines. Parties are to collect emission estimates using a detailed Source Nomenclature - SNAP - at a detailed spatial level. SNAP includes cross references to nomenclature developed for reporting under UNFCCC.

The emission data from CORINAIR are at a higher level of detail than required for reporting under international obligations, and the methodology can therefore provide the basis for aggregation and reporting of emissions in for several purposes, including UNFCCC; the UNECE/EMEP - Long Range Transboundary Air Pollution Convention; and the EU Monitoring mechanism.

The latest version of the CORINAIR methodology can be used for determining air emissions for individual flights. Relevant data for flights, types of aircraft, fuel use and emissions are filed in a database. However, significant differences remain between countries in terms of data availability and resources allocated for the purpose. Therefore, three methodologies have been developed for calculating emissions from air traffic: the Very Simple Methodology, the Simple Methodology and the Detailed Methodology. Some countries use national models that may be even more detailed than the CORINAIR Detailed Methodology, comprising e.g. specific engines and specific LTO operating times. 
Table 2: Overview of CORINAIR methodologies (Source: Stefan Krüger Nielsen)

\begin{tabular}{|c|c|c|c|}
\hline & & LTO & Cruise and climb \\
\hline \multirow[t]{2}{*}{ Very Simple } & Activity & $\begin{array}{l}\text { LTO aggregated } \\
\text { Time-in-mode (ICAO) }\end{array}$ & \begin{tabular}{|l|} 
Fuel residual \\
\end{tabular} \\
\hline & Emission factor & Generic aircraft & Generic aircraft \\
\hline \multirow[t]{2}{*}{ Simple } & Activity & $\begin{array}{l}\text { LTO per aircraft type (generic aircraft) } \\
\text { Time-in-mode (ICAO) }\end{array}$ & Fuel residual \\
\hline & Emission factor & Per aircraft type & One generic aircraft \\
\hline \multirow[t]{2}{*}{ Detailed } & Activity & $\begin{array}{l}\text { LTO per aircraft type (generic aircraft) } \\
\text { (option also engine type) } \\
\text { Time- in-mode: Actual if available } \\
\text { otherwise ICAO }\end{array}$ & $\begin{array}{l}\text { Distances flown } \\
\text { Independent estimate of cruise } \\
\text { fuel use }\end{array}$ \\
\hline & Emission factor & $\begin{array}{l}\text { Per aircraft type (generic aircraft) } \\
\text { (option also engine type) }\end{array}$ & $\begin{array}{l}\text { Per aircraft type (generic } \\
\text { aircraft) and distance flown }\end{array}$ \\
\hline
\end{tabular}

As with the different tiers of the IPCC guidelines, the three CORINAIR methodologies require different types of data:

The Very Simple Methodology only requires the total quantity of fuel consumed for domestic and international flights and the total number of aircraft movements for domestic and international flights. This means that the methodology can be used when the number of aircraft movements is known, but the individual aircraft types and their routes are not.

The Simple Methodology is applicable when there are also data on movements by aircraft type, but the precise destinations are not available. This methodology provides more precise estimates of LTO emissions.

The Detailed Methodology provides more precise estimates of cruise emissions as compared to the simpler methodologies. It is based on data on individual aircraft movements as well as departure and arrival airports of individual aircraft on domestic and international flights.

European countries that participate in ECAC (European Civil Aviation Conference) are encouraged to use the Detailed Corinair Methodology for calculating aircraft emissions. This is likely to improve the ability of European countries to separate better international emissions from emissions for domestic air transport.

\subsection{The TRENDS project}

Eurostat in cooperation with EUROCONTROL and EEA has produced fuel consumption estimates in cooperation with EUROCONTROL within a project called TRENDS (Transport and Environment Database System). The TRENDS model is based on the detailed CORINAIR methodology. EUROCONTROL provides IFR (Instrumental Flight Rule) data, which are used to produce estimates of fuel consumption and emissions for each type of aircraft; airport pair; time period; LTO; and cruise.

EUROCONTROL is in a unique position to provide detailed flight information based on its role in pan-European air traffic management (ATM). EUROCONTROL monitors the airspace, and all aircraft operators provide information about civil aviation flights under Instrumental Flight Rules (IFR) by filing a flight plan with EUROCONTROL.

The detailed flight data in combination with Corinair emission calculation methodology could develop into a system of precise and comprehensive data on European emissions 
from aviation, also enabling the distinction between domestic, intra-EU, and international traffic.

\subsection{Eurostat support for harmonization of data reported to Eurostat and UNFCCC}

Based on the Eurostat energy balance data, Eurostat compiles annual estimates of $\mathrm{CO}_{2}$ emissions in the EU using the IPCC reference approach. Eurostat compares these estimates to national estimates prepared by Member States.

In order to improve the consistency between member state and Eurostat energy data, Eurostat is working with national statistical offices to harmonise energy balances. Eurostat supports projects in the Member States aiming at eliminating differences in energy data reported to Eurostat and to the UNFCCC. The work also covers reporting of fuel consumption for international aviation.

\subsection{ICAO}

Each of ICAO's Member States is to ensure that its international airlines submit the statistics requested by the Council of ICAO in accordance with Article 67 of the Convention on International Civil Aviation. Several different measures of aviation activity are recorded such as tonne-kilometres available (a measure of capacity offered), tonneskilometres performed (a measure of traffic carried) as well as the operational parameters aircraft-kilometres, departures and aircraft hours flown.

The ICAO statistical programme is also capable of providing fuel consumption figures individually for each aircraft performing scheduled flights. The amount of fuel used by each airline is estimated based on information on schedules operated, aircraft used and fuel consumption characteristics of each aircraft type. These data allows for differentiation between national and international flights (as defined by ICAO). This could provide the basis for inventories, although only for scheduled international flights. Furthermore, fuel consumption will be somewhat understated because aircraft are assumed to fly directly between to airports using Great Circle mileage.

The approach can be compared with the IPCC Tier 2 method, which contains the following steps:

estimate the total fuel

split into domestic and international

split each into LTO fuel use and cruise fuel use

apply emissions factors for the gas concerned.

ICAO does not record data for steps 2 and 3. On the other hand, the approach of CAEP is advanced in the sense that it focuses on aircraft type, stage length and the resulting emission profile over the whole stage.

The UNFCCC Secretariat has requested CAEP to explore opportunities to examine and improve the quality of data reporting and comparability of aviation bunker fuel data. 


\subsection{International Energy Agency}

IEA statistics are based on national reporting in the Joint IEA/Eurostat/UNECE annual questionnaires. They cover both domestic and international aviation and are submitted to IEA by its 29 member Countries as well as several other UN ECE member countries.

The IEA approach to bunker emissions differs from that of the IPCC. The IEA includes fuel use by military aviation on both national and international operations in the domestic inventory, while under IPCC there is a separate category "1A5, Other" for all military aviation fuel.

Based on the energy statistics, the IEA calculates $\mathrm{CO}_{2}$ emissions using the default methodology and emission factors of the IPCC Guidelines. The IEA does not calculate emissions of other greenhouse gases. The IEA data on $\mathrm{CO}_{2}$ emissions from aviation can be based on other emission factors than those used by individual Parties in their reporting to the UNFCCC.

For the above reasons, the IEA data shown for emissions from domestic and international aviation in this Section cannot be directly compared with UNFCCC data. A Synthesis and Assessment Report from the UNFCCC (UNFCCC 2002) on the GHG inventories submitted by Annex I countries in 2001 compares data on aviation fuel consumption and emissions between UNFCCC submissions and IEA. The major difference appears in the split between domestic and international emissions.

Table 3: Reported emissions from international aviation. Million tonnes of CO2.

\begin{tabular}{|l|r|}
\hline IEA & 165 \\
\hline UNFCCC & $129-139$ \\
\hline
\end{tabular}

\subsection{ECAC/ANCAT/EMCAL}

The European Civil Aviation Conference (ECAC) has established a "Group of Experts on the Abatement of Nuisances Caused by Air Transport" (ANCAT). Under ANCAT, a sub-group (EMCAL) is dealing with emissions calculations.

ANCAT has produced the "ECAC Recommendation on Methodology for Emissions Calculations" and the accompanying "ECAC/ANCAT/EMCAL Guidance Material".

The ANCAT methodology consists of three methods, ANCAT 1, ANCAT 2 and ANCAT 3, with different levels of accuracy and complexity, similar to the CORINAIR Very Simple, Simple and Detailed methods. ECAC encourages Member States to use ANCAT 3, which is the most detailed method.

\subsection{UNECE Long Range Transboundary Air Pollution Convention}

Under the Long Range Transboundary Air Pollution Convention, UNECE collects emissions data from the LTO phase of the flight for non-CO2 emissions. Only CO2emissions are to be reported for the entire LTO and cruise phase. This differs from reporting under the UNFCCC, where emissions throughout the flight are to be reported for all the relevant gases. 


\subsection{Emission inventory models}

A number of projects and programs have worked to develop models of international aircraft emissions. As a general rule, these model-based inventories are not based on accurate data on flights actually performed by all airlines globally.

For most modelled calculations, there is a fairly good correspondence between emissions reported to UNFCCC and those calculated by the models. IEA figures are a notable exception, which may be explained i.a. by the inclusion of military aviation in the IEA figures.

\subsubsection{NASA}

Under the Atmospheric Effects of Aviation Project (AEAP), United States National Aeronautics and Space Administration (NASA) have produced 3-D inventories for present and projected future aviation.

\subsubsection{Deutsches Zentrum für Luft- und Raumfahrt}

The bottom-up approach applied in the DLR's inventories uses an aircraft movement database and aircraft/engine combinations to calculate fuel use and emissions. For each city pair, output information includes emissions by altitude along the route.

\subsubsection{AERO model}

The project Aviation Emissions and Evaluation of Reduction Options (AERO) was initiated in 1994 by the Dutch Civil Aviation Department to estimate economic and environmental impacts of possible measures to reduce aviation emissions.

The AERO model covers a set of integrated models that range from demand for air transport through the assessment of the environmental impacts of aircraft engine emissions, integrating economic, political, technological, and environmental issues. The model enables the creation of scenarios and evaluation of a range of regulatory, fiscal, operational and technical measures to regulate aviation.

\subsection{Airline companies}

No existing reporting scheme includes detailed information on the actual passenger loads and freight loads transported by the aircraft. This kind of information would be necessary under certain allocation schemes.

It has been suggested that data availability could be improved if airlines were to report data on activity and emissions using standard software developed e.g by the IPCC.

\subsection{Other methodological frameworks and data sources}

\subsubsection{U.S. statistics}

All US airlines over a given size are required by law to report their operating statistics to the Department of Transportation under the so-called "Form 41" arrangement. A comprehensive database thus exists with data for the fuel consumption of airlines and 
their aircraft. This type of data is useful for comparing airlines and their fuel efficiency. Data is not currently being reported at the same level of detail by airlines in other countries, however, the information is likely to be available internally.

\subsubsection{Statistics yearbooks}

Statistics are published in the World Transport Statistics (by the International Road Transport Union) and the Yearbook of Tourism Statistics (by the World Tourism Organisation). These statistics do not include all airlines, however, neither do they distinguish between domestic and international flights and passengers or include nonscheduled services.

\subsubsection{Austrian study}

The Austrian Federal Environment Agency has commissioned a study to estimate emissions from aviation, using different methodologies and differentiating between domestic flights, intra-EU flights and flights to destination outside the EU.

\subsubsection{IPCC Emission Factor Database}

The IPCC is currently developing an Emission Factor Database based IPCC methodology reports and data from other sources. Furthermore, IPCC has initiated a revision of the Revised 1996 IPCC Guidelines for National Greenhouse Gas Inventories. The revised guidelines are expected to be finalized by early 2006, although they will not be implemented until after the first commitment period of 2008-2012. 


\section{Major issues in relation to data and methodologies}

In this chapter, the main issues of importance to data and methodologies for estimating and reporting emissions from international aviation are addressed. These issues are central to the question of subsequent allocation of emissions. In the following chapter, the issues will be considered with emphasis on the Nordic countries.

Data systems and methodologies should be adequate in terms of:

- Coverage

- Precision

- Integrity

- Usefulness according to the allocation methods considered

IPCC and UNFCCC Secretariat experience from national reporting has shown that uncertainties in emission estimates are related primarily to:

- definitions

- data sources for activity data and fuel consumption

- methodologies for applying emission factors to fuel consumption

- institutional issues

\subsection{Separation of national and international bunker fuels}

The single most important methodological issue raised by IPCC/UNFCCC is the separation of national and international bunker fuels and related emissions.

Given the fact that emissions from domestic aviation are subject to the limitation or reduction commitments of Annex I Parties, the separation of fuel use for domestic and international transportation is of obvious importance.

A review of the methodologies applied by Annex I Parties for disaggregating fuel use data into domestic and international components shows that there is no uniform approach to the issue. Among the sources of information are:

- information on fuel taxation (Australia)

- information on the flag or country of registration of carriers (Canada, Portugal)

- information directly from oil companies (Iceland, New Zealand), or information from airlines (Norway)

- on the basis of statistical information on total amounts of fuel, the domestic and international amounts are estimated by using bottom-up models and surrogate data. (Austria, France, Sweden, Denmark and the United Kingdom).

- responses to an EU questionnaire from 2002 revealed that most Member States lack reliable data for separating international from domestic civil aviation because information is mainly based on national and international carriers rather than flight segments. 


\subsubsection{Different definitions}

A major source of differences in reporting of national vs. international emissions is the existence of different definitions among different international institutions and guidelines.

\section{IPCC definitions}

The IPCC Guidelines provide the following definitions relating to domestic and international aviation:

"If an aircraft goes from one airport in one country to another in the same country and then leaves for a third airport in another country, the first flight stage is considered a domestic trip while the second is considered an international trip. It is not important whether the airport is a domestic or an international airport. In addition, the type of activity (landing/take off (LTO) cycles, cruise, domestic, international) is independent of the nationality of the carrier".

The below table provides detailed IPCC guidelines for distinguishing between domestic and international flights at the level of the individual flight stage.

Table 4: IPCC criteria for distinguishing between domestic and international flights.

\begin{tabular}{|l|c|c|}
\hline \multicolumn{2}{|l|}{ Distinction between domestic and international flights } \\
\hline & Domestic & International \\
\hline A. Depart and arrive in same country & Yes & No \\
\hline B. Depart from one country and arrive in another & No & Yes \\
\hline $\begin{array}{l}\text { C. Depart from one country, stop in the same country with- } \\
\text { out dropping or picking up any passengers or freight, then } \\
\text { depart again to arrive in another country }\end{array}$ & No & Yes \\
\hline $\begin{array}{l}\text { D. Depart from one country, stop in the same country and } \\
\text { drop and pick up passengers or freight, then depart finally } \\
\text { arriving in another country }\end{array}$ & Domestic stage & $\begin{array}{c}\text { International } \\
\text { stage }\end{array}$ \\
\hline $\begin{array}{l}\text { E. Depart from one country, stop in the same country, only } \\
\text { pick up more passengers or freight and then depart finally } \\
\text { arriving in another country }\end{array}$ & No & Yes \\
\hline $\begin{array}{l}\text { F. Depart from one country with a destination in another } \\
\text { country, and makes an intermediate stop in the destination } \\
\text { country where no passengers or cargo are loaded. }\end{array}$ & No & $\begin{array}{c}\text { Both segments } \\
\text { international }\end{array}$ \\
\hline
\end{tabular}

It should be noted that it is unclear whether any Annex I countries fully possess the data at the level of detail required to apply these definitions in their reporting. It appears that none of the Nordic countries are using the distinction C, E and F from the above table. Rather, the common approach is to simply use the location of the departure and arrival airport for each flight stage as the criterion for making the national/international distinction.

\section{ICAO definitions}

Under the ICAO process, the following definitions have been for classifying flight stages when reporting air carrier statistical data to ICAO:

A) Domestic flight stage: a flight stage flown between points within the domestic boundaries of a State by an air carrier whose principal place of business is in that State. 
Flight stages between a State and territories belonging to it, as well as any flight stages between two such territories, should be classified as domestic. This applies even though a stage may cross international waters or the territory of another State;

B) International flight stage: a flight stage with one or both terminals in the territory of a State other than the State in which the air carrier has its principal place of business should be classified as international;

C) In the case of multinational airlines owned by partner States, traffic within each partner State should be reported separately as domestic and all other traffic as international.

The ICAO definition differs from IPCC by focusing on the nationality of the air carrier. The result of the differences relate to cabotage, i.e. domestic stages flown by foreign carriers. Under IPCC, such stages will be regarded as domestic, whereas they are international by ICAO standards. With increasing liberalization, this kind of traffic is likely to grow in the future.

\section{IEA Definitions}

IEA has developed the following definitions for fuel consumption in air transport. These definitions are used in the questionnaires that are submitted to IEA annually:

A) Domestic air transport: consumption of aviation fuels by domestic aircraft (commercial, private, agricultural, etc.); includes oil used for purposes other than flying (e.g. bench testing of engines) and military use of aviation fuels; excludes use by airlines of motor-spirit for their road vehicles;

B) International civil aviation: consumption of aviation fuels other than for domestic aircraft activities;

IEA definitions are largely consistent with the IPCC Guidelines. However, military aviation is included in domestic aviation, and the term "domestic aircraft" is used instead of referring to domestic flight segments.

It should be noted that because IEA does not have direct access to the underlying national statistics, it is difficult to evaluate how countries interpret these definitions.

\subsection{The importance of cruising altitude and non-CO2 emissions}

According to IPCC, the contribution to climate change from commercial air transport in terms of total radiative forcing may be 2-4 times higher than that of $\mathrm{CO} 2$ emissions from aircraft alone. This is due to two interrelated factors, one being the effects of non$\mathrm{CO} 2$ emissions, and the other the effects of emissions taking place at high altitudes.

According to IPCC, aircraft emissions at high altitudes contribute to climate change by altering the concentration of GHGs; triggering formation of condensation trails (contrails); and increasing cirrus cloudiness.

In terms of GHGs covered by the Kyoto Protocol, $\mathrm{CO} 2$ accounts for about 99 per cent of the total GHG emissions in the sector. N2O emissions account for 0.8 per cent and $\mathrm{CH} 4$ emissions for the remaining 0.2 per cent. Still, the Kyoto GHGs account for less than half of the radiative forcing caused by aviation (IATA 2001). The remainder relates to gases not covered by the Kyoto Protocol (i.e. water vapour, nitrogen oxides (NOx), sulphur dioxide (SO2), particulate matter, and Non-methane Volatile Organic 
Compounds (NMVOC). This means that a significant part of the industry's contribution to global warming would not be covered by a commitment under the Kyoto Protocol.

CAEP/ICAO has recognised the need for reliable estimates of total aviation emissions and of their distribution, i.a. by altitude. Methods are being developed to estimate the aviation emissions within 3-dimensional cells above the earth's surface. Similar work has been undertaken in both the United States (by NASA) and in Europe (by ANCAT/EC). The EC-funded NEPAIR project is working to develop a new emissions parameter covering all flight phases of aircraft operation.

In the response of the UK to the EU questionnaire, it is suggested that future improved reporting might split annual emissions into different altitude "classes" such as the LTO phase, the climb/descent phase and the cruise phase.

On the other hand, it would be complicated and significantly increase data requirements to apply different allocation principles to emissions according to their radiative forcing effect at different altitudes, e.g. by converting emissions to "CO2-at-sea-level".

\subsection{Separation of fuel consumed by military aircraft from fuel consumed by civil aircraft}

According to UNFCCC guidelines, fuel consumed by military aircraft should be separated from fuel consumed by civil aircraft and reported separately under the Source/sink category 1A5, "Other". This is different from IEA reporting guidelines, where all of a country's military aircraft emissions are included under domestic aviation.

\subsection{Overseas territories}

According to the IPCC/UNFCCC reporting guidelines, emissions from flights to and from overseas territories should be included in national inventories as domestic.

The EU questionnaire from 2002 revealed that for several countries, this is not fully applied in practice and that emissions related to travel to overseas territories are often reported as international.

\subsection{Annex I vs. non-Annex I country emissions}

Around one third of $\mathrm{CO}_{2}$ emissions from international aviation relate to fuel sold in non-Annex I countries, which have no reduction targets under the Kyoto Protocol. Much of the fuel sold in non-Annex I countries is likely to be consumed by one or more of the following:

- $\quad$ airlines from Annex I countries;

- $\quad$ airlines transporting passengers and goods originating from Annex I countries

- flights going to Annex I country destinations.

Depending on the allocation method considered, data on these emissions may or may not be required for allocation to an Annex I party. However, although such information is collected by IEA and the UN, the resulting database is unreliable and incomplete (Velzen). 


\subsection{Passenger/freight loads and their origin/destination}

None of the existing databases or models include detailed information on the actual passenger and freight loads transported by the aircraft, let alone the origin and destination of these loads. Such information will be necessary under certain allocation options.

\subsection{Global models vs. actual emissions}

The existing global models do not include databases on actual flights and are based on less detailed aircraft categories than the detailed CORINAIR methodology.

\subsection{Intra-EU flights domestic or international}

The European Community is an individual signatory to the UNFCCC and the Kyoto Protocol, and it cannot be ruled out that emissions from intra-EU aviation among two Member States will have to be reported as domestic emissions under the EU "bubble" and thus be subject to the Kyoto Protocol emissions reduction target.

Present inventory submissions by the EU sum up the individual emissions of the 15 member States and thus do not include intra-EU flights. None of the Nordic countries are reporting intra-EU emissions separately in the reporting to EU. However, the TRENDS project may provide an opportunity to identify and separate intra-EU flights.

\subsection{Institutional responsibilities}

The quality of data collection and reporting depend upon a number of institutional arrangements related to:

- $\quad$ Procedures for data collection (fuel sales, national/international use)

- Institutional responsibilities for:

- Collection of bunker fuel statistics

- Calculation of emissions

- Reporting international bunker fuels in national communications

According to UNFCCC, most Parties report to have agencies/ institutions that are assigned to the responsibilities of collecting bunker fuel statistics, calculating greenhouse gas emissions, and reporting in national communications.

UNFCCC assessments of institutional issues have not revealed major institutional barriers that should disable the Annex I Parties from reporting on international bunker emissions. 


\section{Methodologies and data for the Nordic countries}

The present chapter provides information on the data sources and methodologies from the Nordic countries. The information derives from various sources, including i.a.:

- interviews with national institutions and individuals;

- National Communications to the UNFCCC;

- $\quad$ the EU questionnaire from 2002;

- a study by carried out by Det Norske Veritas.

The Nordic countries have reported the following figures for international aviation $\mathrm{CO} 2$ emissions in 1990 and 1999:

Table 5: UNFCCC data for international aviation CO2 emissions 1990 and 1999, 1,000 tonnes:

\begin{tabular}{|l|r|r|}
\hline & 1990 & 1999 \\
\hline Denmark & 1.795 & 2.314 \\
\hline Finland & 974 & 1.058 \\
\hline Iceland & 220 & 363 \\
\hline Norway & 605 & 975 \\
\hline Sweden & 1.826 & 2.103 \\
\hline
\end{tabular}

Source: FCCC/WEB/SAI/2001

\subsection{Denmark}

Denmark applies the detailed CORINAIR methodology for estimating emissions, including emission factors. Estimates are made separately for Landing and Take Offs $($ LTOs $<3000 \mathrm{ft})$ and distance-related cruise $(>3000 \mathrm{ft})$. From 2001 the estimates are made on a city-pair level (aircraft type, origin and destination) from Danish Civil Aviation Authority and fuel use factors (per flown distance) per aircraft type. Emissions are calculated by combining activity data and emission factors and subsequently grouping the emission results into domestic and international totals.

A calculation is made using city-pair statistics The calculations are grouped according to domestic and international flights.

Activity data for air traffic consist of air traffic statistics provided by the Danish Civil Aviation Agency (DCAA) and Copenhagen Airport. As from 2001, records are given per flight by CAADK as data for aircraft type and origin and destination airports.

The Danish Energy Authority (DEA) collects monthly data on sales of jet fuel and aviation gasoline by the oil companies to the Danish airports. 
Quality assurance and control of the inventory is achieved by operating the top-down approach (Tier 1) in parallel with the detailed Tier 2 inventory methodology. The modelled fuel use and emission results are adjusted in a fuel balance ensuring that all statistical fuel sold is accounted for.

\subsubsection{Separation of national and international bunker fuels}

For aviation bunkers, the sales statistics do not distinguish between fuel sold for domestic and international purposes. The Danish National Environmental Research Institute, using the CORINAIR methodology, estimates the split between aviation fuel used for domestic and international purposes.

According to the Danish NIR, the distinction made in the Danish emission inventories between domestic and international emissions is made in accordance with the Revised 1996 IPCC Guidelines for National Greenhouse Gas Inventories. The Danish interpretation of this is that "fuel sold (and associated emissions) for flights/sea transportations starting from a seaport/airport in the Kingdom of Denmark, with destinations inside or outside the Kingdom of Denmark, are regarded as domestic or international, respectively." (Although this definition is not in every detail in accordance with the IPCC guidelines as these are described in an earlier Section).

\subsubsection{The importance of cruising altitude and non-CO2 emissions}

In response to the EU Questionnaire in 2002, Denmark stated that "It is our view, that it (as at present) will be sufficient to distinguish between domestic and international flights. In relation to this differentiation it could in case of domestic traffic make sense to add information on the amount of short routes, having cruise levels below an altitude of 10 kilometres.

It is our general view that even though emissions at height seems to give (or result in) a larger effect on the climate (as some gasses influences the green house effect more if emitted at height compared to emissions at ground level) the relevant data will not be much improved if actual cruise levels are included in the reporting scheme."

In terms of non- $\mathrm{CO} 2$ emissions, emissions of the following gases are reported: to UNFCCC: $\mathrm{CO}_{2}, \mathrm{CH}_{4}, \mathrm{~N}_{2} \mathrm{O}, \mathrm{NO}_{x}, \mathrm{CO}, \mathrm{NMVOC}, \mathrm{SO}_{x}$

\subsubsection{Separation of fuel consumed by military aircraft from fuel consumed by civil aircraft}

For military aircraft, emissions are estimated with the Tier 1 method using fuel related emission factors and fuel use from the DEA.

\subsubsection{Overseas territories}

From 2001, the emissions associated with flights inside the Kingdom of Denmark are counted as domestic. The flights from Denmark to Greenland and the Faeroe Islands are classified as domestic flights in the bottom-op inventory data, and for flights from Greenland/Faeroe Islands, virtually all bunkered fuel is for flights going to Denmark. Estimates from previous years (1990-2000) have been updated in accordance with this flight classification. 


\subsubsection{Intra-EU flights considered as national}

None of the Nordic countries are reporting intra-EU emissions separately in the reporting to EU. However, since calculations are based on city-pairs, it would theoretically be possible to separate emissions resulting from intra-EU flights from other international emissions.

\subsection{Finland}

Aviation bunker emissions in the Finnish GHG inventory are calculated using Statistics Fin-land's emission calculation system ILMARI. Calculation of bunker fuel emissions is based on the IPCC Tier 1 methodology. Definition of bunker fuels follows the IPCC Revised 1996 Guidelines and Good Practice Guidance. Statistics Finland uses bunker fuel sales data collected from fuel distributors by Finnish Oil and Gas Federation. Fuels used for domestic and international use are identified by using separate fuel codes.

Until 1997, emissions from aviation were calculated using ILMARI. In 1996, the Technical Re-search Centre of Finland (VTT) completed a calculation system named LIPASTO, which covers emissions and energy consumption of all traffic modes in Finland. The system comprises four sub models, and one of the models is the air traffic model ILMI, which was developed by the Civil Aviation Administration (CAA) of Finland. The model calculates emissions and energy consumption of civil aviation inside Finnish flight information regions (FIRs).

ILMARI uses aggregated data from the ILMI system for domestic aviation. Because the definition of international aviation in the ILMI model is different from the IPCC bunker definition, bunker emissions for GHG inventories are still calculated by ILMARI, using average emission factors taken from domestic aviation (except for $\mathrm{N} 2 \mathrm{O}$ and $\mathrm{CH} 4$, which are not included in the ILMI model at the moment; these will however be included in the future).

Emission factors for ILMARI are taken from different sources:

CO2: IPCC default;

N2O: IPCC default, selected using 1996 Rev. Guidelines Table 1-50;

CH4: $10 \%$ of VOC (as suggested in Table 1-50);

other emission factors (NMVOC, SO2, NOx, CO): ILMI / LIPASTO, domestic emission factors.

Before ILMI / LIPASTO was completed, emission factors for domestic aviation as well as bunkers were taken from other sources. The data has not yet been updated for all years in the Finnish GHG inventories. The time series will be recalculated during 2004 and reported in the following inventories.

The air traffic model ILMI uses the traffic data from CAA's database. The data includes data for

- Aircraft type

- Engine type

- Carrier

- Departure and landing airport

- Total time of a flight 
- $\quad$ Flight time of a flight inside Finnish FIRs

- The number of similar flights between airports

Engine and aircraft performance data are from the engine manufacturers and engine emission factors are based on the ICAO database

\subsubsection{Separation of national and international bunker fuels}

ILMI / LIPASTO was not designed to be used for reporting to UNFCCC. Its main objective was to national needs emissions and energy consumption in Finland (i.e. within the Finnish economic region), not bunker fuels. Flights are thus classified using the following categories: domestic traffic; departing international traffic; arriving international traffic; and over-flights. This categorization is clearly at odds with the UNFCCC/IPCC definitions. As mentioned above, this is the main reason for using ILMARI system instead of ILMI to calculate bunker fuels and emissions.

\subsubsection{The importance of cruising altitude and non-CO2 emissions}

In response to the EU Questionnaire in 2002, Finland stated that:

"There is no reason to act differently than with normal aviation, unless sufficient scientific in-formation on the effects of different emissions in high-altitude is available."

\subsubsection{Separation of fuel consumed by military aircraft from fuel consumed by civil aircraft}

Fuels and emissions by the air force are reported under CRF category '1A5 Other' in accordance with the guidelines.

\subsubsection{Intra-EU flights considered as national}

Finland is reporting that the available data does not enable the separation of emissions resulting from intra-EU flights from other international emissions.

\subsection{Iceland}

Emissions are calculated on the basis on fuel sold, according to the IPCC Tier 1 method. The National Energy Authority collects data on fuel use from three oil companies and data from the country's four international airlines.

\subsubsection{Separation of national and international bunker fuels}

The oil companies report their fuel sales to the National Energy Committee. According to "Fuel Statistic Reporting Guidelines", statistics are to distinguish between domestic and international aviation fuel use. As the international airport is separate from the domestic, the separation of fuel use is relatively straightforward. Flights to Greenland and the Faeroe Islands depart from the domestic airport, but the fuel use is reported as international in accordance with the guidelines. 


\subsection{Norway}

The consumption of aviation bunker fuel in Norway reported to the UNFCCC is estimated as the difference between total purchases of jet kerosene in Norway for civil aviation (Petroleum Statistics) and reported domestic consumption.

The bottom-up approach of Norway is the detailed Tier2 CORINAIR methodology. The methodology is based on detailed information on types of aircraft and number of LTOs as well as average cruise distances.

For international aviation, the following procedure is applied:

- Planes are grouped into standard categories

- Fuel use is calculated for LTOs

- Fuel use for cruise is calculated as a residual, i.e. total fuel use minus fuel for LTO. For international flights, cruise distances are not known, and a standard distance is applied according to plane category

- Emission factors are calculated and applied.

Methodologies for the estimation of emissions are described in the report SN 2002 "Emissions to Air from Norwegian Air Traffic".

\subsubsection{Separation of national and international bunker fuels}

International bunker fuels are calculated from total sales to air transport less use in domestic air transport in a three-step process:

1. Figures on total aviation fuel consumption are derived from sales data collected by Statistics Norway (SN) from the Norwegian petroleum companies. These data do not distinguish between national and international uses.

2. Data on domestic fuel purchase and consumption is collected by SN from all airline companies operating domestic traffic in Norway.

3. The figures on domestic consumption from airlines are deducted from the total sales of jet kerosene to arrive at the total fuel sale for international aviation.

\subsubsection{The importance of cruising altitude and non-CO2 emissions}

Emissions of NH4 and $\mathrm{N} 2 \mathrm{O}$ from international aviation are small compared to the total Norwegian emissions of these gases.

The Norwegian Petroleum Industry Association provides emission factors for $\mathrm{CO}_{2}$ from the combustion of jet fuel and gasoline (SN/SFT 2000). The emission factors for $\mathrm{N}_{2} \mathrm{O}$ and $\mathrm{CH}_{4}$ are uncertain. Default emission factors from the IPCC (IPCC 1997a,b) are used for jet fuel. The $\mathrm{NO}_{\mathrm{x}}, \mathrm{CO}$ and VOC emission factors are aircraft specific as given in EEA (2001).

\subsubsection{Intra-EU flights considered as national}

Since the present level of detail of existing data does not allow for identification of origin-destination and cruise distances, it is not possible to separate emissions resulting from intra-EU flights from other international emisisons. 


\subsection{Sweden}

A consortium consisting of two government agencies and an environment research institute - SMED - is cooperating to calculate emissions from Swedish aviation.

Sweden uses the bottom-up IPCC Tier 2 method for estimating N2O and CH4 emissions from international aviation. $\mathrm{CO} 2$ emissions are calculated using IPCC Tier 1 method.

On the basis of air traffic statistics from airports, The Swedish Civil Aviation Administration (SCAA) calculates the use of civil aviation fuels in accordance with detailed CORINAIR guidelines. The method is based on information on aircraft, engine, departure airport, arrival airport, domestic and international LTO, domestic and international cruise, and purpose of flight.

Emissions are calculated using simulated flight profiles for each aircraft type per city pair and are divided into LTO phase and cruise phases. Engine specific emission factors are taken from the ICAO aircraft engine exhaust emissions data bank.

The air traffic statistics cover movements responsible for approximately $90 \%$ of the fuel used for civil aviation. Results are compared with top-down information from Statistics Sweden on delivered amounts of fuel. The results from the bottom-up calculations from air traffic statistics are checked and corrected to correspond to the top-down calculated amount of fuel delivered.

\subsubsection{Separation of national and international bunker fuels}

The separation of national and international bunker fuels are made on the basis of bottom-up information from SCAA regarding domestic and international flights; amount of fuel needed for different flights; departure airport; arrival airport; and distances between destination. The fuel consumption and emissions are adjusted to match delivered amounts of fuels. The delivered amount of fuel is based on a survey based on information from wholesale dealers on a national level. The survey is carried out by Statistics Sweden.

There are differences in reporting to the UNFCCC and the IEA due to different definitions of domestic and international emissions.

\subsubsection{The importance of cruising altitude and non-CO2 emissions}

For all other gases than CO2, the Swedish Civil Aviation Administration (SCAA) calculates the emissions using the guidelines of EMEP/CORINAIR.

Emissions of SO2, NOx and $\mathrm{CO}$ are based on information from SCAA adjusted for delivered amount of fuel to air traffic. Emissions of NMVOC and $\mathrm{CH} 4$ are calculated on basis of emissions of hydrocarbons from SCAA and emission factors from CORINAIR. $\mathrm{N} 2 \mathrm{O}$ emissions are based on number of LTO cycles, from the SCAA report "Avgasemissioner från civil flygplanstrafik i Sverige i åren 1995-2000”, Pålsson, Anette (2001) and emission factors from CORINAIR. 
6.5.3 Separation of fuel consumed by military aircraft from fuel consumed by civil aircraft

Sweden collects data on emissions by the navy and air force from the Swedish Armed Forces. The emissions are reported under (1A5) "Other".

In previous submissions, emissions from military use of aviation fuel were reported together with emissions from civil aviation under Civil aviation (CRF 1A3a) 19901999. In submission 2003 emissions from military use of aviation fuel were separated and reported under Other - mobile sources (CRF 1A5b).

\subsubsection{Intra-EU flights considered as national?}

While not reported anywhere, emissions from intra-EU flights could be separated as data is available at the level of city-pairs. 


\section{Methods for allocating emissions to parties}

The Parties to the UNFCCC have not yet been able to agree upon a methodology for allocating emissions from international aviation to Parties.

Under the negotiations, SBSTA has considered a number of options for allocating emissions from international aviation. The present chapter provides an introduction to these allocation methods.

From the outset, eight different allocation options were outlined and discussed by SBSTA. These include:

1 No allocation

2 Allocation in proportion to national emissions of Parties

3 Allocation to the country where the fuel is sold

4 Allocation to the nationality of airlines

5 Allocation to the country of destination or departure of aircraft. Alternatively, the emissions related to the journey of an aircraft could be shared by the country of departure and the country of arrival

6 Allocation to Parties according to the country of departure or destination of passenger or cargo. Alternatively, the emissions related to the journey of passengers or cargo could be shared by the country of departure and the country of arrival

7 Allocation to the country of origin of passengers or owner of cargo

8 Allocation according to emissions generated within each party's national space.

SBSTA concluded in 1996 that options 1, 3, 4, 5 and 6 were to be the basis for the further work and that in the case of non-allocation, the responsibility of the international community to address bunker fuels should be recognised. Options 2, 7 and 8 were rejected by SBSTA. Option 2 was rejected mainly because there would be no linkage between aviation activity and the amount allocated, which would go against the polluter pays principle and be an obstacle to regulation. Option 7 was rejected on the grounds of lacking data availability regarding the origin of passengers and freight. Option 8 was discarded mainly because limited coverage due to emissions taking place in international territory above international waters.

\subsection{No allocation to Parties}

The possible decision not to allocate emissions to individual countries should be seen in the context of considerations about establishing a system under ICAO to ensure emissions reductions and limitations.

Several Parties, experts and industry representatives question whether allocation to countries is a viable approach to dealing with the complex international aviation sector.

ICAO - the International Civil Aviation Organisation - is based on the Chicago Convention of 1944 and is a UN body covering legal and technical issues related to interna- 
tional aviation, including environmental issues. The highest body of ICAO is the Assembly, which meets every 3 years. The Council is the governing body. Legally binding annexes to the Chicago Convention are adopted by a two-thirds majority vote of the council. The Committee on Aviation Environmental Protection (CAEP) has 19 member states . Sweden is represented in CAEP by Ms. Karin Sjölin.

For several years, ongoing work within ICAO has been addressing options for emissions limitations. Among the measures considered are:

- Technology and standards

- Operational measures

- Market-based measures:

- Emissions trading

- Voluntary measures

- Fuel taxes and emission-related charges or taxes

CAEP has a number of Working Groups. WG5 consider market-based options for limiting emissions from international aviation. Its work covers the legal and data availability aspects of emissions trading, emissions charges and voluntary agreements.

In preparation of CAEP/6 which is scheduled for the beginning of 2004, a number of working groups are active.

ICAO's decisions are reflected in ICAO Assembly Resolutions referring to the role of ICAO in relation to UNFCCC and climate change. Resolution A33-7 requests the Council:

- To continue to study policy options to limit or reduce the environmental impact of aircraft engine emissions

- To develop concrete proposals and provide advice to UN FCCC as soon as possible

- To place special emphasis on the use of technical solutions while continuing its consideration of market-based measures

- To take into account the potential implications for developing as well as developed countries

Increasingly, there is a clear preference in ICAO toward an open international emissions trading system in which airlines trade emissions among themselves while at the same time opening the system toward purchases of emission credits from other industries. An emissions trading system is seen as a cost-effective measure to limit or reduce aviation $\mathrm{CO} 2$ in the long term. The International Air Transport Association (IATA) also favours an open emissions trading system.

The ICAO Assembly Resolution A33-7 from October 2001 requests the council to:

"...develop as a matter of priority the guidelines for open emissions trading for international aviation focussing on establishing the structural and legal basis for aviation's participation in an open trading system, and including key elements such as reporting, monitoring, and compliance, while providing flexibility to the maximum extent possible consistent with the UNFCCC process."

A range of complex design issues need to be addressed in the deliberations regarding an emissions trading system. The key issues these include: 
- How is an emissions limitation to be defined? Should it be "cap and trade" or in relation to an emissions baseline ${ }^{1}$

- To whom should allowances be allocated (fuel companies, airlines, or states)?

- How should allowances be distributed (through auctions or grandfathering, or combinations)?

- How should the system interact with the Kyoto Protocol? Should it be separate from KP but open to trading with credits?

- What should be the coverage of the system? Options considered include Annex I countries; Annex I countries excluding USA and Australia; Annex I countries + a number of NICs.

Secondary design issues that would also need to be considered include:

- Coverage of gases. Should other gases than $\mathrm{CO} 2$ be included? Should the radiative forcing from non- $\mathrm{CO} 2$ emissions and emissions at altitudes be accommodated by the system in the long run?

- Collection of data, monitoring, verification and reporting

- Liability rules

- Institutional setup

- Compliance rules

\subsection{Allocation to Parties according to the country where the bunker fuel is sold}

The rationale behind allocation according to where the fuel is sold is that the country of departure of the flight should be charged with the emissions and is in the best position to regulate departing traffic and the resulting emissions. Furthermore, it appears to be a relatively straightforward method in terms of data collection, which is also in line with the existing practices and IPCC guidelines. Finally, it is consistent with the way data is collected and emissions allocated for fuel use in other sectors, including road transport.

\subsection{Allocation to Parties according to the nationality of the airline}

Allocation of emissions according to the nationality of the airline is based on the premise that the emissions caused by the airline as a national business entity should be allocated to the country to which the airline belongs.

The exact wording by SBSTA of this allocation option is "allocation to Parties according to

- the nationality of the airline

- the country where the airline is registered or

- the country from where the airline is operated".

\footnotetext{
${ }^{1}$ A target relative to an emissions baseline will typically aim at improving efficiency rather than reducing absolute emissions, e.g. through a reduction of emissions per passenger kilometer.
} 
SBSTA has recognized the difficulty of applying the second and third variant, and so the analysis will use the first variant - the nationality of the airline. However, this is also not an unambiguous definition. SAS is an example of an airline owned jointly by several governments, and the nationality of privately owned airlines is not necessarily easily defined.

In terms of data availability, the method has the advantage of being able to benefit from data collection systems at the level of the individual airline, which can be expected to include detailed information of actual levels of fuel use, distances, origin/destination etc. Much of this information will however not be publicly available at present.

\subsection{Allocation to parties according to the country of destination or departure of the aircraft}

Under this option, emissions are allocated on the basis of the country of aircraft departure or destination. SBSTA is also considering an even split between the countries of departure and destination.

In case emissions are allocated solely to the country of departure, the difference between this method and allocation to the country where fuel is sold is limited to tankering, i.e. the situation where more fuel is taken on board than required for the following flight stage.

Data requirements to evaluate this option would include:

- origin, destination, flight distance and fuel use for flights departing from each country

- $\quad$ origin, destination, flight distance and fuel use for flights arriving in each country (in case of a split between country of departure and destination)

- information on the types of aircraft and the fuel use/emission characteristics of these aircraft.

\subsection{Allocation to Parties according to the country of destination or departure of passengers and cargo}

For this option, too, SBSTA is considering an even split between the countries of departure and destination, in this case with regard to passengers or cargo.

This allocation method would be the most data intensive of the methods that remain under consideration by SBSTA. Each airline would be required to keep records for each flight:

For each shipment/item of goods:

Exporting country, importing country, amount of freight and transport distance total emissions

For each passenger:

Country of departure, country of destination, transport distance. 
The total emissions for each flight stage would have to calculated. Next, they would have to be split between cargo and passengers, and subsequently among individual cargo shipments and passengers, respectively.

At present, information at this level of detail is not available. In terms of data on origindestination for passengers, two levels of detail may be considered.

One is labelled "on-flight origin-destination" which includes brief stopovers in airports to collect and drop passengers. Work is ongoing internationally in e.g. EUROSTAT to enhance data collection related to this.

The more comprehensive origin-destination data which includes stopovers and transfers to other flights would be very difficult to define and obtain.

\subsection{Status of international discussions about allocation methods}

In 1999, EU proposed a twin-track approach to dealing with the allocation of international aviation. The EU expressed that the option of no allocation should be considered further if ICAO makes "demonstrable progress", taking into account the overall emission reduction target of the Kyoto Protocol.

Alternatively, the emissions from international aviation could be included in the national inventories of the Parties. EU proposed that SBSTA should discuss these with a view to being able to reach an agreement on one option by 2005 .

In October 2001 the $33^{\text {rd }}$ ICAO Assembly adopted resolution A33-7 "Consolidated statement of continuing ICAO policies and practices related to environmental protection" which:

- Requests the ICAO Council to develop guidance for States on the application of market-based measures aimed at reducing or limiting the environmental impact of aircraft engine emissions, particularly in relation to climate change; and to develop concrete proposals and provide advice to the COP of UNFCCC;

- Endorses the development of an open emissions trading system for international aviation and requests the ICAO Council to develop guidelines for an emissions trading system, including key elements such as reporting, monitoring, and compliance, while providing flexibility to the maximum extent possible consistent with the UNFCCC process.

CAEP has recently initiated an analysis carried out by a consortium of consultants to investigate further how an emission trading system could work. 


\section{$8 \quad$ Principles and criteria for assessing allocation methods}

In order to perform an evaluation of the proposed allocation methods, a number of principles and criteria have been identified, and the allocation methods are evaluated against these in the Part II of the study.

The identification of principles and criteria has been based upon existing considerations within the Nordic countries, UNFCCC, IPCC, EU and ICAO, as well as the consultant's relevant experience from other work in relation to aviation and other sectors.

The performance of the allocation methods against the identified criteria are key determinants of political and industry acceptance.

\subsection{Allocation should be in accordance with the "Polluter Pays Principle"}

According to literature, the polluter pays principle is the requirement that the person responsible should bear the costs of pollution for causing the pollution and the consequential costs. However, the exact meaning of the principle and its application to various circumstances is subject to interpretation.

According to common interpretations of the principle, the polluters must pay for:

- the cost of pollution abatement;

- the costs of environment recovery and;

- the compensation costs for victims of damages if any, due to pollution.

When used in the context of allocation of GHG emissions with a view to mitigation of emissions, the emphasis is clearly on abatement costs. Furthermore, it is underlying the use of the concept that the "paying" will be linked to the use of economic instruments.

The main challenge in using the concept, which is also reflected in the range of allocation options proposed, is that identification of the polluter is no straightforward task. The range of actors that may be designated as polluters would include:

- The airlines (and thus the countries to which they belong) operating the airplanes that actually emit the greenhouse gases.

- The individuals (and thus the countries to which they belong) flying as passengers

- The economic entities on behalf of which individuals and goods are transported

- The countries between which the individuals and goods are travelling, because these must be expected to benefit from the economic activity. 


\subsection{Allocation should lead to minimum trade distortion among companies}

In an industry that is by nature globalized and is increasingly becoming more competitive, issues of trade distortion and competitiveness are very high on the list of criteria against which the different allocation options are evaluated.

Trade distortion may be analysed at two levels:

1. At the company/country level.

Allocation may lead to distortions among companies from

- Annex I countries with strong reduction companies

- Annex I countries with less restrictive commitments

- Non-Annex I countries without quantitative commitments

2. At the individual flight level:

The distortions from imposing obligations on some airlines on a route but not others are potentially severe.

\subsection{Allocation should reflect that only Annex I countries have Kyoto commitments}

Closely related to the issue of trade distortion among companies is the issue of how allocation is made to reflect the fact that non-Annex I countries have no Kyoto commitments and are reluctant to take on such commitments in the near to medium term.

The issue of "equity" is high on the agenda in the international climate change negotiations, primarily pushed by the developing countries who emphasize their right to pursuing economic development similar to what has been achieved by developed countries.

At the same time, some Newly Industrialized Countries are non-Annex I but with a strong presence in international aviation, and at some stage it is envisaged that these will be included in commitments under the Kyoto Protocol.

The coverage in terms of the share of emissions that are allocated of course depends on the participation of countries. Also affecting coverage is the question of how emissions resulting from travelling between an Annex I and a non-Annex I country are dealt with in the system.

In ICAO/CAEP, different alternatives are considered in terms of participating countries ranging from "Annex I minus" (i.e. excluding USA and Australia) via Annex I to "Annex I plus", which would include a number of NICs.

\subsection{Allocation should be comprehensive in terms of relevant greenhouse gases and radiative forcing}

The environmental effectiveness and integrity of the allocation scheme is a fundamental requirement. It is therefore important that the allocation reflects accepted science and measurement methodologies. Two main issues are important in relation to the question 
of how comprehensive allocation will be in terms of capturing the radiative forcing effect of emissions from international aviation.

One has to do with the gases that are covered by the Kyoto Protocol. Of the emissions caused by aviation, the three gases $\mathrm{CO} 2, \mathrm{~N} 2 \mathrm{O}$ and NH4 (methane) are covered by KP. While calculating $\mathrm{CO} 2$ emissions is relatively straightforward and can be done on the basis of top-down figures on fuel consumption, calculating emissions of $\mathrm{N} 2 \mathrm{O}$ and $\mathrm{NH} 4$ is complex and in principle would require detailed information at the level of type of engine which is available at the advanced Tier 2 level, and even there with some uncertainties. Using standardized emission factors at a more aggregate level has the implication that regulation using economic instruments will not be useful if the effects of technological and operational changes cannot be monitored and measured.

The second issue has to do with the effects of emitting non-Kyoto greenhouse gases such as water vapour at high altitudes as described in an earlier Section. Ideally, a system for allocating and regulating these emissions should be flexible enough to accommodate these emissions at a later stage when more scientific certainty has been established with regard to the effects of these emissions.

Inclusion of the "non-Kyoto" effects may not be effected from the outset, but the assessment of both data collection systems and allocation methods must include an the proposed system's ability to accommodate these effects as soon as the scientific and technical basis is available. In this respect it should also be noted that allocation and regulation including these non-Kyoto effects will actually provide the aviation industry and the airline companies with additional ways to influence emissions and effects through operational changes.

\subsection{Allocation should enable regulation of emissions by responsible authorities}

The important issue here is that the responsible authorities (which is for all but one allocation method the Parties to whom emissions are allocated) should be able to initiate regulation that affects the emissions from the sector.

Three main categories of regulation are available to the authorities:

1. Administrative regulation and incentives, e.g. through

- emission standards and other means of improving aircraft technologies

- operational procedures such as speed limits and initiatives to optimise the flow of traffic and flight routings

- . support for development of more environmentally friendly aircraft technologies

- behavioural measures such as awareness raising campaigns

2. Economic instruments, e.g.

- fuel charges/taxes

- emission charges

- emissions trading 
- removal of direct and indirect subsidies such as VAT and kerosene tax exemptions

3. Voluntary agreements between governments and the aviation industry, e.g. agreements on targets for average fuel efficiency. CAEP is analysing voluntary schemes, mainly as a transitional measure toward comprehensive regulation, e.g. in the form of an emissions trading scheme.

Many variations of these exist, and they may be combined, e.g. by introducing a voluntary emissions trading scheme.

An assessment of the regulatory options should take into consideration the mitigation measures that are available to the industry and how and by whom these are implemented. The following is a brief list of the main types of mitigation options:

1. Transport work (reduction potential)

2. GHG intensity per capacity (efficiency potential)

3. Fuel type (substitution potential)

4. Transport mode (substitution potential)

5. Load factor (optimisation potential)

6. Operational procedures (optimisation potential)

An inherent feature of the international civil aviation industry is its highly internationalized and competitive characteristics. For this reason, national regulatory measures are prone to have distortive effects. To some extent, these effects can be mitigated by undertaking regulation at an international level, e.g. within the EU. One of the arguments continuously put forward in favour of an international emissions trading system for aviation is the fact that it "lifts" the regulatory challenge out of the domain of the nation state. It is thus reasonable that the focus when applying this criterion is on the compatibility of the allocation method with market-based options, and not least an international emissions trading scheme.

The initial preferences put forward by the Nordic EU member states in response to the EU Questionnaire were:

\section{Denmark:}

- Voluntary agreements

- Information on "best practices"

- Emissions trading in an open system

Finland:

- Voluntary agreements

- Improved air traffic management systems 
Sweden:

- En route charges

- Voluntary agreements

\subsection{Allocation should not encourage strategic behaviour}

The allocation method should not encourage airlines or other actors to undertake actions that aim at avoiding emissions being allocated to a particular party and the corresponding regulatory measures. Such actions may include tankering of fuel in another country or outflagging of aircraft or airline companies to other countries.

The negative effects of strategic behaviour may undermine the environmental effectiveness and the economic efficiency of the allocation and regulatory scheme.

\subsection{Allocation should be administratively feasible}

A key issue in relation to administrative feasibility has to do with data collection and subsequent calculation and allocation of emissions.

To the widest extent possible, allocation should be possible on the basis of existing data systems and not require that new, complex data systems are established.

Existing data systems differ widely among Parties and even among the Nordic countries. And although some data systems and emissions calculation methodologies are very detailed, it is still a question to which extent they offer sufficient integrity, reliability and detail to form the basis for monitoring and verification of emissions, e.g. under an emissions trading scheme.

Although there are special characteristics and complexities involved in recording emissions from international aviation, the development of data systems may benefit from the ongoing developments in relation to the Kyoto Protocol, where systems to monitor and verify emissions are being developed for other sectors.

\subsection{Overview of allocation methods and evaluation criteria}

The below provides an overview of the allocation methods that will be assessed and the criteria against which this will take place in the subsequent phase of the project. 


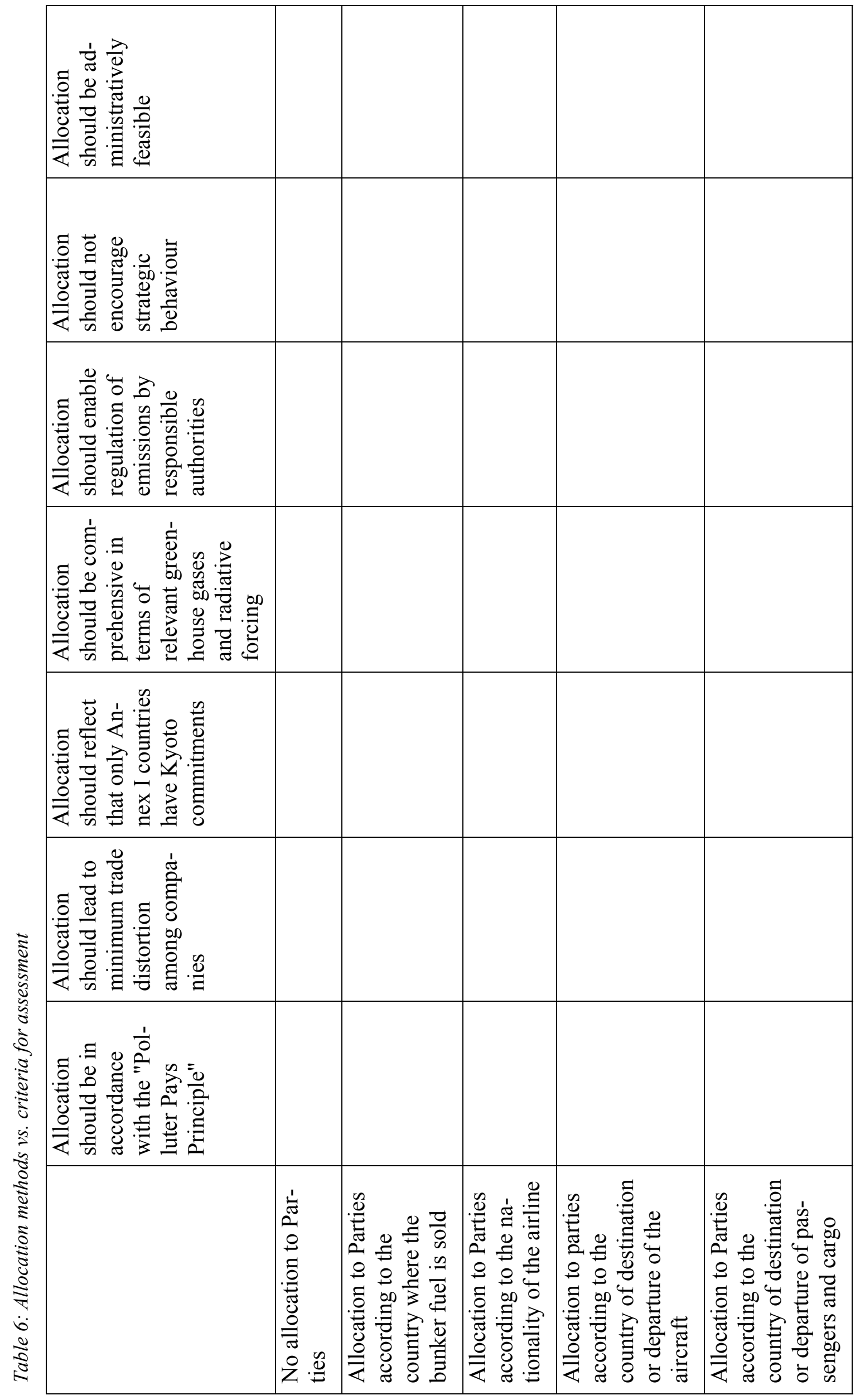




\section{Literature}

CORINAIR 2002, "EMEP CORINAIR Emission Inventory Guidebook - 3rd edition October 2002 UPDATE”, European Environment Agency, Copenhagen.

Davidson, Marc D. and R.C. Wit 2002, "Aviation and Climate Change - Search for effective global market-based options that secure interests of developing countries"

ECON 2003, "GHG Emissions from International Shipping and Aviation", Swedish Environmental Protection Agency.

EU 2001, Council Conclusions on Preparation of CoP7 in Marrakesh from 29 October to 9 November (29 October; article 5).

European Civil Aviation Conference 2003, "Summaries of discussions and decisions of the five CAEP meetings of the Steering Group in Orlando", presented at sixty-first meeting of the Group of Experts on the Abatement of Nuisances Caused by Air Transport

Finstad, Anne et al. 2002, "Emissions to Air from Norwegian Air Traffic". Report SN 2002 Utslipp til luft fra norsk luftfart 1989-2000 (Emissions to Air from Norwegian Air Traffic 1989-2000). Anne Finstad, Ketil Flugsrud og Kristin Rypdal. SN-report 2002:08.

IATA 2001, "Emissions trading for aviation", Workstream 3: Key findings and conclusions, Arthur Andersen 2001.

ICAO 2001, “A33-7 Consolidated statement of continuing ICAO policies and practices related to environmental protection", Resolution adopted at the 33rd Session of the ICAO Assembly, International Civil Aviation Organisation, Montreal, October 2001.

IPCC 1996, "Revised 1996 IPCC Guidelines for National Greenhouse Gas Inventories: Reference Manual"

IPCC 1999, "Aviation and the global atmosphere", Intergovernmental Panel on Climate Change, Cambridge University Press, UK

IPCC 2000, "Good Practice Guidance and Uncertainty Management in National Greenhouse Gas Inventories", Intergovernmental Panel on Climate Change, National Greenhouse Gas Inventories Programme, Technical Support Unit

Ministry of Environment, Denmark, 2003, "Denmark’s National Inventory Report"

Ministry of Environment, Finland, 2003, "National Inventory Report"

Ministry of Environment, Norway, 2003, "Denmark’s National Inventory Report"

Ministry of Environment, Sweden, 2003, "Sweden's National Inventory Report"

Nielsen, Stefan Krüger 2003a, "Greenhouse gas emissions from international aviation and allocation options", Environmental Project No. 769 2003, Danish Environmental Protection Agency 
Nielsen, Stefan Krüger 2003b, "Short summary of responses by EU Member States and the European Commission to the PAM questionnaire", Report for EU Climate Change Experts Meeting May 2003

UK Department for Transport, 2003, "Aviation and the Environment - Using Economic Instruments", Department for Transport

UNFCCC 1999a, "Methods used to Collect Data, Estimate and Report Emissions from International Bunker Fuels", draft report prepared for the UNFCCC secretariat by Det Norske Veritas (DNV)

UNFCCC 1999b, "Methodological issues - Emissions resulting from fuel used for international transportation", FCCC/SBSTA/1999/INF.4, United Nations Framework Convention on Climate Change

UNFCCC 1999c, "Methodological issues - Emissions resulting from fuel used for international transportation - ways to strengthen the exchange of information between the International Civil Aviation Organisation, the International Maritime Organisation and UNFCCC”, FCCC/SBSTA/1999/INF.9, United Nations Framework Convention on Climate Change

UNFCCC 1999d, "Methodological issues - Emissions resulting from fuel used for international transportation - submissions from parties", FCCC/SBSTA/1999/MISC.8, United Nations Framework Convention on Climate Change

UNFCCC 2001, "Methodological issues - Ongoing Activities on Reporting and Review of Greenhouse Gas Inventories in Parties Included in Annex I to the Convention - Report on the use of the UNFCCC reporting guidelines on annual inventories - note by the secretariat", FCCC/SBSTA/2001/5, United Nations Framework Convention on Climate Change

UNFCCC 2002, "Synthesis and Assessment Report on the Greenhouse Gas Inventories Submitted in 2001 - Note by the secretariat", FCCC/WEB/SAI/2001, United Nations Framework Convention on Climate Change

UNFCCC 2003, "Methodological issues. Emissions resulting from fuel used in international aviation and maritime transportation", Note by the secretariat FCCC/SBSTA/2003/INF.3, United Nations Framework Convention on Climate Change

Velzen, A. and R.C.N. Wit 2000, "National allocation of international aviation and marine CO2-emissions - A study commissioned by the Dutch Civil Aviation Authority", Centre for energy conservation and environmental technology (CE), Delft, the Netherlands.

Winther, M. 2001, “1998 fuel use and emissions for Danish IFR Flights”, Environmental Project No. 628, Danish Environmental Protection Agency, Copenhagen. 


\section{Part II:}

Assessment of Allocation Methods 



\section{Table of Contents}

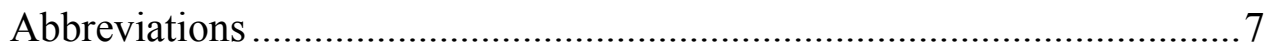

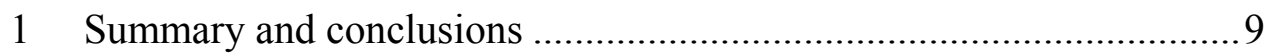

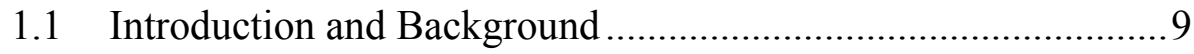

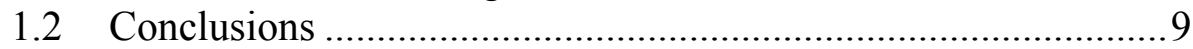

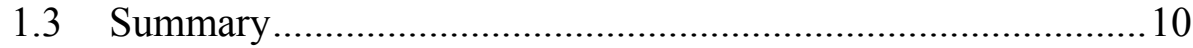

2 Introduction and background ........................................................23

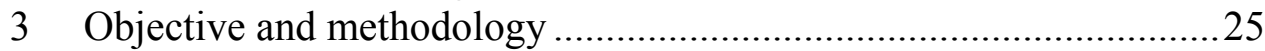

4 Qualitative assessment of alternative allocation methods

- approach and context ...................................................................22

4.1 Allocation, regulation and commitments are closely linked.....29

5 Qualitative assessment of allocation method 2: Allocation to

Parties according to the country where the bunker fuel is sold .......... 33

5.1 Background and interpretation ................................................ 33

5.2 Allocation should enable regulation of emissions by

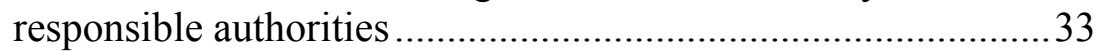

5.3 Allocation should be in accordance with the "Polluter Pays Principle" ............................................................................ 34

5.4 Allocation should lead to minimum trade distortion among

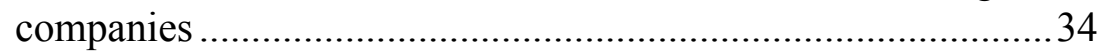

5.5 Allocation should reflect that only Annex I countries have

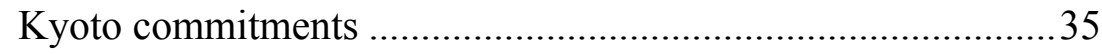

5.6 Allocation should be comprehensive in terms of relevant greenhouse gases and radiative forcing .................................... 35

5.7 Allocation should not encourage strategic behaviour ................36

5.8 Allocation should be administratively feasible ..........................36

6 Qualitative assessment of allocation method 3: Allocation to

Parties according to the nationality of the airline ...............................37

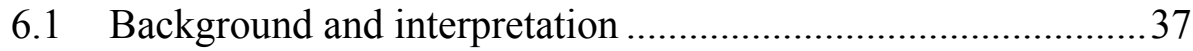

6.2 Allocation should enable regulation of emissions by

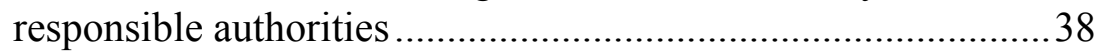

6.3 Allocation should be in accordance with the "Polluter Pays

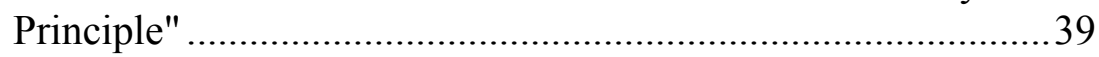

6.4 Allocation should lead to minimum trade distortion among

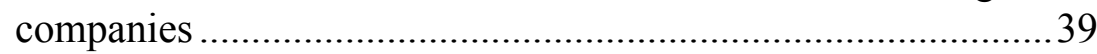

6.5 Allocation should reflect that only Annex I countries have Kyoto commitments ..............................................................40

6.6 Allocation should be comprehensive in terms of relevant greenhouse gases and radiative forcing .....................................4 40

6.7 Allocation should not encourage strategic behaviour ...............40

6.8 Allocation should be administratively feasible .........................41 
7 Qualitative assessment of allocation method 4: Allocation to parties according to the country of destination or departure of the aircraft .....

7.1 Background and interpretation .............................................. 43

7.2 Allocation should enable regulation of emissions by responsible authorities.

7.3 Allocation should be in accordance with the "Polluter Pays Principle"

7.4 Allocation should lead to minimum trade distortion among companies

7.5 Allocation should reflect that only Annex I countries have Kyoto commitments

7.6 Allocation should be comprehensive in terms of relevant greenhouse gases and radiative forcing ................................ 45

7.7 Allocation should not encourage strategic behaviour ...............46

7.8 Allocation should be administratively feasible ........................46

8 Qualitative assessment of allocation method 5: Allocation to Parties according to the country of destination or departure of passengers and cargo

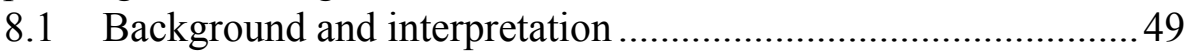

8.2 Allocation should enable regulation of emissions by responsible authorities

8.3 Allocation should be in accordance with the "Polluter Pays

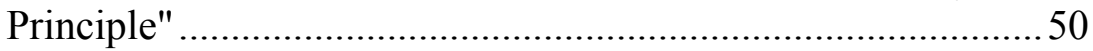

8.4 Allocation should lead to minimum trade distortion among companies

8.5 Allocation should reflect that only Annex I countries have

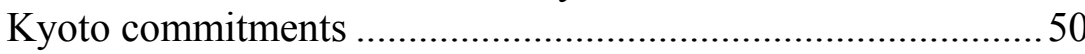

8.6 Allocation should be comprehensive in terms of relevant greenhouse gases and radiative forcing...................................5 51

8.7 Allocation should not encourage strategic behaviour ...............51

8.8 Allocation should be administratively feasible ........................52

9 Qualitative assessment of allocation method 1: No allocation to

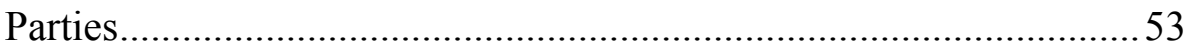

9.1 Background and interpretation ...............................................53

9.2 Allocation should enable regulation of emissions by responsible

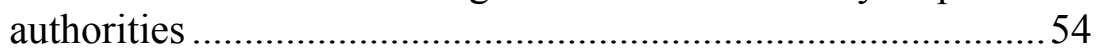

9.3 Allocation should be in accordance with the "Polluter Pays

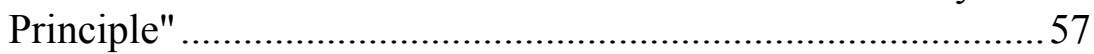

9.4 Allocation should lead to minimum trade distortion among

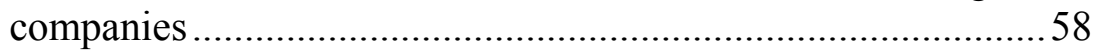

9.5 Allocation should reflect that only Annex I countries have Kyoto commitments

9.6 Allocation should be comprehensive in terms of relevant greenhouse gases and radiative forcing..................................59

9.7 Allocation should not encourage strategic behaviour ...............59

9.8 Allocation should be administratively feasible .........................60 
10 Quantitative assessment of alternative allocation methods 61

10.1 Quantitative assessment of alternative allocation methods - approach and context.

10.2 Method 2: Allocation to Parties according to the country where the bunker fuel is sold. 61

10.3 Method 3: Allocation to Parties according to the nationality of the airline

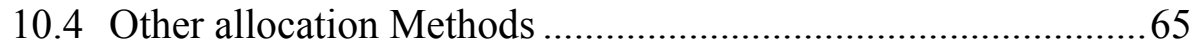

10.5 Comparison of allocation methods ...........................................66

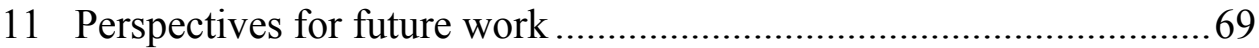

11.1 Emissions trading from a Nordic perspective ..........................69

11.2 EU regulation from a Nordic perspective...............................69

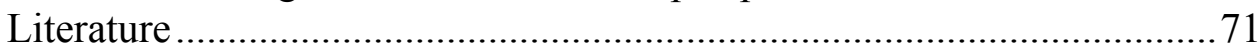




\section{Abbreviations}

ANCAT Group of Experts on the Abatement of Nuisances Caused by Air Transport (under ECAC)

Annex I coun- Industrialised countries under the UNFCCC (and for simtries plicity assumed to be identical to Annex B countries under the Kyoto Protocol)

CAEP Committee on Aviation Environmental Protection

COP Conference of the Parties (of UNFCCC)

CORINAIR CORe INventory of AIR emissions

ECAC European Civil Aviation Confence

EEA

European Environment Agency

EMCAL

ANCAT Subgroup on Emissions Calculations

EMEP

European Union Emission Inventory Programme

IATA

International Air Transport Association

ICAO

International Civil Aviation Organization

IEA

International Energy Agency

IPCC

Intergovernmental Panel on Climate Change

LTO

Landing and Take Off

NIR

National Inventory Report

SBSTA

Subsidiary Body for Scientific and Technological Advice

TRENDS

Transport and Environment Database System Project

UNECE

United Nations Economic Commission for Europe

UNFCCC

United Nations Framework Convention on Climate

Change 


\section{Summary and conclusions}

\subsection{Introduction and Background}

This report has been produced for the Working Group on Sustainable Mobility under the Nordic Council of Ministers.

The report includes a review and assessment of the data and methodologies in relation to calculation and reporting of the energy consumption and greenhouse gas emissions from international aviation, as well as issues related to allocation of these emissions to countries. The emphasis is on the assessment of opportunities, advantages and disadvantages of the different methodologies and principles for allocation to the Nordic countries.

$\mathrm{CO}_{2}$ emissions from international aviation are not covered by the reduction and limitation commitments under the Kyoto Protocol. However, the emissions from international aviation are growing rapidly, and if they are to be included in the reduction efforts by Annex I countries, they will have to be allocated to parties who are or will become responsible in relation to the reduction commitments of the Protocol.

The Nordic governments have expressed concern about the increase of international greenhouse gas emissions from international aviation, and are therefore interested in an analysis and assessment of the options for quantifying and allocating the emissions from international aviation to the Nordic countries.

\subsection{Conclusions}

Based on the qualitative and quantitative assessment of different allocation methods the following general conclusions may be drawn:

- GHG emission from aviation consists of several gases, including $\mathrm{CO}_{2}, \mathrm{~N}_{2} \mathrm{O}$, methane and vapour. The contribution to climate change may be 2-4 times larger than that of $\mathrm{CO}_{2}$ emissions alone. This aspect is important to consider in a potential future allocation and commitment regime as the specific GHG emission from individual flights can be influence by the flying pattern and thus provide the flight operators with options to reduce emissions. This report however only deals with $\mathrm{CO}_{2}$ emissions.

- Allocation, commitments and regulation can not be separated. Basically it is the commitments that makes the allocation important. Whether allocation to a party is an asset or a liability clearly depends on the reduction commitments of the party and on the regulatory options realistically available

- A number of different allocation methods exist, either based on allocation of $\mathrm{CO}_{2}$ emission to countries or allocation to the aviation industry itself. Extensive data requirements are likely to disqualify several of the options, but also difficulties for the countries to implement adequate regulation that is in accordance with the allocation method is a major concern. There is a high risk that allocation to countries is difficult to match with adequate regulatory measures to meet commitments. The industry is highly mobile and operates globally, and there is a high risk that national 
regulation, e.g. $\mathrm{CO}_{2}$ taxes, will make airlines change their routes and their tankering pattern to avoid the regulation.

- Unilateral regulation is particularly exposed to the risk of distorting the aviation market and therefore difficult to implement. This risk is less in case of multilateral regulation, for instance at EU level, or in case of industry based commitments and regulation.

- There are many arguments in favour of an industry based allocation and commitment system, particularly concerning the industries access to relevant data and the better opportunities for regulating emissions without distorting the aviation market. There is an increasing interest in the European aviation industry for establishing an emissions trading scheme, for instance in relation to the coming $\mathrm{EU} \mathrm{CO}_{2}$ emissions trading scheme.

- Allocation of $\mathrm{CO}_{2}$ to the Nordic countries in total is $7 \%$ higher when allocated according to the fuel consumption of the airlines in the Nordic countries than when allocated according to the sales of bunker fuel in each country. However the difference between allocation methods is larger for several of the individual Nordic countries, particularly are the allocation higher for Finland and Iceland when the nationality of the airlines is used whereas allocation is larger to Denmark when allocation according to the sales of bunker fuel is used.

- An allocation system that include flights to and from countries in Annex I of the Kyoto Protocol account for $85 \%$ of the $\mathrm{CO}_{2}$ emission from international aviation from the Nordic airline companies, the remaining $15 \%$ originates from flights to Non-Annex I countries.

The following section provides a rather extensive summary of both Report Part I and Report Part II.

\subsection{Summary}

The overall objective of the Study is to contribute to a common understanding among the Nordic countries regarding the inclusion of greenhouse gases from international aviation in the UNFCCC and its Kyoto Protocol. The immediate objective is to:

- Identify the availability and quality of data reported to UNFCCC by the Nordic countries on emissions from international aviation

- Identify and assess different opportunities, advantages and disadvantages of different methods to allocate emissions to countries, seen from a Nordic perspective. The assessment of alternative methods is based on principles and criteria that are of relevance to the Nordic countries.

The methodological approach of the Study has been to focus on three elements, the first two of which are reported in Part I of the Report, while the second is reported in Part II:

Part I: $\quad$ 1. Data availability and emission calculation methodologies

2. Allocation of emissions to countries

Part II: $\quad 3$. Assessment of allocation methodologies

\subsubsection{Data availability and emission calculation methodologies}

Reporting requirements, guidelines and methodologies are established by UNFCCC and IPCC and include different levels of detail and approach (Tier 1/top-down vs. the more 
detailed Tier 2/bottom-up). Reporting from Annex I countries for the most part comply with the requirements, although a number of sources of inconsistency have been identified:

- $\quad$ varying interpretations of e.g. definitions, assumptions, etc.

- erroneous data or data simplification

- uncertainties in the socio-economic data

- uncertainties in the scientific understanding of processes leading to emissions.

The most important international methodological frameworks and data sources for emissions calculation and reporting comprise the following:

CORINAIR

CORINAIR is a joint European system managing a European air emission inventory and database system. All of the Nordic countries are covered by the CORINAIR project, which is not limited to emissions relevant to climate change. The emission data from CORINAIR are at a higher level of detail than required for reporting under international obligations. The latest version of the CORINAIR methodology can be used for determining air emissions for individual flights. However, significant differences remain between countries in terms of data availability.

TRENDS

The TRENDS project between Eurostat, EUROCONTROL and EEA have produced detailed fuel consumption and emissions estimates. Detailed flight data from EUROCONTROL in combination with Corinair emission calculation methodology could develop into a system of precise and comprehensive data on European emissions from aviation, also enabling the distinction between domestic, intra-EU, and international traffic.

\section{Other sources}

$I C A O$ 's Member States are to ensure that its international airlines submit the statistics requested by the Council of ICAO. The ICAO statistical programme is capable of providing detailed fuel consumption figures for individual flights. This could provide the basis for inventories, although only for scheduled international flights.

International Energy Agency, IEA, statistics are based on national reporting using a Joint IEA/Eurostat/UNECE annual questionnaire. The IEA data differ from IPCC in that they include military aviation fuel use. Other differences compared to IPCC are: 1) IEA does not calculate emissions of other greenhouse gases and 2) other emission factors can be used.

The European Civil Aviation Confence, (ECAC), has established a "Group of Experts on the Abatement of Nuisances Caused by Air Transport" (ANCAT). Guidelines developed under ANCAT are parallel to the different tiers provided under IPCC and CORINAIR.

The Long Range Transboundary Air Pollution Convention, UNECE collects emissions data on $\mathrm{CO} 2$ emissions for the whole duration of the flight, and on non-CO2-emissions from the LTO phase only.

Emission inventory models for international aircraft emission have been developed in several projects. As a general rule, these model-based inventories are not based on accurate data on flights actually performed by all airlines globally. 


\section{Major issues in relation to data and methodologies}

The main issues of importance to data and methodologies for estimating and reporting emissions from international aviation include:

\section{Separation of national and international bunker fuels}

A review of the methodologies applied by Annex I Parties for disaggregating fuel use data into domestic and international components shows that there is no uniform approach to the issue, to a large extent due to different definitions and guidelines among different institutions, including IPCC, IEA and ICAO.

\section{The importance of cruising altitude and non-CO2 emissions}

According to IPCC, the contribution to climate change from commercial air transport in terms of total radiative forcing may be 2-4 times higher than that of $\mathrm{CO} 2$ emissions from aircraft alone. This is due to two interrelated factors, one being the effects of non$\mathrm{CO} 2$ emissions, and the other the effects of emissions taking place at high altitudes. Methodological work is ongoing aiming to provide reliable estimates of total aviation emissions.

\section{Separation of fuel for military aircraft from fuel for civil aircraft}

According to UNFCCC guidelines, fuel consumed by military aircraft should be separated from fuel consumed by civil aircraft and reported separately under the Source/sink category 1A5, "Other". This is different from IEA reporting guidelines, where all of a country's military air-craft emissions are included under domestic aviation.

\section{Overseas territories}

According to the IPCC/UNFCCC reporting guidelines, emissions from flights to and from overseas territories should be included in national inventories as domestic, but this is not fully applied in practice.

\section{Annex I vs. non-Annex I country emissions}

Around one third of $\mathrm{CO}_{2}$ emissions from international aviation relate to fuel sold in nonAnnex I countries. Part of this is likely to be consumed by airlines from Annex I countries, airlines transporting passengers and goods originating from Annex I countries and/or flights going to Annex I country destinations. These data are unreliable but could become necessary in order to calculate and allocate emissions to Annex I countries.

\section{Passenger/freight loads and their origin/destination}

None of the existing databases or models includes detailed information on the actual passenger and freight loads transported by the aircraft, let alone the origin and destination of these loads.

\section{Intra-EU flights domestic or international}

The European Community is an individual signatory to the UNFCCC and the Kyoto Protocol, and it cannot be ruled out that emissions from intra-EU aviation among two Member States will have to be reported as domestic emissions under the EU "bubble" and thus be subject to the Kyoto Protocol emissions reduction target.

\section{Methodologies and data for the Nordic countries}

\section{Denmark}

Denmark applies the detailed CORINAIR methodology for estimating emissions, including emission factors. Activity data for air traffic consist of air traffic statistics provided by the Danish Civil Aviation Agency (DCAA) and Copenhagen Airport. As from 
2001, records are given per flight by CAA-DK including aircraft type and origin and destination airports.

The Danish Energy Authority (DEA) collects monthly data on sales of jet fuel and aviation gasoline by the oil companies to the Danish airports. For aviation bunkers, the sales statistics do not distinguish between fuel sold for domestic and international purposes.

\section{Finland}

There are differences in the definitions of international transportation (international bunker emissions) in two systems applied. The overall Finnish GHG inventory is based on the IPCC Tier 1 methodology. Statistics Finland receives statistics on total bunker fuel sales from fuel distributors in Finnish Petroleum Federation (FPF).

In 1996, the Technical Research Centre of Finland (VTT) completed a calculation system named LIPASTO, which covers emissions and energy consumption of all traffic modes in Finland. The model calculates emissions and energy consumption of civil aviation inside Finnish flight information regions (FIRs) and thus does not apply the IPCC definitions of national vs. international.

\section{Iceland}

Emissions are calculated on the basis on fuel sold, according to the IPCC Tier 1 method. The National Energy Authority collects data on fuel use from three oil companies and data from the country's four international airlines. As the international airport is separate from the domestic, the separation of fuel use is relatively straightforward.

\section{Norway}

The consumption of aviation bunker fuel in Norway reported to the UNFCCC, is estimated as the difference between total purchases of jet kerosene in Norway for civil aviation (Petroleum Statistics) and reported domestic consumption. The bottom-up approach of Norway is the detailed Tier2 CORINAIR methodology. The methodology is based on detailed information on types of aircraft and number of LTOs as well as average cruise distances.

\section{Sweden}

A consortium consisting of two government agencies and an environment research institute - SMED - is cooperating to calculate emissions from Swedish aviation. Sweden uses the bottom-up IPCC Tier 2 method for estimating $\mathrm{N} 2 \mathrm{O}$ and $\mathrm{CH} 4$ emissions from international aviation. $\mathrm{CO} 2$ emissions are calculated using IPCC Tier 1 method. The bottom-up figures are ultimately checked with and adjusted to correspond to the topdown figures.

The Swedish Civil Aviation Administration (SCAA) calculates the use of civil aviation fuels in accordance with detailed CORINAIR guidelines. The method is based on information on aircraft, engine, departure airport, arrival airport, domestic and international LTO, domestic and international cruise, and purpose of flight.

The separation of national and international bunker fuels is done on the basis of bottomup information from SCAA regarding domestic and international flights. While not reported anywhere, emissions from intra-EU flights could be separated as data is available at the level of city-pairs. 


\subsubsection{Methods for allocating emissions to parties}

The Parties to the UNFCCC have not yet been able to agree upon a methodology for allocating emissions from international aviation to Parties, but the technical subcommittee SBSTA has considered various methods for allocating emissions and has selected a number of these for further consideration. These include:

1. No allocation to Parties

2. Allocation to the country where the fuel is sold

3. Allocation to the nationality of airlines

4. Allocation to the country of destination or departure of aircraft

5. Allocation to Parties according to the country of departure or destination of passengers or cargo.

\section{No allocation to Parties}

The possible decision not to allocate emissions to individual countries should be seen in the context of considerations about establishing a system for instance under ICAO to ensure emissions reductions and limitations.

Several Parties, experts and industry representatives question whether allocation to countries is a viable approach to dealing with the complex international aviation sector. Increasingly, there is a clear preference in ICAO toward an open international emissions trading system in which airlines trade emissions among themselves while at the same time opening the system toward purchases of emission credits from other industries. An emissions trading system is seen as a cost-effective measure to limit or reduce aviation $\mathrm{CO} 2$ in the long term. The International Air Transport Association (IATA) also favours an open emissions trading system.

A range of complex design issues need to be addressed in the deliberations regarding an emissions trading system. The key issues these include:

- How is an emissions limitation to be defined? Should it be "cap and trade" or relative to an emissions baseline

- To whom should allowances be allocated (fuel companies, airlines, or states)?

- How should allowances be distributed (through auctions or grandfathering, or combinations)?

- How should the system interact with the Kyoto Protocol? Should it be separate from KP but open to trading with credits?

- What should be the coverage of the system? Options considered include Annex I countries; Annex I countries excluding USA and Australia; Annex I countries +a number of NICs.

\section{Allocation to the country where the fuel is sold}

The rationale behind allocation according to where the fuel is sold is that the country of departure of the flight should be charged with the emissions and is in the best position to regulate departing traffic and the resulting emissions. Furthermore, it appears to be a relatively straightforward method in terms of data collection, which is also in line with the existing practices and IPCC guidelines. Finally, it is consistent with the way data is collected and emissions allocated for fuel use in other sectors, including road transport. 


\section{Allocation to Parties according to the nationality of the airline}

Allocation of emissions according to the nationality of the airline is based on the premise that the emissions caused by the airline as a national business entity should be allocated to the country to which the airline belongs.

\section{Allocation to the country of destination or departure of aircraft}

Under this option, emissions are allocated on the basis of the country of aircraft departure or destination. SBSTA is also considering an even split between the countries of departure and destination.

\section{Allocation to Parties according to the country of departure or destination of passenger or cargo}

The rationale for this allocation method appears to be the notion that it is more "fair" than other methods. It is based on the premise that emissions should be allocated to the countries that "export" and/or "import" cargo or passengers as these are seen as the polluters. Data requirements are extensive and at present, information at this level of detail is not available.

\section{Principles and criteria for assessing allocation methods}

A number of principles and criteria have been identified against which the allocation methods have been evaluated.

\section{Allocation should enable regulation of emissions by responsible authorities} Three main categories of regulation are available to the Parties:

- Administrative regulation and incentives, e.g. through emission standards; operational procedures; support for technology development

- Economic instruments, e.g. taxes, charges and emissions trading.

- Voluntary agreements between governments and the aviation industry.

An inherent feature of the international civil aviation industry is its highly internationalized and competitive characteristics. For this reason, national regulatory measures are prone to have distortive effects. To some extent, these effects can be mitigated by undertaking regulation at an international level, e.g. within the EU. Assessment of the regulatory options should take into consideration the mitigation measures that are available to the industry, including reduced transport work, reduced GHG intensity per capacity, improved load factor, route optimisation etc.

\section{Allocation should be in accordance with the "Polluter Pays Principle"} Application of the PPP requires identification of the "polluter", which is no straightforward task for international aviation. The range of actors that may be designated as polluters would include:

- The airlines (and thus the countries to which they belong) operating the air-planes that actually emit the greenhouse gases.

- The individuals (and thus the countries to which they belong) flying as passengers

- The economic entities on behalf of which individuals and goods are trans-ported

- The countries between which the individuals and goods are travelling, be-cause these must be expected to benefit from the economic activity.

\section{Allocation should lead to minimum trade distortion among companies} In an industry that is by nature global and is increasingly becoming more competitive, issues of trade distortion and competitiveness are high on the list of criteria against which the different allocation options are evaluated. Trade distortion may be analysed at company/country level, and allocation may lead to distortions among companies from 
- Annex I countries with strong reduction companies

- Annex I countries with less restrictive commitments

- Non-Annex I countries without quantitative commitments

Distortion may also arise at the individual flight level. The distortions from imposing obligations on some airlines on a route but not others are potentially severe.

Allocation should reflect that only Annex I countries have Kyoto commitments Closely related to the issue of trade distortion among companies is the issue of how allocation is made to reflect the fact that non-Annex I countries have no Kyoto commitments and are reluctant to take on such commitments in the near to medium term.

The issue of "equity" is high on the agenda in the international climate change negotiations, primarily pushed by the developing countries who emphasize their right to pursuing economic development similar to what has been achieved by developed countries.

At the same time, some Newly Industrialized Countries are non-Annex I but with a strong presence in international aviation, and at some stage it is envisaged that these will be included in commitments under the Kyoto Protocol.

\section{Allocation should be comprehensive in terms of relevant greenhouse gases and radiative forcing}

The environmental effectiveness and integrity of the allocation scheme is a fundamental requirement. It is therefore important that the allocation reflects accepted science and measurement methodologies. A key issue is the ability to capture the largest possible share of the radiative forcing effect of emissions from international aviation.

Of the emissions caused by aviation, the three gases CO2, N2O and NH4 (methane) are covered by the Kyoto Protocol. While calculating CO2 emissions is relatively straightforward and can be done on the basis of top-down figures on fuel consumption, calculating emissions of $\mathrm{N} 2 \mathrm{O}$ and $\mathrm{NH} 4$ is complex and would require detailed activity data. The same is true for the effects of emitting non-Kyoto greenhouse gases such as water vapour at high altitudes. Ideally, a system for allocating and regulating these emissions should be flexible enough to accommodate these emissions once more scientific certainty has been established.

Allocation and regulation including these non-Kyoto effects will actually provide the aviation industry and the airline companies with additional ways to influence emissions and effects through operational changes.

\section{Allocation should not encourage strategic behaviour}

The allocation method - and the related regulation mechanisms applied - should not encourage airlines or other actors to undertake actions that aim at avoiding emissions being allocated to a particular party and the corresponding regulatory measures. Such actions may include tankering of fuel in another country or "outflagging" of aircraft or airline companies to other countries.

\section{Allocation should be administratively feasible}

A key issue in relation to administrative feasibility has to do with data collection and subsequent calculation and allocation of emissions. To the widest extent possible, allocation should be possible on the basis of existing data systems and not require that new, complex data systems are established. Existing data systems differ widely among Parties and even among the Nordic countries. 


\subsubsection{Qualitative assessment of alternative allocation methods}

\section{General findings}

\section{Allocation, regulation and commitments are closely linked}

There is a very close interrelationship between

- allocation method

- quantitative commitments to reducing or limiting emissions and

- regulation of emissions

The allocation method has a strong bearing on the options available to the responsible party to regulate emissions and thus meet its commitments. In turn, commitments can only be evaluated when seen in the context of allocation methods and the regulatory options available to the Party. The analysis show that the outcome of the assessment of the allocation methods against the criteria depends not only on the allocation method but on the combination of allocation method and the expected measures used to regulate emissions.

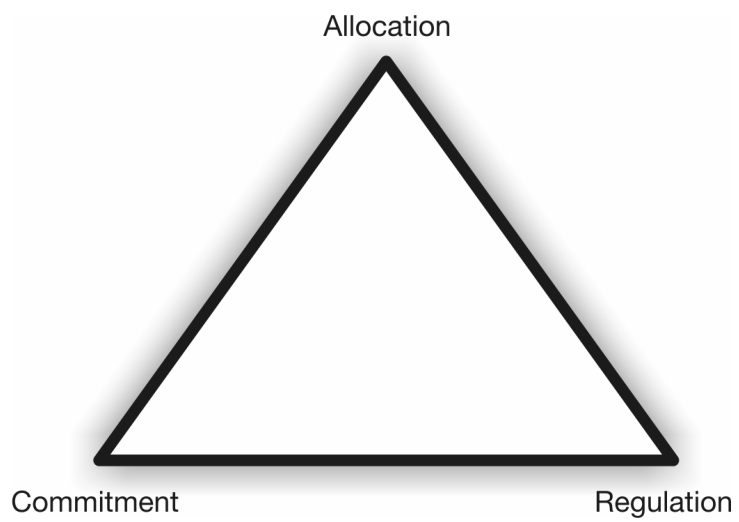

The type and intensity of regulation considered by a party will reflect i.a.:

- the allocation method

- the ability to apply the regulatory instrument without creating distortion of competition

- the country's overall reduction/limitation commitment relative to a base year and the burden this puts on the country relative to a "business as usual" scenario.

- the country's approach to complying with its obligations, including decisions on which sectors shall bear the costs of achieving compliance.

Even though most of the regulation options (with emissions trading as the exception) are normally considered in the context of national allocation, it is generally the case that they do not easily lend themselves to national implementation. They are often unlikely to win political support or to be effective if implemented at the level of individual countries. Rather, they require international cooperation, which at a regional level could be within the EU or at a global level could be under ICAO jurisdiction. This can be explained by the following three features of the international aviation industry:

- Most allocation methods will lead to allocation to a given country of emissions caused by airlines from other countries over which the country has little regulatory control. 
- Existing international agreements limit regulatory "interference" with the industry, e.g. in the form of taxation. The Chicago Convention exempts international aviation from taxation.

- Competition concerns, as unilateral regulatory measures will often be distortive to the disadvantage of the country's own airlines, possible providing incentives to strategic behaviour which will in turn divert traffic from the country in question.

\section{National Allocation}

National allocation will impose responsibilities on national authorities and is likely to require or at least favour national regulation, for instance in terms of taxes and charges. It is widely recognised that national allocation is inherently problematic given the global character of the industry.

There is no straightforward way to assess the significance of the size of allocated amounts as the allocated amounts only can be properly assessed when the associated commitments and regulatory regime are taken into account. Whether or not allocation of emissions to a country is on balance an asset or a liability primarily depends on:

- The base year emissions, the limitation commitments and the emission scenarios.

- Risk and uncertainty. The bigger the share of international emissions allocated to a country, the bigger the uncertainty and exposure to changes in the industry.

- Ability to enforce regulation. A key issue is the country's ability to design and enforce regulation of that part of the industry's activities that lead to allocation to the country of emissions.

\section{Allocation to the aviation industry}

Allocation that is not based on countries/Parties as responsible entities may be more in line with the global character of the industry. Most regulatory schemes are implemented more effectively and with less distortive effects at a supra-national level.

In the ongoing discussions about allocation to the industry rather than to Parties, this option is linked to international regulation through an emissions trading scheme. The findings show that this approach may offer advantages compared to national allocation methods in relation to regulation, trade distortion, coverage and strategic behaviour. Proponents of industry-based allocation and emissions trading scheme see a linkage to the Kyoto mechanisms as a prerequisite and the main justification of the scheme, since access to emission allowances and credits from other industries is the only way that the industry can avoid the consequences of relatively high mitigation costs within the industry.

\section{Regulation and not allocation is the source of distortion}

Possible distortive effects do not result from the allocation method per se, but as a result of the specific regulation applied by a Party.

- The most distortive effect would take place in the case of regulation - e.g. in the form of activity-based taxes and charges - were to be applied unilaterally by a Party. The scale of the distortive effects would depend on the specific regulation and its application.

- Coordinated regulation among several countries, e.g. within the EU, would reduce the risk of distorting competition.

- Even if coordinated regulation were to take place among all Annex B countries, potential distortion may arise from the fact that countries not belonging to Annex B have no quantitative commitments under Kyoto. 


\section{Qualitative assessment of allocation methods:}

Method 2.Allocation to Parties according to the country where the bunker fuel is sold There is general agreement that allocation based on the country where the fuel is sold is the most manageable on the basis of data available today. Furthermore, this allocation method is apparently attractive since the country where the fuel is sold would be able to regulate the amount of departing traffic, e.g. through taxation and charges directly on fuel or indirectly on e.g. goods and passengers.

However, these regulation methods are difficult or impossible to implement as strictly national initiatives and require internationally coordinated efforts to avoid distortions of competition and strategic behaviour. Trade distortion would not result from the allocation method per se, but as a result of the specific regulation applied by a Party.

If regulation takes the form of a fuel tax placed on departing flight, a strategic response from the airlines may be an increase in tankering, i.e. the situation where more fuel is taken on board than required for the following flight stage.

The allocation method is inherently focused on $\mathrm{CO} 2$ emissions. The data collected would not be a sufficient basis for the calculation of other emissions and effects.

\section{Method 3: Allocation to Parties according to the nationality of the airline}

Defining the nationality of an airline is likely to be a complicated issue. SAS is a prime example, being an airline with shared ownership by three countries as well as private shareholders. Given the dynamic and volatile structure of the international airline industry, these complexities are likely to increase in the future.

Allocation based on nationality of airlines is most compatible with those types of regulation that target the company-level, such as voluntary agreements with airlines on efficiency or an airline-based emissions trading scheme.

Much of the activity of the airlines regulated would take place under circumstances over which the government may have little control, e.g. if airlines operate routes that do not depart or arrive in its home country. Furthermore, international competition would make unilateral, uncoordinated regulation potentially distortive. The possibility to outflag airlines is likely to increase in future, which will further reduce the ability to regulate at the national level.

Although only emissions from airlines in Annex I countries would be allocated, it remains to be decided which international routes should be covered. If two airlines - one from Annex I and one from a non-Annex I country - were to operate the same route, potential distortion may be significant.

The allocation method would benefit from data collection systems at the level of the individual airline, which can be expected to include detailed information of actual levels of fuel use, distances, origin/destination etc. These data collection systems could potentially be expanded to include non- $\mathrm{CO} 2$ effects.

\section{Method 4: Allocation to parties according to the country of destination or depar- ture of the aircraft}

Under most assumptions, this allocation method is likely to produce results that are similar to allocation based on the country where fuel is sold. If allocation to the country of departure is applied, the scope for regulation should also be similar to allocation based on fuel sale, as the country of departure should be able to put into effect regulation of departing traffic. 
Regulation is difficult or impossible to implement as strictly national initiatives and require internationally coordinated efforts to avoid trade distortions and strategic behaviour.

Like for other methods, it will have to be decided how routes to and from non-Annex I countries are dealt with under this method. The minimum coverage would include only journeys between Annex I countries.

The allocation requires that flight data are collected on individual flights. This provides an opportunity to put in place data collection systems that may be adapted to include emissions and effects that are beyond the Kyoto gases.

\section{Method 5: Allocation to Parties according to the country of destination or depar- ture of passengers and cargo}

This allocation method would be the most complex of the ones that are under consideration by SBSTA. The complexity refers both to the exact interpretation of the method and to the collection of the data that would be required to implement it. The most comprehensive interpretation of the method would involve the tracking of passengers and goods beyond individual flights to include stopovers and transfers to other flights. A less complicated and data intensive version is based on what is termed on-flight origindestination which includes brief stopovers in airports to collect and drop passengers.

Whereas unilateral and uncoordinated regulation is generally problematic, this allocation method is likely to create even more problems for regulators. It will be difficult to design and enforce regulation that targets the full journey, reaching beyond the first flight stage. For each flight, emissions will accrue to different Parties according to a complex allocation scheme. There will thus be no clear counterpart for airlines in negotiating regulatory measures, and jurisdiction will often be unclear.

The data requirements for this allocation method will be very demanding and may in reality turn out to be prohibitive. For each flight stage, total emissions would have to be calculated. The data requirements for this would be similar to those for allocation based on arrival/departure of the aircraft. As the second step in the allocation procedure, the calculated emissions will be distributed among individual cargo shipments and/or passengers. For this, additional data would be required at the passenger/cargo level, and even passengers and cargo from non-Annex I countries would have to be recorded

\section{Method 1: No allocation to parties}

Work is ongoing within ICAO on analysing alternative options for allocating and limiting emissions from the aviation industry through a system based on the airlines rather than on national parties. The focus is increasingly on establishing the basis for an emissions trading system which could be developed according to different principles and coverage. Results from the ICAO work is expected in 2004.

Allocation to the industry would provide advantages in terms of better access to data, options for establishing regulation with less distortive effects than national allocation, option for coverage all gases, and reduced risk of strategic behaviour in terms of flagging out or strategic tankering.

The legal and institutional part of establishing an industry based allocation, commitment and regulation system is however challenging. The institutional responsibilities, the legal framework, monitoring and verification procedures, enforcement and sanctions etc. must be established at a supra national level, and this obviously is a very challenging task. 


\subsubsection{Quantitative assessment of alternative allocation methods}

Quantitative assessment has been made for Method 2, Allocation to the country where the bunker fuel is sold, and Method 3, Allocation according to the nationality of the airline. Further more Method 3 is assessed with regards to the geographical coverage, namely the emissions if:

- flights between those countries that ratifies the Kyoto Protocol (assuming that Russia ratify) are included,

- $\quad$ also flights to and from USA are included, and finally

- all international flights of Nordic airlines are included.

These data are collected from most of the airlines with international flights in the Nordic countries.

Allocation methods 3 (for all international flights) allocates 7\% more emissions to the Nordic countries as a whole ( 6.9 million $\mathrm{tCO}_{2}$ ) compared with the method based on bunker sales of fuel (method 2). However the choice of method has larger bearings for several of the individual Nordic countries.

Allocation according to Method 2, bunker fuel sale, and Method 3, nationality of the airline, and according to geographical coverage

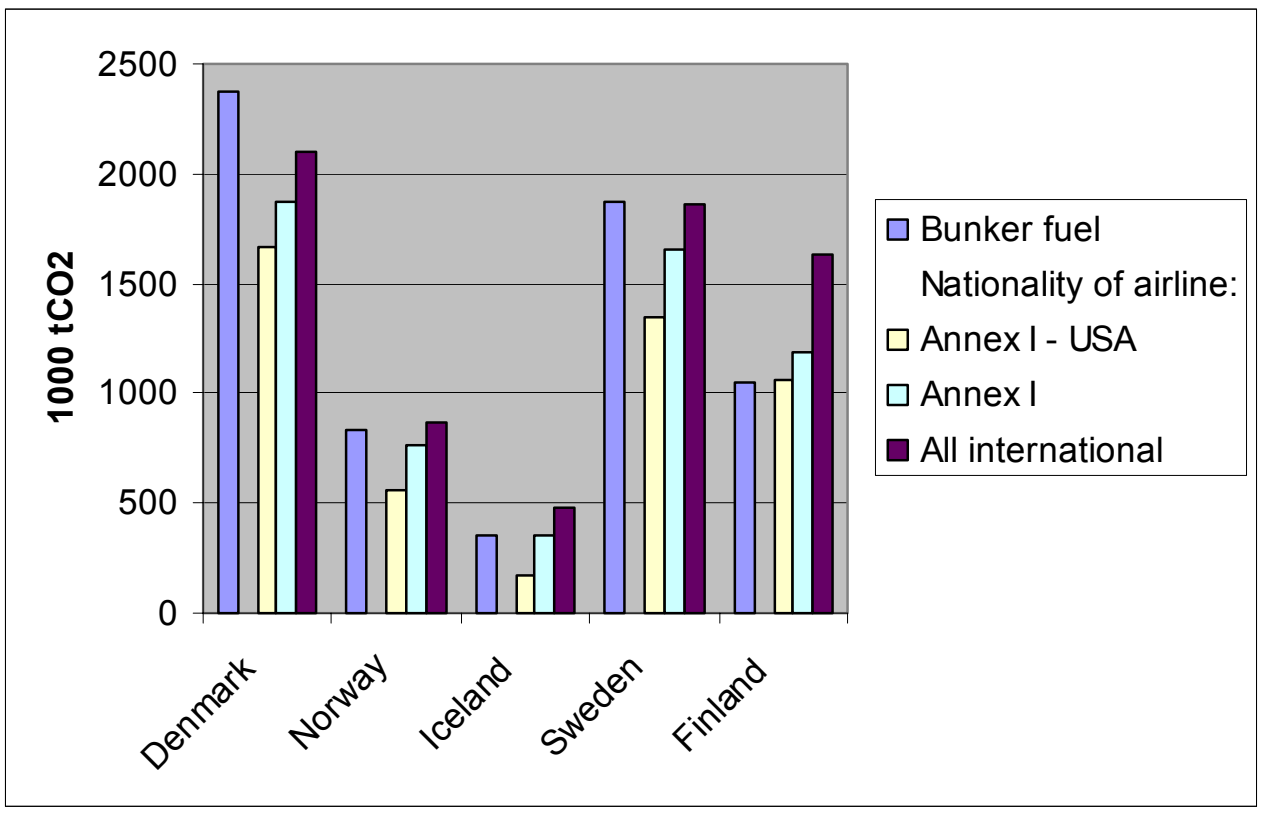

Under the Bunker fuel allocation method (Method 2) Denmark with its large airport in Kastrup will be allocated a relatively large share of international aviation emissions due to the many departing flights that bunkers fuel. Finland and Iceland on the other hand have relatively large airline industries, particularly Finnair and Icelandair, whereas the national airports do not work as a larger hub. Therefore the allocations to Finland and Iceland are larger when allocating according to the nationality of the airline than when allocating according to the fuel bunkering.

Norway and Sweden are less sensitive to the allocation method as long as all international flights are included.

Method 4 and to some extent also Method 5 are expected to result in allocations close to that of Method 2, though no quantitative assessment has been undertaken due to exten- 
sive data requirements. Method 1, no allocation to countries, would result in allocations as Method 3, but not to the countries but to the different airline companies. This distribution can not be presented due to confidentiality of data.

\subsubsection{Further work}

Emissions trading is the focus of increasing attention, not only within ICAO, but also at the European level.

Parts of the industry, including SAS, are promoting the development of an emissions trading scheme that provides access to allowances from the EU emission trading scheme as an alternative to charges and taxes. To promote such ideas analysis of options and consequences for airlines and for the Nordic countries in general could be considered. Important aspects included in an analysis of an aviation emission trading scheme are the coverage of the scheme, the relation to the Kyoto Protocol, different allocation mechanisms, linkage to the EU emissions trading scheme, legal issues, inclusion of non-Kyoto GHG etc.

EU may decide to unilaterally pursue regulation of the European aviation industry, and the possible design options for an EU-driven emissions trading scheme and the impacts on the Nordic countries and aviation industry could be an important endeavour, which would also enable the Nordic countries to play a proactive role in the political and technical process of designing such a scheme. 


\section{Introduction and background}

The present Report has been produced as part of a Study for the Working Group on Sustainable Mobility under the Nordic Council of Ministers.

The Study includes a review and assessment of the data and methodologies in relation to calculation and reporting of the energy consumption and greenhouse gas emissions from international aviation, as well as issues related to allocation of these emissions to countries. The emphasis is on the assessment of opportunities, advantages and disadvantages of the different methodologies and principles for allocation to the Nordic countries.

$\mathrm{CO}_{2}$ emissions from international aviation are not covered by the reduction and limitation commitments under the Kyoto Protocol. However, the emissions from international aviation are growing rapidly, and if they are to be included in the reduction efforts by Annex I countries, they will have to be allocated to parties who are or will become responsible in relation to the reduction commitments of the Protocol.

The issue has been dealt with on a continuous basis in the UNFCCC negotiations, and will be dealt with at SBSTA (the UNFCCC Subsidiary Body for Scientific and Technological Advice) 20 in the summer of 2004. On behalf of the Community, the European Commission has expressed the wish that bunker fuels be included in the Kyoto Protocol from the second commitment period starting in 2013.

The Nordic governments similarly support the inclusion of emissions from international aviation in the KP, and therefore are interested in an analysis and assessment of the options for quantifying and allocating the emissions from international aviation to the Nordic countries.

Article 2, Paragraph 2 of the Kyoto Protocol states that "The Parties included in Annex I shall pursue limitation or reduction of emissions of greenhouse gases not controlled by the Montreal Protocol from aviation and marine bunker fuels, working through the International Civil Aviation Organization (ICAO) and the International Maritime Organization, respectively". ICAO has subsequently agreed upon a working programme in this area, implemented through its Committee on Aviation Environmental Protection (CAEP). 


\section{Objective and methodology}

The overall objective of the Study is to contribute to a common understanding among the Nordic countries regarding the inclusion of greenhouse gases from international aviation in the UNFCCC and its Kyoto Protocol.

The immediate objective is to:

- Identify the availability and quality of data reported to UNFCCC by the Nordic countries on emissions from international aviation

- Identify and assess different opportunities, advantages and disadvantages of different methods to allocate emissions to countries, seen from a Nordic perspective. The assessment of alternative methods is based on principles and criteria that are of relevance to the Nordic countries.

The methodological approach of the Study has been to focus on three elements, the first two of which are reported in Part I of the Report, while the second is reported in Part II:

\section{$\underline{\text { Part I: }}$}

\section{Data availability and emission calculation methodologies}

The existing data available to the Nordic countries for their assessment of energy consumption and GHG emissions have been described along with the methodologies applied to the calculation of emissions from domestic and international aviation.

According to the IPCC/UNFCCC guidelines, the Annex I countries should include emissions from international aviation in their inventories. However, SBSTA has noted that the quality of reporting by Annex I Parties on bunker fuel emissions needs to be improved. In particular, issues related to the calculation of domestic vs. international emissions are a cause of concern.

\section{Allocation of emissions to countries}

SBSTA has considered various methods for allocating emissions and has selected a number of these for further consideration. These include:

A. No allocation

B. Allocation to the country where the fuel is sold

C. Allocation to the nationality of airlines

D. Allocation to the country of destination or departure of aircraft

E. Allocation to Parties according to the country of departure or destination of passenger or cargo.

An important activity is to establish a number of principles and criteria against which the above methodologies can be assessed. These principles and criteria are defined on the basis of existing considerations among the Nordic countries, within UNFCCC and within the international aviation community, e.g. ICAO and CAEP. 


\section{Part II:}

\section{Assessment of allocation methodologies}

The assessment of allocation methods includes two main activities:

- An evaluation of the proposed allocation methods against the principles and criteria identified.

The purpose of this exercise has been to get a picture of how the individual methods perform in relation to the established criteria. The assessment is primarily qualitative.

- A quantitative assessment of the consequences of the most relevant methodologies.

Based on existing data, an initial assessment of how the different allocation methods are likely to affect the Nordic countries has been made. For practical reasons, a number of assumptions are made, and the quantitative assessment aims at estimating the order of magnitude of differences in allocation resulting from the selected methods rather than attempting to calculate total emissions for the Nordic countries.

The consultant has consulted key persons and available literature regarding the data and methodological issues. 


\section{Qualitative assessment of alternative allocation methods - approach and context}

The purpose of the evaluation of the proposed allocation methods against the principles and criteria identified is to get a picture of how the individual methods perform in relation to the established principles and criteria. These principles and criteria have been established in Part I of the Report.

The below table recapitulates the allocation methods and criteria as they have been identified earlier. The sequence is so that the methods for allocating emissions to countries will be dealt with first, before the special case of no allocation to countries.

An important step in performing both the qualitative and quantitative assessments of the allocation options is to reach an unambiguous interpretation of the allocation method. As will be seen from the following, this is in itself a complex task which involves a range of not just technical but also policy issues.

A further complicating factor is the fact that the different criteria for assessment are closely linked and sometimes contradictory. In particular, the relationship between allocation, regulation and commitments should be emphasized and is dealt with in the following Section.

During the Danish EU presidency, a questionnaire to the Member States was distributed. The responses from the Nordic countries have been studied and will be referred to where deemed relevant. 


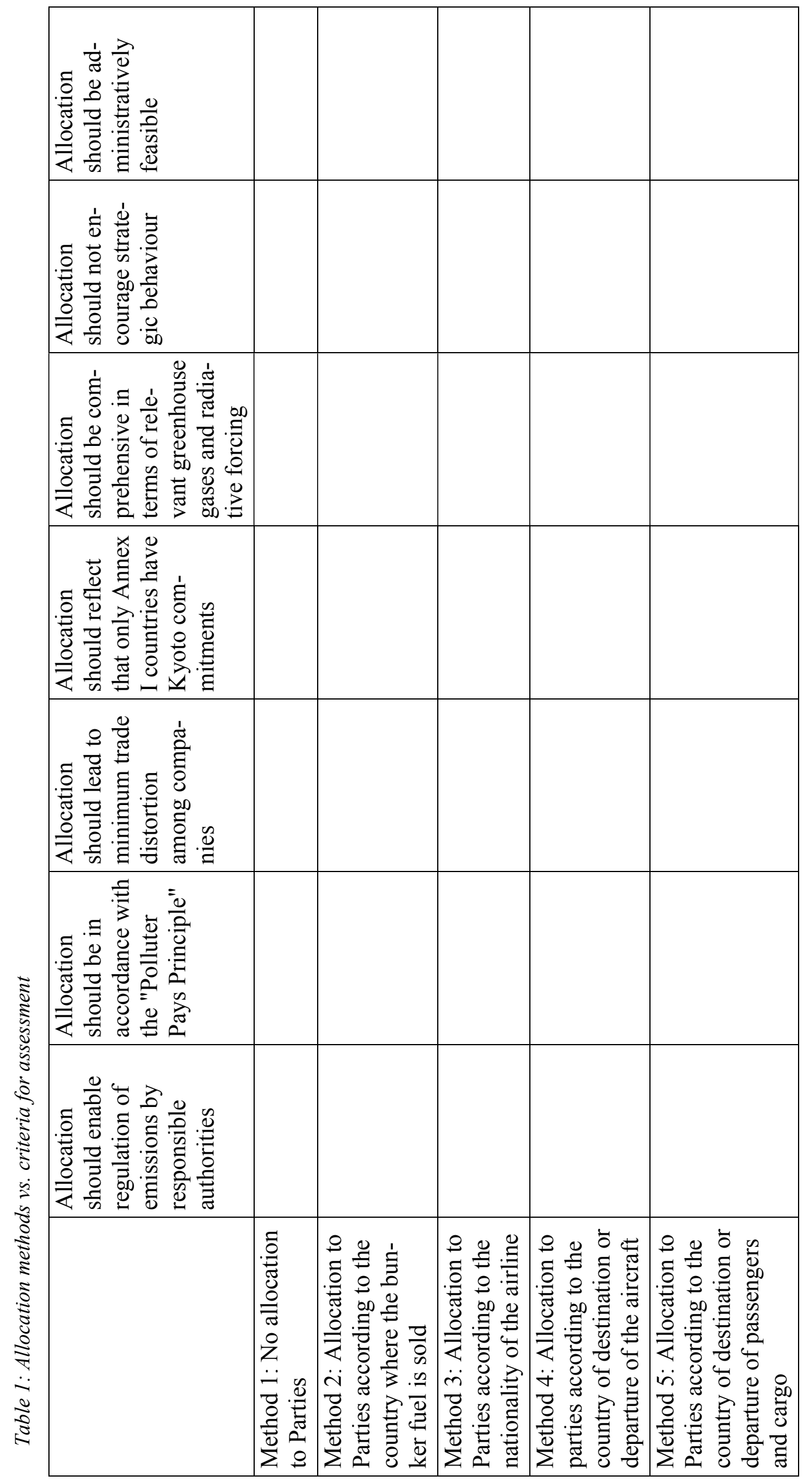




\subsection{Allocation, regulation and commitments are closely linked}

There is a very close interrelationship between

1. allocation method;

2. quantitative commitments to reducing or limiting emissions; and

3. regulation of emissions

These three issues can hardly be dealt with separately. The allocation method has a strong bearing on the options available to the responsible party to regulate emissions and thus meet its commitments. In turn, commitments can only be evaluated when seen in the context of allocation methods and the regulatory options available to the Party.

The key distinguishing factor among allocation regimes is whether allocation is done to countries/Parties or, alternatively, to the industry, possibly under ICAO jurisdiction. Country allocation is based on the expectation that mitigation of emissions from international bunkering will belong under the framework of the UNFCCC and its Kyoto Protocol, either as an amendment to the KP or as a separate add-on following the same principles. Allocation to the industry rather than to Parties should be seen in the context of alternative regulation options under consideration, such as an emissions trading scheme under ICAO that is open toward trading with other sectors, or other initiatives that are not Kyoto Protocol-based.

The implication of this is that it makes little sense to address allocation separately from regulation and commitments. The following analysis of the allocation methods will show that the outcome of the assessment of the allocation methods against the criteria will often depend not only on the allocation method but on the combination of allocation method and the expected measures used to regulate emissions. A good illustration of this issue is allocation according to where fuel is bunkered. This allocation method may create incentives to strategic behaviour in the form of tankering, but this will depend on whether the country concerned applies regulatory measures that affect the price of fuel or otherwise raise the costs of bunkering in the country.

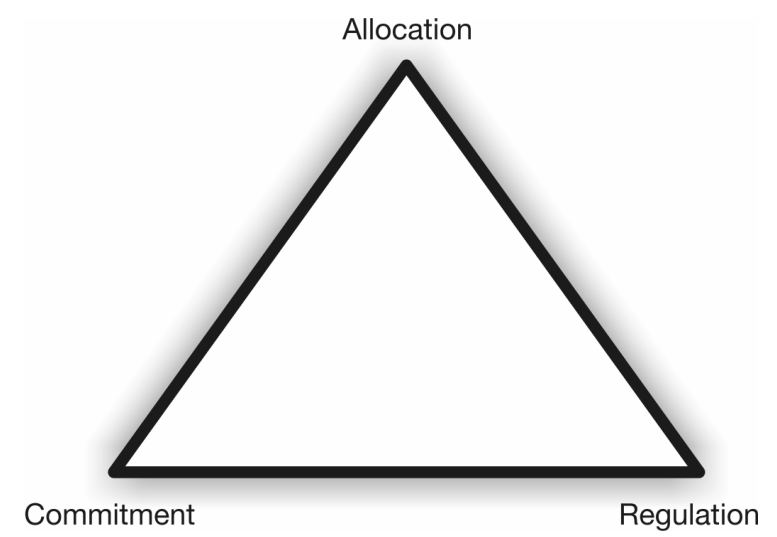

Key Issues for Regulation

The type and intensity of regulation considered by a party will reflect i.a.:

- the allocation method

- the ability to apply the regulatory instrument without creating distortion of competition

- the country's overall reduction/limitation commitment relative to a base year and the burden this puts on the country relative to a "business as usual" scenario 
- the country's approach to complying with its obligations, including decisions on which sectors shall bear the costs of achieving compliance.

The most important options for regulation of emissions from international aviation that are usually considered include the following (as presented in e.g. the EU questionnaire): Voluntary agreements with airlines on reducing emissions per tonne-kilometre Voluntary agreements with aircraft producers on reducing the greenhouse gas intensity of new aircraft

More stringent emission standards for new aircraft

Phase-out schemes for the most greenhouse gas intensive aircraft

En-route charges

Fuel taxation

Emission charges

Revenue neutral aircraft efficiency charge

Emission trading (open or closed trading system combined with a cap)

Landing charges

Passenger/cargo charges

High abatement costs in aviation in association with relatively inelastic demand require that taxes and charges be very high in order to have a significant impact on emissions from the industry. For this reason, these regulatory instruments are in less favour among several Parties.

Even though most of these regulation options (with emissions trading as the exception) are normally considered in the context of national allocation, it is generally the case that they do not easily lend themselves to national implementation. They are often unlikely to win political support or to be effective if implemented at the level of individual countries. Rather, they require international cooperation, which at a regional level in practice is likely to be within the EU or at a more global level, most likely under ICAO jurisdiction. This can be explained by the following three features of the international aviation industry:

Most allocation methods will lead to allocation to a given country of emissions caused by airlines from other countries over which the country has little regulatory control.

Existing international agreements limit regulatory "interference" with the industry, e.g. in the form of taxation. The Chicago Convention exempts international aviation from taxation.

Competition concerns, as unilateral regulatory measures will often be distortive to the disadvantage of the country's own airlines, possible providing incentives to strategic behaviour which will in turn divert traffic from the country in question.

It has thus become increasingly clear that the main distinction and political choice to be made is whether to base commitments, allocation, and regulation on:

A) national allocation to countries/Parties, as under the Kyoto Protocol, or

B) the industry and the airline companies

\subsubsection{National allocation}

National allocation will - whether the legal framework is a revision/addendum to the Kyoto protocol or a separate agreement under the UNFCCC - impose responsibilities 
on national authorities and is likely to require or at least favour national regulation, for instance in terms of taxes and charges.

Focusing on the national level offers advantages in the sense that it is a logical extension of the existing international climate agreements, where commitments are on Parties and decisions on measures to achieve compliance are on Parties individually or within "bubbles".

Several comments (including comments received from Nordic governments) reflect the position that national allocation is inherently problematic given the global character of the industry. Finland stated in the response to the EU questionnaire that the national allocation options "do not take into account the global character of these transport modes".

Sweden refers to the basic problem related to regulating the sector and its emissions at the level of the nation-state, emphasizing the risk of distortions arising from differences in policies and measures adopted at the national level by Parties. At the same time, it is very difficult to reach international agreement on coordinated implementation of regulatory measures such as en route charges.

For the European countries, the EU could be a vehicle for passing of coordinated European regulation, thereby limiting the risk of trade distortion and enhancing the political acceptability of regulating the sector.

\section{Complexities in assessing allocated amounts of emissions}

The qualitative and quantitative assessment of the individual national allocation methods is often based on the underlying assumption that a country will benefit from having as little emissions allocated as possible. This view should however be qualified.

There is no straightforward way to assess the significance of the size of allocated amounts. Allocated amounts can only be properly assessed when the associated commitments and regulatory regime are at the same time taken into account. For instance it is not clear whether a large or a small allocation is preferable to a country unless the associated commitments are specified at the same time.

Whether or not allocation of emissions to a country is on balance an asset or a liability should be seen in the context of several issues:

1. The base year emissions, the limitation commitments and the emission scenarios. If the base year emissions are relatively high and commitments are moderate, allocation may end up freeing up AAUs.

2. Risk and uncertainty. The bigger the share of international emissions allocated to a country, the bigger the uncertainty and exposure to changes in the industry. The upside of this would be that in case of a significant downturn in the industry, a Party may end up with a windfall gain in terms of surplus AAUs, or "hot aviation air".

3. Ability to enforce regulation. A key issue is the country's ability to design and enforce regulation of that part of the industry's activities that lead to allocation to the country of emissions. The complementarity of allocated emissions and ability to regulate - without distorting competition - is more important than the absolute amount of allocated emissions. 


\subsubsection{Allocation to the aviation industry}

Allocation that is not based on countries/Parties as responsible entities may be more in line with the global character of the industry. Most regulatory schemes are implemented more effectively and with less distortive effects at a supra-national level.

In the ongoing discussions about allocation to the industry rather than to Parties, this option is linked to international regulation through an emissions trading scheme. As will be seen from the following chapter, this approach may offer advantages towards several of the assessment criteria, including those addressing regulatory measures, trade distortion, coverage and strategic behaviour compared to national allocation methods.

Currently focus within ICAO/CAEP, among representatives of the industry, and to some extent among Governments and the EU as well, is on industry-based allocation and open emissions trading scheme with linkages to other emissions trading schemes, particularly the Kyoto mechanisms and, for European airlines, the EU emissions trading scheme. In fact, the proponents of such a system see this linkage as a prerequisite and the main justification of the scheme, since getting access to emission allowances and credits from other industries is the only way that the industry can avoid the consequences of relatively high mitigation costs within the industry, leading to a more economically efficient solution to the challenge of reducing emissions.

The option of establishing a parallel scheme to the coming EU emissions trading scheme has been brought forward by UK aviation industry and EU Environment Commissioner. Furthermore, during interviews for the present Study, SAS has expressed an interest in exploring the opportunities for a European emissions trading scheme. Such a scheme could be brought forward by the European aviation industry, without requiring full ICAO consensus and without jeopardizing the future extension of a system to cover a larger share of international aviation. 


\section{Qualitative assessment of allocation method 2: Allocation to Parties according to the country where the bunker fuel is sold}

\subsection{Background and interpretation}

As stated in Part I, the apparent rationale behind allocation according to where the fuel is sold is that the country of departure of the flight should be charged with the emissions, which is largely the case for this allocation method. The exception is tankering, i.e. the situation where more fuel is taken on board than required for the following flight stage

The method is consistent with the way data is collected and emissions allocated for fuel use in international road transport, where emissions are allocated to the Party where the fuel is sold.

Furthermore, it appears to be a relatively straightforward method in terms of data collection, which is also in line with the existing practices and IPCC guidelines, according to which emissions should be estimated on the basis of fuel taken on board by each departing aircraft.

\subsection{Allocation should enable regulation of emissions by responsible authorities}

This allocation method is apparently attractive since the country where the fuel is sold would be able to regulate the amount of departing traffic, e.g. through taxation and charges directly on fuel or indirectly on e.g. goods and passengers.

However, these regulation methods are difficult or impossible to implement as strictly national initiatives and require internationally coordinated efforts to avoid distortions of competition and strategic behaviour.

National regulation may create incentives to strategic behaviour, e.g. in the form of tankering, to avoid the regulatory measures. This is likely to happen if a country applies regulatory measures which

a) affect the price of fuel or otherwise raise the costs of bunkering in the country, and

b) are designed and implemented in a unilateral or uncoordinated way.

It should be noted that these possible distortive effects are not the result of the allocation method per se, but of the regulation method applied by the Party. These concerns are therefore valid not specifically for this allocation method. 


\subsection{Allocation should be in accordance with the "Polluter Pays Principle"}

As explained in Part I, application of the PPP requires identification of the "polluter", which is no straightforward task for international aviation. The range of actors that may be designated as polluters would include:

- The airlines (and thus the countries to which they belong) operating the airplanes that actually emit the greenhouse gases.

- The individuals (and thus the countries to which they belong) flying as passengers

- The economic entities on behalf of which individuals and goods are transported

- The countries between which the individuals and goods are travelling, because these must be expected to benefit from the economic activity.

Allocation to the country where the fuel is sold is not fully in agreement with any of the above categories of polluters, but on the other hand the country of departure will benefit from the economic activity related to the flight. The flight will also partly be a result of economic activities of entities and residents belonging to the country.

Concerns in relation to the Polluter Pays Principle arise from two issues:

One is the tankering, which means that the sale of fuel and thus allocation of emissions is not associated with a flight from the country in question but merely reflect cost and operational considerations by the airline ${ }^{1}$.

Another has to do with countries with a high level of international transit and transfer traffic, such as Denmark. A relatively large proportion of this traffic will be a result of the economic activities of individuals and economic entities from other countries, although of course there is still an economic activity taking place within the aviation sector that benefits the country hosting the hub airport.

\subsection{Allocation should lead to minimum trade distortion among companies}

As emphasized above, possible distortive effects do not result from the allocation method per se, but as a result of the specific regulation applied by a Party.

1. The maximum distortive effect would take place in the (unlikely) event that regulation - e.g. in the form of activity-based taxes and charges ${ }^{2}-$ were to be applied unilaterally by a Party and would only cover activity by the country's own airlines. Serious dis-

\footnotetext{
${ }^{1}$ The IPCC report "Aviation and the Global Atmosphere lists the following factors that can influence decisions on tankering:

- Genuine high fuel costs, e.g. because of expensive distribution infrastructure

- Fuel availability at some remote airports

- Government-imposed fuel pricing, e.g. induced by taxation

- Monopoly distribution of fuel, which can involve cross-subsidies

- Concern over fuel quality

- Slot availability (where limited aircraft turnaround time allows insufficient time for refueling)

${ }^{2}$ Once again it should be emphasized that while allocation is based on fuel sale, the regulation can in principle take any form, and thus "activity-based taxes and charges" could also be landing charges, passenger/cargo charges or en-route charges.
} 
tortions may arise from imposing obligations on only part of the airlines operating a route.

2. Less distortive would be unilateral regulation applying to all flights departing from the country in question. This could still lead to distortions; airlines may be able to shift part of their operations and routes to other countries with less strict regulation.

3. Coordinated regulation among several countries, e.g. within the EU, would further reduce the risk of distorting competition.

4. Even if coordinated regulation were to take place among all Annex B countries, potential distortion may arise from the fact that countries not belonging to Annex B have no quantitative commitments under Kyoto. To the extent that all airlines, regardless of nationality, are subject to the regulation applied by Annex B countries, e.g. in the form of a fuel tax, this would be of limited significance. A remaining source of distortion would be the possible encouragement of strategic behaviour in the form of changed route planning or using more Non-Annex B airports as hubs.

\subsection{Allocation should reflect that only Annex I countries have Kyoto commitments}

Obviously, allocation based on fuel sold in the country under the Kyoto Protocol would only include fuel sold in Annex B countries.

The common interpretation of the allocation option is that it comprises all fuel sold for international aviation regardless of the routes flown and regardless of the airline flying on the specific routes.

This would mean that on the one hand emissions from flights departing from nonAnnex I countries to Annex I countries would not be allocated to any party, while on the other hand emissions from flights going from Annex I to non-Annex I countries would be covered and thus be subject to whatever regulation is applied by the Annex I countries.

The allocation thus reflects that only Annex I countries have Kyoto commitments, but this does not mean that there will be no economic impact from this on non-Annex I countries. Firstly there will be a direct impact on their aviation industry because regulation will also apply to some of the activities of non-Annex I airlines. Secondly there will be indirect economic effects on other sectors from the increases in costs of international air transport, potentially leading to higher costs of developing country exports.

\subsection{Allocation should be comprehensive in terms of relevant greenhouse gases and radiative forcing}

As explained in Part I, several of the emitted substances and gases causing radiative forcing are beyond the Kyoto regime. Ideally, a system for allocating and regulating these emissions should be flexible enough to accommodate these emissions at a later stage when more scientific certainty has been established with regard to the effects of these emissions.

The allocation method is inherently focused on CO2 emissions. There is a linear relationship between fuel consumption and $\mathrm{CO} 2$ emissions. The methodology centres on the point of sale of fuel and thus does not involve the collection of detailed flight data. 
This would not be a sufficient basis for the calculation of other emissions and effects which have a less linear relationship to fuel consumption, i.e. NH4, radiative forcing caused by water vapour and other non-Kyoto gases, as well as the impact of flight altitude. If detailed data were to be collected in order to make coverage of radiative forcing more complete, this would reduce the comparative advantage which this allocation method holds in terms of administrative simplicity compared to other allocation methods.

\subsection{Allocation should not encourage strategic behaviour}

As it has been explained above, it is not the allocation method per se, but the regulation applied by the Parties which may lead to distortion and encourage strategic behaviour. If unilateral regulation is applied that raises the costs of buying fuel in the country, this will create incentives to

a) tankering, understood here as a change in the pattern of refuelling without changing the flight pattern.

b) make strategic route planning to avoid the added costs associated with fuelling in the country in question.

The degree to which tankering and strategic route planning are applied will depend on operational cost-benefit calculations by the airlines. In a Nordic and European context where most neighbouring countries are also Annex I countries and assuming similar regulation, the effects are likely to be relatively modest.

\subsection{Allocation should be administratively feasible}

There is general agreement that allocation based on the country where the fuel is sold is the most manageable on the basis of data available today, thus living up to the criteria that allocation should be possible on the basis of existing data systems and not require that new, complex data systems are established.

As mentioned earlier, the allocation method is in line with the existing IPCC guidelines calling for calculation based on fuel taken on board by each departing aircraft. This means that the ongoing methodological work taking place under IPCC as described in Part would be of use in the implementation of this allocation method. This relates i.a. to the distinction between domestic and international aviation. 


\section{Qualitative assessment of allocation method 3: Allocation to Parties according to the nationality of the airline}

\subsection{Background and interpretation}

As explained in Part I of the Report, allocation of emissions according to the nationality of the airline is based on the premise that the emissions caused by the airline as a national business entity should be allocated to the country to which the airline belongs. The exact wording by SBSTA of this allocation option is "allocation to Parties according to

- the nationality of the airline

- the country where the airline is registered or

- the country from where the airline is operated".

Although the first variant "nationality of the airline" has been selected as the more operational among the definitions, this is not an unambiguous definition either.

SAS is a prime example of the complexities involved in defining nationality of airlines, being an airline with shared ownership by three countries as well as private shareholders.

Given the dynamic and volatile structure of the international airline industry, the complexities are likely to increase in the future. Ownership and thus nationality of (part of) airlines are increasingly liable to change and to be very difficult to determine unambiguously.

Both ownership, market share and levels of activity of airlines can change rapidly. Such changes will have an impact on the amount of emissions allocated to a Party, whereas the Party will still have commitments according to the base year. An allocation method that is based on nationality of airlines thus involves uncertainty and risk regarding the expected allocations.

In its response to the EU questionnaire, Finland highlighted that the nationality of airlines "can change very fast and is often unclear". Furthermore, Finland stated that nationality "does not correlate with the market activity". Similarly, Sweden highlighted that "the trends in global liberalization make the identification of the nationality of a multinational air carrier increasingly complex". 


\subsection{Allocation should enable regulation of emissions by responsible authorities}

In order for allocation of emissions based on nationality of airlines to be a useful basis for regulation, the nationality of airlines would have to be unambiguous and stable. Under such circumstances, regulation by the national authority would appear to be feasible, as the relevant country would be able to exercise some control over the airline. Allocation based on nationality of airlines is most compatible with those types of regulation that target the company-level, such as voluntary agreements with airlines on efficiency or an airline-based emissions trading scheme. Other regulatory measures such as charges and levies are not easily applied to the airlines of an individual country. Doing so may create significant distortions, e.g. if charges are applied to some flights on a route while not to others.

However, even under ideal circumstances with clear and stable nationality of airlines, there would be significant limitations on the ability of the Parties to regulate the airlines. Much of the activity of the airlines regulated would take place under circumstances over which the government may have little control. It is increasingly the case that airlines operate routes that do not depart or arrive in its home country (cabotage). Furthermore, international competition would make unilateral, uncoordinated regulation potentially distortive and unlikely to get political approval. The possibility to outflag airlines is likely to increase in future, which will further reduce the ability to regulate at the national level.

Obviously, the situation in which ownership and nationality of an airline is shared among several countries represents a further challenge to effective regulation, as it requires coordination among the Parties as to the type of regulation.

For a company such as SAS with joint ownership, it would also have to be decided according to what formula the distribution of SAS' total allocation among the countries would take place. The individual countries' share in ownership could be one solution, whereas an activity-based distribution would create significantly different results for SAS.

For this as well as for other allocation methods, regulation at the EU level could limit the risk of trade distortion. Furthermore, the EU might consider creating a special "bubble" for international aviation emissions. This would mean that although emissions would be allocated to the individual countries based on nationality of airlines, a political decision within the EU would entail that emissions from international aviation would effectively become a shared responsibility with regulation applied at the EU level.

Among the methods considered for national allocation, allocation based on airline nationality is the one which provides the best background for designing an emissions trading scheme based on airlines as the responsible entity to which allowances are allocated. Such a scheme would operate under a supranational umbrella, which could be the EU or ICAO. If an international emissions trading scheme is considered as the regulatory mechanism, it should at the same time be considered whether it is necessary and beneficial or perhaps even counterproductive to use national allocation or whether it would be better to avoid this, cf. the assessment of the option "No Allocation to Parties". 


\subsection{Allocation should be in accordance with the "Polluter Pays Principle"}

In a previous section, the airlines and the countries to which they belong are designated as one possible "polluter" to be held responsible in accordance with the PPP.

In this case, it is the airline industry as such that carries the responsibility for emissions rather than the underlying economic activities that demand air transport.

This interpretation also means that some countries, in particular those with large airlines, would be held responsible for a relatively large proportion of aviation emissions. These countries would have more emissions allocated through this method than based on the country where fuel is sold, because both flight stages to and from a destination in a different country would be allocated to the country of the airline. Conversely, some countries - e.g. "holiday countries" such as Spain and Greece - would have less emissions allocated than with other options because a significant share of aviation to and from these countries is operated by foreign airlines.

Identifying the company owning and operating the asset that burns the fuel as the polluter to whom emissions are allocated could in a sense be seen as parallel to exports of electricity, by which emissions are allocated to the country where electricity is produced, although customers in other countries benefit from the product/service being provided.

\subsection{Allocation should lead to minimum trade distortion among companies}

Once again it should be kept in mind that possible distortive effects do not result from the allocation method per se, but as a result of the specific regulation applied by a Party. Unilateral and uncoordinated regulation by an individual Party only applying to the country's own airline could lead to important trade distortions. In particular, serious distortions may arise from imposing obligations on only some of the airlines operating a route. It could also happen that different airlines operating the same routes may be subject to different regulation.

Coordinated regulation among several countries, e.g. within the EU, would reduce the risk of distorting competition.

It should be kept in mind that even though allocation is only expected to be made to Annex I countries, some specific regulation may still be designed to cover also airlines from non-Annex I countries operating flight to and from Annex I countries.

It should also be recognized that the more extensive the coverage of emissions in terms of flight routes, the more difficult will it be for Annex I countries to regulate all flights covered, and the more pronounced the risk of trade distortions (cf. the following section on coverage). If e.g. emissions from flights between non-Annex I countries were allocated to the Annex I airline operating the flight, it would be difficult to enforce regulation by the Party to which the airline belongs, and it would be next to impossible to ensure that other airlines operating the same route would be covered also by similar regulation.

To the extent that international liberalization of the aviation industry lessens the importance of nationality, the outflagging of airlines or parts of airline operations must increasingly be taken into consideration as a potential source of trade distortion. 


\subsection{Allocation should reflect that only Annex I countries have Kyoto commitments}

An obvious interpretation of the allocation method is that only emissions from airlines belonging in Annex I countries are allocated to those countries.

As mentioned before, this does not necessarily mean that airlines from non-Annex I countries would not be subject to some of the regulatory measures put in place by Annex I countries. Annex I countries would have an interest in making regulation as broad as possible in terms of airlines and routes covered in order to avoid trade distortions.

Although only emissions from airlines in Annex I countries are allocated, it remains to be decided which of the international flights by these companies should be covered.

Key decisions include whether coverage should include

- all flights operated by airlines from non-Annex I countries, regardless of countries of departure and destination

- flights between Annex I countries and flights between an Annex I and a non-Annex I country

- flights between Annex I countries and flights departing in an Annex I and arriving in a non-Annex I country

- only flights between Annex I countries.

Under the most comprehensive interpretation which would allocate all international emissions on flights operated by an Annex I airline, a significantly larger share of total international emissions than using other allocation methods. This of course is a reflection of the fact that a large share of international aviation is carried out by airlines from Annex I countries.

\subsection{Allocation should be comprehensive in terms of relevant greenhouse gases and radiative forcing}

The allocation method would be based on flight data collected at the company level. As discussed in Part I of the Report, relatively detailed data is or could be made available from airlines at company level.

The detailed data available at company level would provide the basis for calculation of $\mathrm{CO} 2$ emissions, but in the longer term the data could be used in an extended allocation scheme to calculate effects of other emissions and effects which have a less linear relationship to fuel consumption, i.e. NH4, radiative forcing caused by water vapour and other non-Kyoto gases, as well as the impact of flight altitude.

\subsection{Allocation should not encourage strategic behaviour}

As explained earlier, it is not the allocation method per se, but the regulation applied by the Parties which encourage strategic behaviour. Furthermore, the type of strategic behaviour available to the airline companies depends on the regulation in place.

If regulation were company-specific and only applies to airlines from one party or a group of Parties, outflagging of airlines or parts of airline operations could be a way by which the airlines would try to evade regulation. If on the other hand regulation - such as fuel taxes - could be designed to apply to all airlines on a route, and preferably all 
alternative routes as well, the potential for strategic behaviour would be smaller, as the benefit from outflagging and strategic route planning would be reduced.

\subsection{Allocation should be administratively feasible}

In order to provide a complete picture of the emissions of relevant Kyoto gases ( $\mathrm{CO} 2$ and NH4), data requirements to fully implement this option would include:

- origin, destination, flight distance and fuel use for each international flight operated by the airline

- information on the types of aircraft and the fuel use/emission characteristics of these aircraft for each flight.

The allocation method would be able to benefit from the data collection systems at the level of the individual airline. As explained in further detail in Part I, it is feasible to collect detailed information from the airlines actual levels of fuel use, distances, origin/destination etc.

Disaggregate information is already being collected from airlines, e.g. by the US authorities through the "Form 41" reporting procedure ${ }^{3}$.

\footnotetext{
${ }^{3}$ Source: "Source \& Accuracy Statement, Form 41, Schedules T100 and T100(f) Air Carrier" Bureau of Transportation Statistics, under US Department of Transportation.
} 


\section{Qualitative assessment of allocation method 4: Allocation to parties according to the country of destination or departure of the aircraft}

\subsection{Background and interpretation}

Under this option, emissions are allocated in one of three ways:

A) to the country of departure of the aircraft

B) to the country of destination of the aircraft; or

C) divided between the country of departure and destination. Under this option, a 50/50 split between the two countries is usually suggested.

Usually option B) is not considered to be relevant as the results of using this option would be similar to A), while A) provides the better match between allocation and ability to regulate.

Under certain assumptions, the allocation using this method will be almost the same as under allocation based on fuel sale. These assumptions are:

1. Option A) is used, i.e. emissions are allocated $100 \%$ to the country of departure

2. The same coverage of routes applies to both methods. This could be either all flights departing from an Annex I country or only flights departing and arriving in an Annex I country.

3. There is no tankering.

A 50/50 split of emissions between country of departure and destination is also likely to produce results that are very similar to those based on fuel sales as most route patterns are based on return flights with similar flight lengths of arriving and departing flights on a given route. It should be noted, however, that aircraft movements are likely to become more complex in future than simple return trips ${ }^{4}$.

In response to the EU questionnaire, the Danish Government stated that this allocation method would be the preferred one. Denmark also referred to an earlier recommendation by N-ALM (Nordic working group for environmental problems of aviation) to relate all emissions from a particular flight to the country of departure.

\footnotetext{
${ }^{4}$ In the European context, this tendency will be strengthened by a recent European Court ruling, saying that bilateral agreements between countries restricting international traffic rights to the national flag carriers of the countries concerned are contrary to the Treaty.
} 


\subsection{Allocation should enable regulation of emissions by responsible authorities}

A comparison with allocation to the country where the fuel is sold shows that given the assumption that allocation to the country of departure is applied and that the routes covered are the same under the two methods, the possibility to regulate should be similar.

The country of departure should thus in principle be able to put into effect regulation of departing traffic, e.g. through taxation and charges directly on fuel or indirectly on e.g. goods and passengers.

As explained in the section on fuel-based allocation, regulation is difficult or impossible to implement as strictly national initiatives and require internationally coordinated efforts to avoid distortions of competition and strategic behaviour. Regulation could be agreed internationally - e.g. at the EU level - on standards, levies or incentives to encourage reductions in emissions.

As compared to allocation based on the country of fuel sale, this allocation method differs slightly in that while tankering shifts allocation to another country than the country of departure, allocation under this method is not influenced by tankering.

If allocation is made to the country of arrival or as a split between the two, regulation is made more difficult by the fact that

1) Regulation influencing incoming flights is more difficult, in particular as regards charges and levies.

2) A split allocation accentuates the requirement to coordinate regulation internationally.

\subsection{Allocation should be in accordance with the "Polluter Pays Principle"}

The considerations regarding the polluter pays principle for this option are similar to those for fuel sale dealt with above.

The countries of departure and destination will benefit from the economic activity related to the flight. The demand for flight transport will partly be a result of economic activities of entities and residents belonging to the countries.

However, just as it is the case for allocation based on fuel sale, countries with a high level of international transit and transfer traffic, including e.g. Denmark, will have considerable amounts of emissions allocated that are the result of economic activities of individuals and economic entities from other countries, often travelling on flights operated by foreign carriers.

One concern of relevance to PPP is eliminated compared to the country of fuel sale. Tankering, which under the fuel sale method allocates emissions to a country which are not associated with a flight from the country in question, does not lead to emissions being allocated to that country. 


\subsection{Allocation should lead to minimum trade distortion among companies}

Once again, it is noted that possible distortion does not result from the allocation method per se, but of the regulation method applied by the Party. Many of the considerations are similar to those related to allocation based on the country where fuel is sold.

Unilaterally applied regulation, in particular regulation imposed on only some airlines operating a route, is prone to cause trade distortions.

Given the fact that emissions are allocated to a country regardless of the nationality of the airline, regulation should also be applied uniformly. However, this is not easily applied in practice. Coordination of regulation with EU and other European airlines would be less difficult than coordination with other Annex I countries.

Applying regulation that includes non-Annex I country airlines would be the most challenging, as the governments of these countries will be reluctant to impose Kyotoderived restrictions in view of the fact that they do not have quantitative commitments under the Kyoto Protocol.

\subsection{Allocation should reflect that only Annex I countries have Kyoto commitments}

If allocation is made $100 \%$ to the country of departure of the aircraft and with the same coverage of routes as the method based on fuel sale, the same considerations apply as for that method.

As it is the case for other methods, it will have to be decided how routes to and from non-Annex I countries are dealt with under this method. The minimum coverage would include only journeys between Annex I countries.

If routes between Annex I and non-Annex I countries are included and emissions are allocated to the country of departure, emissions from all outbound flights would be included. Emissions resulting from flights from non-Annex I countries to Annex I countries would not be covered, while on the other hand emissions from flights from Annex I to non-Annex I countries would be fully covered and thus be subject to whatever regulation is applied by the Annex I countries.

The allocation thus reflects that only Annex I countries have Kyoto commitments, but as stated earlier, regulation can still have economic impacts on non-Annex I countries, directly on the aviation industry and indirectly on other sectors.

If emissions are split 50/50 between the countries of departure and arrival, the challenge will arise for flights departing from a non-Annex I country with destination in an Annex I country that half of the emissions of those flights should be allocated to the country of arrival. It may be questioned whether the non-Annex I country from where the flight departs would be very motivated to invest resources and effort in ensuring that the emissions resulting from a departing flight are properly accounted for and allocated.

\subsection{Allocation should be comprehensive in terms of relevant greenhouse gases and radiative forcing}

Although the allocated emissions of $\mathrm{CO} 2$ resulting from the application of this methodology is similar to allocation based on fuel sold, these two methodologies differ signifi- 
cantly in terms of their ability to accommodate and account for non- $\mathrm{CO} 2$ emissions and related greenhouse effect.

The disadvantage of allocation based on fuel sale is that the method is focused on fuel consumption and from a data collection perspective ignores non-CO2 substances and gases causing radiative forcing ( $\mathrm{NH} 4$, radiative forcing caused by water vapour and other non-Kyoto gases, as well as the impact of flight altitude).

Allocation based on flight data on individual flights provide the opportunity to put in place data collection systems that may be adapted to include such emissions at a later stage when more scientific certainty has been established with regard to the effects of these emissions and corresponding regulatory measures have been designed.

\subsection{Allocation should not encourage strategic behaviour}

As mentioned earlier, a comparative advantage of this allocation method as compared to allocation based on fuel sale is the fact that tankering will not influence allocation, as emissions are based on the point of departure and not where fuel is sold. It should be kept in mind, however, that tankering may still be applied as strategic behaviour by airlines. This is because tankering is not done in response to the allocation itself but rather to the regulation. This means that regulation which increases the cost of fuel would still encourage strategic tankering.

A remaining source of distortion would be the possible encouragement of strategic behaviour in the form of changed route planning or using more Non-Annex I airports as transit hubs.

\subsection{Allocation should be administratively feasible}

In order to provide a complete picture of the emissions of relevant Kyoto gases $(\mathrm{CO} 2$ and NH4), data requirements to fully implement this option would include:

- origin, destination, flight distance and fuel use for flights departing from each country

- $\quad$ origin, destination, flight distance and fuel use for flights arriving in each country (if emissions are split between country of departure and destination)

- information on the types of aircraft and the fuel use/emission characteristics of these aircraft.

Although this information is currently not systematically collected with a view to assessing emissions, airlines can be expected to possess most of the required information. Furthermore, airlines are already reporting detailed data, e.g. through the US "Form 41" procedure. Air traffic control authorities such as Eurocontrol are also collecting detailed flight information. To the extent that coverage is to include flights to and from nonAnnex I countries, information is less reliable and complete and the task of establishing credible data collection systems more challenging.

Sharing emissions of between the country of departure and country of destination would not change very much by the way of allocated amounts, but would make the collection of data and management of the allocation process more difficult.

The positions of the Nordic countries in relation to this allocation option are mixed. As mentioned earlier, Denmark has stated a preference for this method, whereas Norway has stated that both this method and the following one (allocation according to the country of destination or departure of passengers and cargo) would be "difficult or inaccurate 
to implement on the basis of existing data". Finland responded to the EU questionnaire saying that "It is clearly not feasible to create a statistical system. Conversely, Sweden finds that "it would be possible to require that each air carrier report its consumption of fuel for each leg operated". 


\section{Qualitative assessment of allocation method 5: Allocation to Parties according to the country of destination or departure of passengers and cargo}

\subsection{Background and interpretation}

This allocation method would be the most complex of the ones that are under consideration by SBSTA. The complexity refers both to the exact interpretation of the method and to the collection of the data that would be required to implement it.

There are basically two definitions that could be applied for the purpose of this allocation method

The most comprehensive one would involve the tracking of passengers and goods beyond individual flights to include stopovers and transfers to other flights.

A less complicated and data intensive version is based on what is termed on-flight origin-destination which includes brief stopovers in airports to collect and drop passengers. On-flight origin-destination is commonly defined as "the point of embarkation and point of disembarkation of the passenger covered by one flight coupon". Work is ongoing internationally in e.g. EUROSTAT to enhance data collection related to this definition.

Emissions will be distributed to passengers or cargo. Like it is the case for allocation to the country of departure or arrival of the aircraft, there are three options for allocating emissions:

A) to the country of departure of the passengers or cargo

B) to the country of destination of the passengers or cargo; or

C) as a 50/50 split between the country of departure and destination.

\subsection{Allocation should enable regulation of emissions by responsible authorities}

It is a general feature of all allocation options that unilateral and uncoordinated regulation has strong limitations, i.a. due to concerns for trade distortions. Allocation based on the country of departure of goods and passengers is likely to create even more problems for regulators.

Even though allocation is not based on fuel sale or airline nationality, it will still be the countries of departure or fuel sale and the countries hosting the airlines and big airports that are in the best position to implement regulation. It will be difficult to design and enforce regulation that targets the full journey, reaching beyond the first flight stage. 
For each flight, emissions will accrue to different Parties according to a complex allocation scheme. There will thus be no clear counterpart for airlines in negotiating regulatory measures, and jurisdiction will often be unclear. Parties will have different commitments of varying stringency and will have different preferences with regard to the type of regulation.

Sharing emissions among the country of departure and arrival will add to the difficulty of regulating, as regulation targeting incoming flights is more difficult.

\subsection{Allocation should be in accordance with the "Polluter Pays Principle"}

The rationale for selecting this allocation method appears to be the notion that it is more "fair" than e.g. the previous one based on aircraft alone.

It is based on the premise that emissions should be allocated to the countries that "export" and/or "import" cargo or passengers as these are seen as the countries demanding air transport and thus acting as the polluters.

This allocation method thus relieves countries hosting 1) transit airports and 2) large international airlines from some of the emissions that would have been allocated to them under other allocation options. While this is often seen as argument in favour of this allocation option, it should be noted that from a PPP perspective, the method ignores the fact that hub airports and large international airlines are themselves economic activities that benefit the countries that host them. Consequently, it is not evident that these should not be regarded as "polluters" as well.

\subsection{Allocation should lead to minimum trade distortion among companies}

Again it is noted that possible trade distortion arises from the regulation method applied by the Parties rather than from the allocation method. As mentioned above, regulation will be made difficult by the fact that emissions from a single flight will be allocated to a number of parties according to a complex calculation procedure, and there is no direct relationship between the allocation method and the ability to regulate.

As it is the case with the previous allocation method, coordination of regulation with EU and other European airlines would be less difficult than coordination with other Annex I countries. Applying regulation that includes non-Annex I country airlines would be the most challenging, as the governments of these countries will be reluctant to impose Kyoto-derived restrictions in view of the fact that they do not have quantitative commitments under the Kyoto Protocol.

\subsection{Allocation should reflect that only Annex I countries have Kyoto commitments}

An assessment of the methodology against this criterion will depend upon the exact definition and coverage applied.

At least two dimensions are particularly relevant here:

1) Coverage of routes. 
It will have to be decided how routes to and from non-Annex I countries are dealt with under this method. The minimum coverage would include only journeys between Annex I countries.

One option would be to include travel between Annex I and non-Annex I countries and emissions allocated to the (Annex I) country of departure. Travel from non-Annex I countries to Annex I countries would not be covered. Emissions from flights from Annex I to non-Annex I countries would be fully covered and thus be subject to whatever regulation is applied by the Annex I countries.

Due to the fact that the allocation method reaches across individual flight stages, a complicating factor would be journeys that originate in non-Annex I countries and has subsequent flight stages in Annex I countries.

2) Allocation to country of departure, destination, or split allocation.

Considerations are similar to allocation based on departure or arrival of aircraft. If allocation is split, it would require that passengers and cargo originating in non-Annex I countries would have to be tracked. Split allocation would thus place an administrative burden on non-Annex I countries, and it may be questioned whether these countries would be inclined to accept the costs associated with this.

Even in a situation where only the country of departure gets the allocation, passengers and cargo from non-Annex I countries would have to be recorded in order to ensure that the emissions from a given flight are properly distributed among passengers.

The allocation reflects that only Annex I countries have Kyoto commitments, but as stated earlier, regulation can still have economic impacts on non-Annex I countries, directly on the aviation industry and indirectly on other sectors.

\subsection{Allocation should be comprehensive in terms of relevant greenhouse gases and radiative forcing}

In terms of its ability to accommodate and account for non-CO2 emissions and related greenhouse effect, this allocation method does not differ from the previous one

As the allocation method requires detailed flight data at the level of individual flights, this would provide the opportunity to put in place data collection systems that may be adapted to include such emissions at a later stage when more scientific certainty has been established with regard to the effects of these emissions and corresponding regulatory measures have been designed.

\subsection{Allocation should not encourage strategic behaviour}

Similar to the other allocation methods that are not based on fuel sale, tankering will not influence allocation, as emissions allocation is not based on the point of sale of the fuel. Still tankering may lead to strategic behaviour by airlines in response to higher fuel prices imposed by regulators.

In comparison with allocation based on aircraft departure/arrival, this allocation method reaches beyond the individual flight stage. This means that changed route planning using more non-Annex B airports for transit would become less effective as a means of avoiding emissions allocation. 


\subsection{Allocation should be administratively feasible}

The data requirements for this allocation method will be very demanding and may in reality turn out to be prohibitive.

For each flight stage, total emissions would have to be calculated. The data requirements for this would be similar to those for allocation based on arrival/departure of the aircraft.

As the second step in the allocation procedure, the calculated emissions will be distributed among individual cargo shipments and/or passengers. For this, additional data would be required at the passenger/cargo level.

A system for tracking passengers and cargo would be necessary, and this would be cross-referenced to the flight emissions in order to calculate emissions/passenger. Distributing emissions between passengers and cargo would be an additional challenge.

For each shipment/item of goods, airlines would have to keep records of:

Exporting country, importing country, amount of freight and transport distance total emissions.

For each passenger, records would have to include:

Country of departure, transit/stopovers, country of destination.

As mentioned before, information at this level of detail is presently not available. At the international level, work has been ongoing for several years, e.g. by EUROSTAT, to enhance data collection regarding on-flight origin/destination, i.e. flights on a single flight coupon. If the method is applied only to on-flight origin-destinations, the difference between this allocation method and allocation to the country of departure will be considerably smaller than if applied to a full journey including several flight coupons.

While collecting data on a flight-coupon basis is a complicated task in itself, extending the method to include journeys on several flight coupons including possible stopovers, will increase the complexity and difficulties considerably.

Expert sources that have been consulted for this Report ${ }^{5}$ have stated that the comprehensive flight interpretation would be virtually impossible to implement due to the difficulty of clearly defining and delineating what constitutes one journey and the very complex data recording and tracking systems.

It is likely that both airlines and Parties would object to this method due to the high data demands. The costs and administrative burden would have to be weighed against the benefits. The main benefit compared appears to be that less emissions are allocated to transit airports under this option, which is perceived by some as a more fair outcome. As stated in the previous Section, Norway finds that this allocation method would be "difficult or inaccurate to implement on the basis of existing data".

\footnotetext{
${ }^{5}$ Pers. comm.., Henrik Gravesen, Danish CAA,
} 


\section{Qualitative assessment of allocation method 1: No allocation to Parties}

\subsection{Background and interpretation}

As explained in Part I of the present Report, the possible decision not to allocate emissions to individual countries should be seen in the context of considerations about establishing a system under ICAO to ensure emissions reductions and limitations.

For several years - and encouraged by successive meetings related to the UNFCCC and the Kyoto Protocol, ICAO has been addressing options for emissions limitations.

Among the measures considered are:

- Technology and standards

- Operational measures

- Market-based measures:

- Emissions trading

- Voluntary measures

- Fuel taxes and emission-related charges or taxes

Increasingly, work in ICAO/CAEP focuses on an open international emissions trading system in which airlines trade emissions among themselves while at the same time opening the system toward purchases of emission credits from other industries. An emissions trading system is seen as a cost-effective measure to limit or reduce aviation $\mathrm{CO} 2$ in the long term. The International Air Transport Association (IATA) also favours an open emissions trading system.

In preparation of CAEP/ 6 which is scheduled for the beginning of 2004, a number of working groups are active. Special focus is on work analyzing and discussing various design options for an emissions trading scheme. An important issue in this context is ICAO's jurisdiction and its ability to apply regulatory measures and participate in an emissions trading scheme under the Chicago Convention. The Convention can be amended, but changing the multitude of bilateral agreements that implement the Convention will be a complex task ${ }^{6}$.

In addition to the work going on within ICAO/CAEP, there is increasing awareness about the potential benefits from an emission trading scheme among the European countries. BAA, the main owner of British airports, have called for an emissions trading scheme providing access to trading with allowances from the EU emission trading scheme. During research for this Report, SAS has expressed a similar interest in exploring emissions trading at a European level, covering flights between EU countries, and potentially also including domestic flights within the EU.

\footnotetext{
${ }^{6}$ A separate issue is the Chicago Convention's ban on taxes on aviation fuel used in international flights.
} 


\subsection{Allocation should enable regulation of emissions by responsible authorities}

As explained above, non-allocation to Parties is closely linked to the alternative of regulating emissions through an international, probably ICAO-based system.

The ICAO Assembly Resolution A33-7 from October 2001 requests the council to:

"...develop as a matter of priority the guidelines for open emissions trading for international aviation focussing on establishing the structural and legal basis for aviation's participation in an open trading system, and including key elements such as reporting, monitoring, and compliance, while providing flexibility to the maximum extent possible consistent with the UNFCCC process."

To recap from Part I of the Report, the primary design issues include:

- How is an emissions limitation to be defined? Should it be "cap and trade" or in relation to an emissions baseline ${ }^{7}$

- To whom should allowances be allocated (fuel companies, airlines, or states)?

- How should allowances be distributed (through auctions or grandfathering, or combinations)?

- How should the system interact with the Kyoto Protocol? Should it be separate from KP but open to trading with credits?

- What should be the coverage of the system? Options considered include Annex I countries; Annex I countries excluding USA and Australia; Annex I countries + a number of NICs.

Secondary design issues that would also need to be considered include:

- Coverage of gases. Should other gases than $\mathrm{CO} 2$ be included? Should the radiative forcing from non-CO2 emissions and emissions at altitudes be accommodated by the system in the long run?

- Collection of data, monitoring, verification and reporting

- Liability rules

- Institutional setup

- Compliance rules

Analytical work is ongoing within ICAO/CAEP regarding various design options and their consequences. Due to the sensitivity of the issue, very little information has been made available from the ICAO Secretariat and the parties involved. The analytical work focuses on a number of possible schemes defined according to a number of key features:

- Jurisdiction

- Parties engaged

- Cap vs. credit

- Covered entities

For all of the proposed schemes, the Airlines are the covered entities who hold the allowances, trade and are held liable for remaining in compliance with the emission limitations/reductions.

- Basis for measurement

\footnotetext{
7 A target relative to an emissions baseline will typically aim at improving efficiency rather than reducing absolute emissions, e.g. through a reduction of emissions per passenger kilometre.
} 
For all of the proposed schemes, the basis for measuring emissions is the route along which the individual flight takes place.

- Geographic coverage of operations

- Distribution mechanism

The trading schemes under consideration are each characterized by their relationship with these features. The options considered are briefly presented below:

\section{ICAO Allowances System with Airlines}

\section{Jurisdiction}

Under this scheme, "ICAO receives allowances", meaning that this would be a scheme within the overall Kyoto-framework with an add-on for international aviation. Allowances are allocated to ICAO and used in a scheme where the countries ratifying the Kyoto Protocol ("Annex I minus") participate. It appears that under this scheme, ICAO would to some extent act like a "Party".

Parties engaged

Given that the system is Kyoto compatible, the parties engaged will be "Annex I minus".

Cap vs. credit

The system is cap and trade. Trading is both internally among airlines and external with other sectors through trading in AAUs/ERUs/CERs.

Geographic coverage of operations

The coverage of the scheme is limited to flights that hava "Annex I minus" countries, i.e. countries that have ratified the Kyoto Protocol, as both origin and destination.

Distribution mechanism

Allowances are distributed free of charge to airlines (grandfathering), while a portion of allowances are kept for auctioning to new entrants.

\section{Aviation Trading System with ICAO Guidance}

This scheme is identical in its basic features with the previous scheme "ICAO Allowances System with Airlines" apart from the issue of jurisdiction.

Jurisdiction

Under this scheme, "parties receive allowances". Similar to the previous scheme in that it is within the Kyoto Protocol framework, but allowances are not transferred from Parties to ICAO as operators of the ETS. Rather, ICAO's role is to facilitate and support the scheme.

\section{Parties engaged}

Given that the system is Kyoto compatible, the parties engaged will be "Annex I minus".

Cap vs. credit

The system is cap and trade. Trading is both internally among airlines and external with other sectors through trading in AAUs/ERUs/CERs.

Geographic coverage of operations

The coverage of the scheme is limited to flights that have "Annex I minus" countries as both origin and destination, i.e. the countries that have ratified the Kyoto Protocol.

Distribution mechanism 
Allowances are distributed free of charge to airlines (grandfathering), while a portion of allowances are kept for auctioning to new entrants.

\section{ICAO Cap System for Airlines}

\section{Jurisdiction}

This scheme would be ICAO-based and separate from the Kyoto Protocol while having access to purchasing credits and quotas in the form of AAUs/ERUs/CERs from the Kyoto system for use to ensure compliance under the scheme. This means that the institutional setup, decisions about base year and commitments and the management of the scheme is mainly ICAO-based.

Parties engaged

As this scheme is outside of the Kyoto Protocol framework, it has the potential to have wider coverage, either as a global system or covering "Annex I plus", which would mean the Annex I countries plus non-Annex I countries with large airlines such as Singapore, Hong Kong and Thailand.

Cap vs. credit

The system is cap and trade

Geographic coverage of operations

The geographical coverage would be routes with origin and destination in the countries that are engaged, e.g. "Annex I" or "Annex I plus".

\section{ICAO Binding Dual Target System for Airlines}

\section{Jurisdiction}

This scheme would also be ICAO-based and separate from the Kyoto Protocol, also in the sense that the airlines would not have access to buying quotas and credits from the Kyoto system.

\section{Parties engaged}

As this scheme is outside of the Kyoto Protocol framework, it has the potential to have wider coverage. Parties envisaged as participants are "Annex I plus", which would mean the Annex I countries plus non-Annex I countries with large airlines such as Singapore, Hong Kong and Thailand. The system could be open to optional inclusion of domestic emissions.

Cap vs. credit

As opposed to the other options presented so far, this scheme fundamentally differs from the others in that it does not include an absolute cap on emissions. Rather, it is a "baseline and credit" scheme, under which emissions are allowed to increase with increased activity. The constraint is relative, or efficiency-based, requiring that companies improve their performance e.g. by gradually reducing emissions per RTK. To the extent that companies overperform relative to the baseline, they are able to sell surplus credits to other airlines. The baseline is binding, meaning that failure to comply must be compensated through purchase of credits.

Geographic coverage of operations

As this scheme is outside of the Kyoto Protocol framework and furthermore is likely to be seen as less constraining on airlines, it has the potential to have wider coverage. The coverage envisaged in the analytical work under CAEP is "Annex I plus", which would 
mean the Annex I countries plus non-Annex I countries with large airlines such as Singapore, Hong Kong and Thailand.

Distribution mechanism

In a "credit and baseline" system, allowances are not distributed. Rather, a baseline for each the airline is fixed based on more or less objective criteria and negotiations with ICAO.

\section{ICAO assisted Voluntary Emissions Trading System}

\section{Jurisdiction}

This scheme is conceived as a voluntary, industry driven trading scheme. Its inclusion in the considerations by CAEP was made on the initiative of the US Government.

Parties engaged

As the scheme is voluntary, it can in principle be open to all airlines globally.

Cap vs. credit

Similar to the previous ICAO-based scheme, this is "baseline and credit" scheme, with the important feature that the baseline is non-binding, meaning that the participating airlines will not face compulsory penalty fees or other enforcement mechanisms in the case on non-compliance.

\subsection{Allocation should be in accordance with the "Polluter Pays Principle"}

The assessment of the different design options under consideration under CAEP in terms of their agreement with the PPP should consider three aspects of the schemes:

1. The parties engaged in trading

2. The geographical coverage of the schemes

3. The entities covered by the schemes

\section{Parties engaged in trading}

Although the different schemes under consideration differ in terms of coverage, the parties engaged are in most versions the Annex I countries, possibly with the exception of Annex I countries that have expressed that they will not ratify the Kyoto Protocol (USA and Australia), or with the addition of a few of the more developed non-Annex I countries with important international airlines (typically Singapore, Hong Kong and Thailand). Coverage thus is in accordance with the accepted principle of "shared but differentiated responsibilities" under the UNFCCC, putting the major burden of mitigation on the developed countries.

\section{Geographical coverage of the schemes}

Similarly, the coverage in the alternative schemes analyzed under CAEP is restricted to flights that have both origin and destination in the - typically Annex I - countries engaged in the scheme. Coverage is thus relatively restricted in that all flights between, to or from non-Annex I countries are left out.

\section{Entities covered}

The entities involved are the airlines operating the routes covered by the system. The rationale behind this is that airlines are best suited to make operational decisions that influence emissions, be it through operational procedures, procurement of planes, or purchase of credits. 
The costs of complying with the emission limitations placed on the covered airlines will be passed on to the consumers demanding air transport on the routes covered by the scheme, and thus an emissions trading scheme would be in accordance with the PPP.

\subsection{Allocation should lead to minimum trade distortion among companies}

To the extent that all airlines flying on a given route are covered by the scheme, emissions trading can ensure that marginal abatements costs are equalized across companies in different countries. Emissions trading can thus be superior to other regulatory regimes when it comes to avoiding distortions that may result from different regulation of the industry in different countries. If regulation is left to the individual national governments, these may choose to protect the sector against the effects of international competition by shifting part of the burden of mitigating emissions to other sectors that are less exposed to international competition.

An important issue in avoiding trade distortions is that all airlines operating on a given route are covered by the scheme. It is not clear from the limited information available how this is handled under the schemes. In principle, airlines from non-Annex I countries should be included to the extent that they fly on covered routes. If routes covered are restricted to those that have both origin and destination in Annex I countries, there will only be very limited traffic by non-Annex I airlines (although this may change in future). If coverage is extended to flights between Annex I and non-Annex I countries, inclusion of non-Annex I airlines will be indispensable in order to avoid distortions and ensure support for the scheme.

Although an ETS can help to ensure that companies are treated equally, distortions of competition may arise from details regarding design of the scheme. The way initial allocations of emission allowances are made will not influence the marginal abatement costs of the airlines, but since allowances have a market value, generous allocations can effectively constitute a subsidy of the sector or of individual companies.

\subsection{Allocation should reflect that only Annex I countries have Kyoto commitments}

This issue is addressed in the Section above on the polluter pays principle.

As explained above, the different schemes vary in terms of country participation. Options 1 and 2 are both directly Kyoto-compatible, which may have the disadvantage of restricting participation to countries that are Annex I and have ratified/will ratify the Kyoto Protocol (Annex I minus).

Option 3 is ICAO-based and independent from the Kyoto Protocol, but with linkage to trading with the Kyoto mechanisms. Such a scheme has the advantage of being more flexible toward participation of more non-Kyoto countries, whether Annex I or not. It should be noted that it is an open issue whether the major part of the legal framework for such a scheme should be established under the UNFCCC or under ICAO. In any event, the Parties to the Kyoto Protocol would have to agree upon the conditions for linking the two schemes and allowing international aviation to access the Kyoto market for AAUs/ERUs/CERs. 
An important issue is whether emissions from flights between Annex I and non-Annex I countries are included or not. Excluding them would significantly reduce the coverage and thus the environmental effectiveness of the scheme. On the other hand, the inclusion of these emissions may cause opposition from non-Annex I countries. One option could be to somehow compensate the developing countries for economic losses resulting from their inclusion in the scheme ${ }^{8}$.

A quantitative analysis carried out by CE Delft confirms that market-based options (taxes/charges or emissions trading) limited to traffic within and between Annex B countries, regardless of the nationality of the carrier, would avoid distorting competition without affecting developing countries negatively

\subsection{Allocation should be comprehensive in terms of relevant greenhouse gases and radiative forcing}

Emissions trading with airlines as the responsible entities is potentially well suited for gradual expansion to include non-Kyoto gases and the effects of flight altitude.

There are two reasons for this. One is that the scheme will be based on detailed flight information, to a wide extent made available by the airlines themselves. The other has to do with the fact that the airlines are the ones controlling the operational decisions on types of aircraft, flight patterns etc., that will influence the extended, non-CO2 effects of aviation.

It should be noted that in order to include emissions and effects that are not covered by the Kyoto Protocol, a legal instrument would have to be agreed as one of the following options:

- $\quad$ as an addendum to the Kyoto Protocol

- as a separate protocol under the UNFCCC

- $\quad$ as an agreement made under ICAO.

\subsection{Allocation should not encourage strategic behaviour}

The key issues influencing the scope for trade distortion and strategic behaviour have been addressed in the above. To the extent that all airlines operating on a route are covered by the scheme and face the same mitigation costs, the scope for strategic behaviour within the system will probably be limited. Should this condition not be fulfilled, if for example non-Annex I airlines are not covered by the schemes, there would be a strong incentive to act strategically to operate the routes with aircraft that are not covered by the scheme.

The fact that only part of the international routes are covered would give some incentive to adjusting route planning so as to limit the number of flights and distances flown between Annex I countries.

\footnotetext{
${ }^{8}$ Financial compensation to developing countries has also been proposed as a way of ensuring global participation in market based schemes. The recycling revenues from charges or auctioned allowances has been proposed, but the question of how to distribute revenues to national treasuries would be a controversial issue.
} 


\subsection{Allocation should be administratively feasible}

There are two main administrative issues related to setting up and managing an emissions trading scheme for international aviation.

One is the recording of activity data and the subsequent calculation and allocation of emissions. Reference is made to the earlier section on allocation based on the nationality of the airline. There it was stated that although information is currently not systematically collected with a view to assessing and allocating emissions, airlines can be expected to possess most of the required information.

In addition to this, the whole setting up of the emissions trading scheme including the legal framework; decisions on institutional responsibilities; monitoring and verification of airlines and emissions; enforcement etc. is an important challenge for which no precedent exists at the international level. The introduction of the European emissions trading scheme will provide valuable insights into the practicalities and legalities of an international emissions trading scheme, 


\section{Quantitative assessment of alternative allocation methods}

\subsection{Quantitative assessment of alternative allocation methods - approach and context}

The section aim to assess the quantitative effects of different allocation principles to the Nordic countries, i.e. how will the different principle affect the amount of $\mathrm{CO}_{2}$ emission allocated to the different countries. The quantitative assessment is subject to the available data, which is rather limited, and focus is put on two key allocation methods. These data are to the extent possible utilised also to draw conclusions on the remaining methods.

The two key allocation methods for quantitative assessment are:

- Method 2: Allocation to parties according to the country where the bunker fuel is sold

- Method 3: Allocation to parties according to the nationality of the airline

The data on emissions according to these two allocation methods only concerns $\mathrm{CO}_{2}$ emission from fuel consumption. Emissions of other GHG from aviation as well as the estimated greenhouse potential of emissions in different altitudes has not been considered.

Data on $\mathrm{CO}_{2}$ emissions according to bunker fuels for international aviation has been collected from the Nordic countries national inventories in their 3. National Communications. These data concerns $\mathrm{CO}_{2}$ emissions according to bunker fuels sold in 2001 .

Data on emissions according to the nationality of the airline has been calculated on basis of the fuel consumption of the different airline companies for international flights. Data on the fuel consumption has been collected directly from the airline companies and concerns 2002 consumption. The data have been collected under a confidentially clause and data for individual airline companies therefore can not be presented.

\subsection{Method 2: Allocation to Parties according to the country where the bunker fuel is sold}

This allocation method is based on recalculation of the bunker fuels sold into $\mathrm{CO}_{2}$ emission, using a set of emission factors. This method basically comply with the reporting format under the Climate Convention and national data therefore can be provided from the national inventories.

As presented earlier the key problem related to data in this case regards the distribution of bunker fuel in each country between sales for domestic aviation, which is covered by the Kyoto Protocol, and bunker fuel sales for international aviation. The $\mathrm{CO}_{2}$ emissions have been calculated by the individual Nordic countries on basis of the fuel sales, and therefore the emission factors used for recalculation of fuel into $\mathrm{CO}_{2}$ emission may differ slightly between countries. This is however assumed to be of little importance. 
Table 9.1 Allocation according to aviation bunker fuel sales. Emission of $\mathrm{CO}_{2}$ in 1000 tonnes in 2001

\begin{tabular}{|l|c|c|c|c|}
\hline & International & Domestic & $\begin{array}{l}\text { Aviation in } \\
\text { total }\end{array}$ & $\begin{array}{l}\text { Total national } \\
\text { emission 2001 } \\
\left(\mathrm{CO}_{2} \text { eqvivalents }\right)\end{array}$ \\
\hline Denmark & 2,378 & 168 & 2,546 & 65,879 \\
\hline Finland & 1,054 & 360 & 1,414 & 64,037 \\
\hline Iceland & 349 & 24 & 374 & 2,522 \\
\hline Sweden & 1,871 & 625 & 2,496 & 37,402 \\
\hline Norway & 835 & 1,062 & 1,898 & 37,265 \\
\hline Total & 6,487 & 2,241 & 8,728 & 207,104 \\
\hline
\end{tabular}

Source: 3. National Inventory Reports 2003 from each country: tables 1.A(a)s3, 1.C and Summary 2 The data on bunker fuel sales for international flights does not provide information about the destination of the flights. This means that the emissions can not be split and allocated according to destination of the flights, e.g. emissions related to flights to Annex 1 countries and flights to Non-annex 1 countries.

\subsection{Method 3: Allocation to Parties according to the nationality of the airline}

This allocation method include mission of $\mathrm{CO}_{2}$ according to the fuel consumption for international flights by airline companies registered in the Nordic countries.

Information about fuel consumption has been collected from all major airline companies in the Nordic countries with international flights. The following airline companies have been approached:

Table 9.2 Major airline companies with international flights in the Nordic countries that has been approached.

\begin{tabular}{|l|l|}
\hline Airline company & Has supplied data \\
\hline Denmark: & X \\
SAS & $\mathrm{x}$ \\
Cimber Air & $\mathrm{x}$ \\
Danish Air Transport Aps & $\mathrm{x}$ \\
Maersk Air & $\mathrm{x}$ \\
Star Air & $\mathrm{x}$ \\
My Travel & $\mathrm{x}$ \\
Sterling European & $\mathrm{x}$ \\
Sun Air & $\mathrm{x}$ \\
Aviation Assistance & \\
Atlantic Airways, Faeroe Islands & \\
\hline Finland: & $\mathrm{x}$ \\
Finnair, Finnair Cargo & $\mathrm{x}$ \\
Blue 1/Air Botnia Oy &
\end{tabular}




\begin{tabular}{|l|l|}
\hline Flying Finn Oy & \\
\hline Iceland: & $\mathrm{x}$ \\
Icelandair, Icelandair Cargo, Loftleidir & Only flight leasing \\
Air Atlanta & $\mathrm{x}$ \\
Bluebird Cargo & \\
Iceland Express & \\
\hline Sweden: & $\mathrm{x}$ \\
SAS & $\mathrm{x}$ \\
Britannia Airways AB & $\mathrm{x}$ \\
City Airline & \\
Skyways & $\mathrm{x}$ \\
Novair & $\mathrm{x}$ \\
Malmö Aviation & Only domestic flights \\
Falcon Air & $\mathrm{x}$ \\
West Air Sweden & $\mathrm{x}$ \\
\hline Norway: & $\mathrm{x}$ \\
SAS & $\mathrm{x}$ \\
Widerøe & $\mathrm{x}$ \\
Braathens & \\
Norwegian Air Shuttle & \\
\hline
\end{tabular}

The fuel consumed for international aviation by the listed airline companies cover the vast majority of total fuel consumption for international aviation in airline companies in the Nordic countries.

The $\mathrm{CO}_{2}$ emission from the international flights from the Nordic airline companies has been calculated on basis of the following emission factors:

Table $9.3 \mathrm{CO}_{2}$ emission factors

\begin{tabular}{|c|c|}
\hline Tonnes $\mathrm{CO}_{2} /$ tonne jet fuel & $\begin{array}{l}\text { Tonnes } \mathrm{CO}_{2} / 1,000 \text { Litres jet } \\
\text { fuel }\end{array}$ \\
\hline 3.156 & 2.525 \\
\hline
\end{tabular}

Among the airline companies approached information about fuel consumption for international aviation has been provided by most companies, including the larger companies, ensuring reliable data.

The joint ownership of SAS in Sweden, Norway and Denmark raise difficulties with regards to allocating the airline company's $\mathrm{CO}_{2}$ emission between the three countries. The company is a major player in the aviation sector of the Nordic countries and the allocation of its emissions obviously affects the total allocation on the three countries.

The allocation principle is the nationality of the airline, rather than where the activities take place. The ownership of SAS is shared between the countries, in that Sweden owns $3 / 7$, Norway $2 / 7$ and Denmark 2/7 of the company. This distribution key provides the best indicator for the distribution of the airline company on the three countries, i.e. the 
nationality of the airline. If SAS emission was to be allocated according to the place of activity this would in reality mean to the country where the bunkering took place, and thus mixing this method with method 2.

Consequently the $\mathrm{CO}_{2}$ emission from SAS' international flights is distributed between the three countries according to their share of the company as a proxy for the nationality of the company.

Information about the $\mathrm{CO}_{2}$ emission from the airline companies is split according to geography, referring to the different countries status in the Kyoto Protocol, that is flights to and from:

- Annex I countries that have ratified the Kyoto Protocol. This is defined as Annex I countries minus USA and Australia, i.e. Europe, Canada and Japan (Russia and Ukraine are assumed to ratify the Protocol)

- Annex I countries

- Non-annex I countries, defined as the rest of the world.

Table 9.4 Allocation according to fuel for international flights by airline companies in the Nordic countries. Emission of $\mathrm{CO}_{2}$ in 1000 tonnes in 2002

\begin{tabular}{|l|c|c|c|c|}
\hline & $\begin{array}{c}\text { To and from } \\
\text { annex 1 } \\
\text { Countries } \\
\text { minus USA }\end{array}$ & $\begin{array}{c}\text { To and from } \\
\text { annex 1 } \\
\text { Countries } \\
\text { including } \\
\text { USA }\end{array}$ & $\begin{array}{c}\text { To and from } \\
\text { Non-annex 1 } \\
\text { countries } \\
\text { (rest of world) }\end{array}$ & $\begin{array}{c}\text { International } \\
\text { aviation in } \\
\text { total }\end{array}$ \\
\hline Denmark & 1,671 & 1,876 & 223 & 2,100 \\
\hline Finland & 1,067 & 1,183 & 452 & 1,635 \\
\hline Iceland & 172 & 353 & 131 & 484 \\
\hline Sweden & 1,347 & 1,654 & 211 & 1,865 \\
\hline Norway & 564 & 769 & 96 & 865 \\
\hline Total & 4,821 & 5,834 & 1,114 & 6,948 \\
In percent & $69 \%$ & $84 \%$ & $16 \%$ & $100 \%$ \\
\hline
\end{tabular}

It should be noted that the numbers for each country are not complete, meaning that the table slightly underestimate the emissions from the airline companies in the Nordic countries. In total however the deficit is limited only to few percentage.

The table shows that the geographical coverage of an allocation scheme based on airline companies affects the allocated amounts significantly. If the scheme include only flights between those Annex 1 countries that has ratified the Kyoto Protocol (i.e. Annex $1 \mathrm{mi}$ nus USA in the table) nearly $70 \%$ of the total international $\mathrm{CO}_{2}$ emission of the Nordic airline companies will be included in the scheme, whereas $84 \%$ will be included if the coverage is extended to include flights to all Annex 1 countries (i.e. including USA). $16 \%$ of the emissions originate from flights to Non-Annex 1 countries.

The importance of the geographical coverage differs between the Nordic countries. Flights to Annex 1 countries minus USA are relatively more important to Danish and Finnish airline companies, whereas flights to USA has a higher weight for particularly Iceland and Norway, but also Sweden. The importance of flights outside Annex II countries also differs, in that more than $25 \%$ the total emission from Finnish and Icelandic 
airlines originates from these destinations, whereas the share is less than half for the other Nordic countries.

\subsection{Other allocation Methods}

The other allocation methods have not been evaluated quantitatively for the Nordic countries, but in this section similarities and differences to the Methods 2 and 3 above is commented.

\subsubsection{National allocation Methods 4 and 5}

The results for Method 4 (Allocation according to country of aircraft departure/ destination) are expected to differ only little to those of option 2 (based on bunker fuel sales). Differences could origin from slight differences in average flight length (and associated emissions) of departing versus arriving flights in any given country and from tankering. A Dutch analysis ${ }^{9}$ on the AERO model support this assessment, though it should be noted that the AERO model excludes tankering, which means that a potential source of differences between Method 2 and Methods 4 and 5 is not taken into account. Besides tankering it is fair to conclude that Method 4 would provide allocation very similar to Method 2.

Method 5 (Allocation to Parties according to the country of destination or departure of passengers and cargo) is complicated data-wise, particularly if data should be collected tracking passengers and freight beyond individual flights and include stopovers and transfer to other flights. If the method is given a simpler interpretation to include onflight origin-destination, including brief stopovers, this will ease data collection and make the method more realistic. In this case the allocation is likely to be fairly close to the allocation according to Method 2 (according to the country where the bunker fuel is sold). Calculation on the AERO model generally supports this assessment

\subsubsection{Method 1: No allocation to Parties}

The data collected for Method 3 reveals the $\mathrm{CO}_{2}$ emission from the Nordic airline companies. However the data is provided under a confidentiality clause and it is therefore not possible to provide the data on company level. However the data provided can be used to illustrate the importance of the geographical coverage of a scheme, that is the bearing of the coverage on the allocation to the airline industry in the Nordic countries in total.

\footnotetext{
${ }^{9}$ Velzen 2000
} 
Table 9.5 Allocation to Nordic airline companies according to geographical coverage. Emission of $\mathrm{CO}_{2}$ in 1000 tonnes in $2002^{l}$

\begin{tabular}{|c|c|c|c|}
\hline $\begin{array}{l}\text { Annex I - } \\
\text { USA }\end{array}$ & Annex I & $\begin{array}{l}\text { Total Interna- } \\
\text { tional }\end{array}$ & $\begin{array}{l}\text { International } \\
\text { and domestic }\end{array}$ \\
\hline 4,821 & 5,834 & 6,948 & 9,189 \\
\hline
\end{tabular}

1: Domestic in 2001, based on bunker fuel sales for domestic aviation, table 9.1

\subsection{Comparison of allocation methods}

Below, in Figure 9.1 an overview of the allocation and its dependence on Methods 2 and 3 and the geographical coverage of Method 3 is presented.

It should be noted that data on bunker fuel is for 2001 whereas data for emissions according to nationality of airline is for 2002. Changes in aviation activity between 2001 and 2002, including the effects of September 11 on the aviation industry, may therefore cause a slight inconsistency when comparing between the two years.

Figure 9.1 Allocation according to Method 2 and 3, and according to geographical coverage

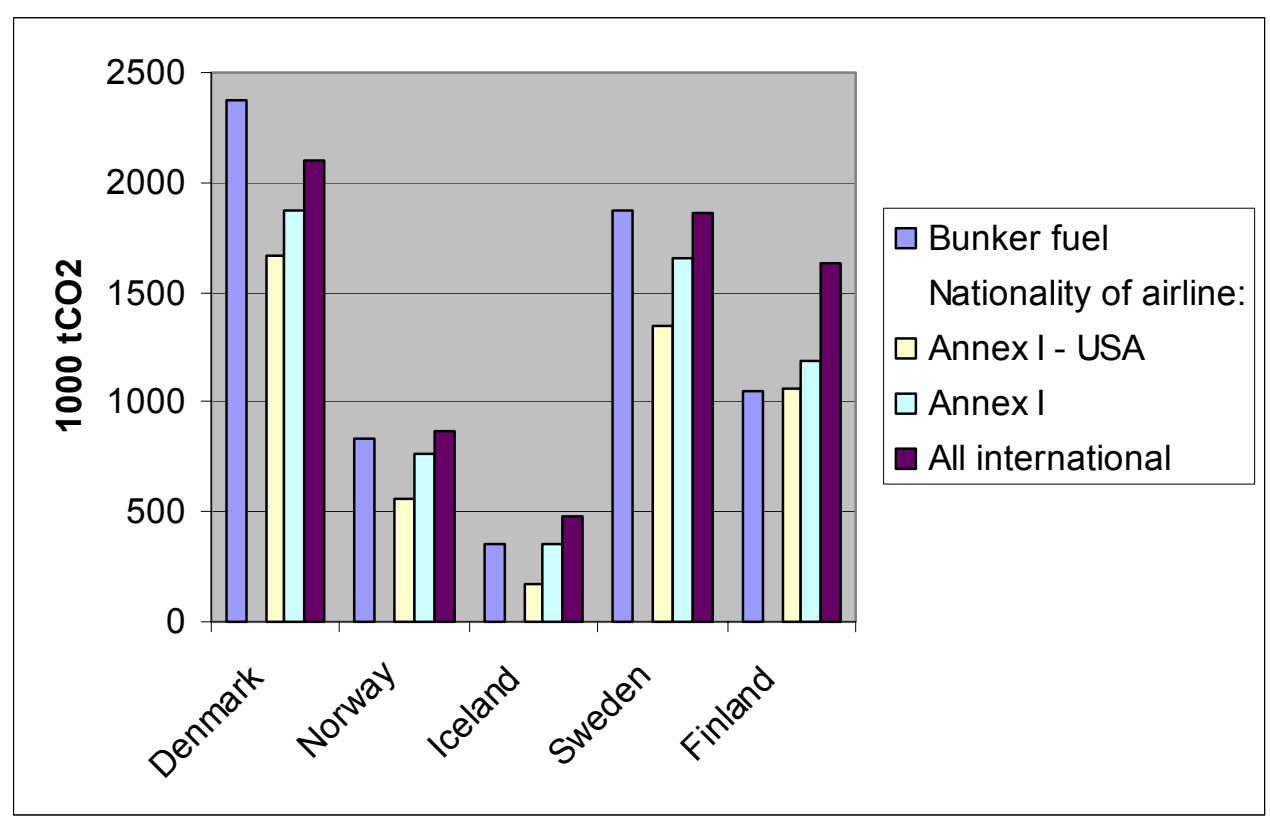

Allocation methods 2 and 3 allocates fairly close to the same amount of $\mathrm{CO}_{2}$ to the Nordic countries in total when the allocation is based on covering all international flights, namely 6.5 - 6.9 million $\mathrm{tCO}_{2}$. However the distribution of these emissions between the Nordic countries differs according to methods.

Under the Bunker fuel allocation method (Method 2) countries with a relatively welldeveloped aviation industry (in terms of number of departing flights) will be allocated a relatively large share of international aviation emissions. This effect can be seen for Denmark, which host a relatively large airport in Kastrup which serve as a hub and therefore attracts transit flights. Due to the larger number of departing flights fuel bunkering is high. Demark therefore is allocated a larger amount of $\mathrm{CO}_{2}$ when using this method than if the nationality of the airline (Method 3 ) is used as allocation method. 
The situation in Finland and Iceland is the opposite of that of Denmark. Finland and Iceland have relatively large airline industries, particularly Finnair and Icelandair, whereas the national airports does not work as a larger hub. Therefore the allocation to Finland and Iceland is larger when allocating according to the nationality of the airline than when allocating according to the fuel bunkering.

Norway and Sweden are less sensitive to the allocation method as long as the same geographical coverage is in place. 


\section{Perspectives for future work}

\subsection{Emissions trading from a Nordic perspective}

Emissions trading is the focus of increasing attention, not only within ICAO, but also at the European level.

As mentioned in the Report, parts of the industry are actively promoting the development of an emissions trading scheme that provides access to allowances from the EU emission trading scheme as an alternative to charges and taxes.

SAS has expressed a similar preference for emissions trading at a European level and have expressed an interest in contributing to analyses of possible design options and their consequences for Nordic aviation.

An assessment could analyse emissions trading from a Nordic perspective, i.e. focusing on the consequences for airlines from the Nordic countries and for the Nordic countries in general. Among the key issues that it would relevant to address are the following:

- Overall Jurisdiction (ICAO, Kyoto, or a separate protocol under UNFCCC)

- Parties engaged (Annex I, Annex I plus/minus, global)

- Cap vs. credit

- Geographic coverage of operations

- Distribution mechanism

- $\quad$ Linkages to the EU ETS

- Legal issues in relation to UNFCCC/Kyoto and Chicago Convention.

- Macro- and sectoral economic consequences.

- The inclusion of non-Kyoto gases and effects

\subsection{EU regulation from a Nordic perspective}

Independent of the outcome of ICAO and UNFCCC/Kyoto negotiations, the EU may decide to unilaterally pursue regulation of the European aviation industry. As noted above, emissions trading is receiving increasing attention as a potential regulation mechanism in Europe.

Analysing the possible design options for an EU-driven emissions trading scheme and the impacts on the Nordic countries and aviation industry could be an important endeavour, which would also enable the Nordic countries to play a proactive role in the political and technical process of designing such a scheme.

Emissions trading is not the only regulation option under consideration within the EU context. A comparative analysis from a Nordic perspective of the different regulation options considered within the EU could provide important input to the process of designing and discussing regulation at the EU level. 


\section{Literature}

CORINAIR 2002, "EMEP CORINAIR Emission Inventory Guidebook - 3rd edition October 2002 UPDATE", European Environment Agency, Copenhagen.

Davidson, Marc D. and R.C. Wit 2002, "Aviation and Climate Change - Search for effective global market-based options that secure interests of developing countries"

ECON 2003, "GHG Emissions from International Shipping and Aviation", Swedish Environmental Protection Agency.

EU 2001, Council Conclusions on Preparation of CoP7 in Marrakesh from 29 October to 9 November (29 October; article 5).

European Civil Aviation Conference 2003, "Summaries of discussions and decisions of the five CAEP meetings of the Steering Group in Orlando", presented at sixty-first meeting of the Group of Experts on the Abatement of Nuisances Caused by Air Transport

Finstad, Anne et al. 2002, "Emissions to Air from Norwegian Air Traffic". Report SN 2002 Utslipp til luft fra norsk luftfart 1989-2000 (Emissions to Air from Norwegian Air Traffic 1989-2000). Anne Finstad, Ketil Flugsrud og Kristin Rypdal. SN-report 2002:08.

IATA 2001, "Emissions trading for aviation", Workstream 3: Key findings and conclusions, Arthur Andersen 2001.

ICAO 2001, "A33-7 Consolidated statement of continuing ICAO policies and practices related to environmental protection", Resolution adopted at the 33rd Session of the ICAO Assembly, International Civil Aviation Organisation, Montreal, October 2001.

IPCC 1996, "Revised 1996 IPCC Guidelines for National Greenhouse Gas Inventories: Reference Manual"

IPCC 1999, "Aviation and the global atmosphere", Intergovernmental Panel on Climate Change, Cambridge University Press, UK

IPCC 2000, "Good Practice Guidance and Uncertainty Management in National Greenhouse Gas Inventories", Intergovernmental Panel on Climate Change, National Greenhouse Gas Inventories Programme, Technical Support Unit

Ministry of Environment, Denmark, 2003, "Denmark’s National Inventory Report"

Ministry of Environment, Finland, 2003, "National Inventory Report"

Ministry of Environment, Norway, 2003, "Denmark’s National Inventory Report"

Ministry of Environment, Sweden, 2003, "Sweden's National Inventory Report"

Nielsen, Stefan Krüger 2003a, "Greenhouse gas emissions from international aviation and allocation options", Environmental Project No. 769 2003, Danish Environmental Protection Agency

Nielsen, Stefan Krüger 2003b, "Short summary of responses by EU Member States and the European Commission to the PAM questionnaire", Report for EU Climate Change Experts Meeting May 2003

UK Department for Transport, 2003, "Aviation and the Environment - Using Economic Instruments", Department for Transport 
UNFCCC 1999a, "Methods used to Collect Data, Estimate and Report Emissions from International Bunker Fuels", draft report prepared for the UNFCCC secretariat by Det Norske Veritas (DNV)

UNFCCC 1999b, "Methodological issues - Emissions resulting from fuel used for international transportation”, FCCC/SBSTA/1999/INF.4, United Nations Framework Convention on Climate Change

UNFCCC 1999c, "Methodological issues - Emissions resulting from fuel used for international transportation - ways to strengthen the exchange of information between the International Civil Aviation Organisation, the International Maritime Organisation and UNFCCC”, FCCC/SBSTA/1999/INF.9, United Nations Framework Convention on Climate Change

UNFCCC 1999d, "Methodological issues - Emissions resulting from fuel used for international transportation - submissions from parties", FCCC/SBSTA/1999/MISC.8, United Nations Framework Convention on Climate Change

UNFCCC 2001, "Methodological issues - Ongoing Activities on Reporting and Review of Greenhouse Gas Inventories in Parties Included in Annex I to the Convention - Report on the use of the UNFCCC reporting guidelines on annual inventories - note by the secretariat", FCCC/SBSTA/2001/5, United Nations Framework Convention on Climate Change

UNFCCC 2002, "Synthesis and Assessment Report on the Greenhouse Gas Inventories Submitted in 2001 - Note by the secretariat", FCCC/WEB/SAI/2001, United Nations Framework Convention on Climate Change

UNFCCC 2003, "Methodological issues. Emissions resulting from fuel used in international aviation and maritime transportation", Note by the secretariat

FCCC/SBSTA/2003/INF.3, United Nations Framework Convention on Climate Change Velzen, A. and R.C.N. Wit 2000, "National allocation of international aviation and marine CO2-emissions - A study commissioned by the Dutch Civil Aviation Authority", Centre for energy conservation and environmental technology (CE), Delft, the Netherlands.

Winther, M. 2001, "1998 fuel use and emissions for Danish IFR Flights”, Environmental Project No. 628, Danish Environmental Protection Agency, Copenhagen. 
Obtain your Nord and TemaNord reports from:

\author{
BELGIUM \& LUXEMBOURG \\ Jean de Lannoy \\ Avenue du Roi, 202, 1190 Brussels \\ Tel +32 (0)25385169 \\ Fax +32 (0)2538 0841 \\ jean.de.lannoy@euronet.be
}

\section{CANADA}

Renouf Publishing Company Ltd

5369 Canotek Road, Ottawa,

Ontario K1J 9J3

Tel + 1 (613) 7452665

$\mathrm{Fax}+1$ (613) 7457660

order.dept@renoufbooks.com

www.renoufbooks.com

\section{CHINA}

CNPIEC

Europe Division 16 Gongti East Road,

P.O. Box 88, Beijing

Tel +86105066 688-8

Fax +86 105063101

\section{DENMARK}

Svensk-Norsk Bogimport A/S

Esplanaden 8 B, 1263 København K

Tel +4533142666 Fax +4533143588

snb@bog.dk

www.snbog.dk

\section{ESTONIA}

Astro Raamatud AS

Pärnu mnt 142, 11317 Tallinn

Tel +372 6548485 Fax +3726548475

book@astro.ee

\section{FAROE ISLANDS}

H.N. Jacobsens Bókahandil

Postboks 55, 110 Tórshavn

Tel +298 311036 Fax +2983178 73

hnj@hnj.fo

www.hnj.fo

\section{FINLAND}

Akademiska Bokhandeln

PB 128, Centralgatan 1,

00101 Helsingfors

Tel +358 912141

akatilaus@akateeminen.com

www.akateeminen.com

\section{FRANCE}

Librairie LAVOISIER

14 , rue de Provigny,

94236 Cachan Cedex

Tel +33 (1) 47406700

Fax +33 (1) 47406702

group@lavoisier.fr

www.lavoisier.fr

\section{GERMANY}

UNO-Verlag GmbH

Am Hofgarten 10, 53113 Bonn

Tel +49 (0)228949020

$\mathrm{Fax}+49$ (0)228 9490222

info@uno-verlag.de

www.uno-verlag.de

\section{HUNGARY}

Euro Info Service

PO Box 1039, 1245 Budapest

Tel +36 (1) 3292487

Fax +36 (1) 3492053

euroinfo@euroinfo.hu

\section{ICELAND}

Mál og Menning

Laugavegi 18, 101 Reykjavik

Tel +354 (9)5152500

Fax +354 (9)515 2505

verslun@mm.is

\section{LATVIA}

Jana Rozes Gramàtnica

Kr. Barona iela 5, 1011 Riga

$\mathrm{Tel}+371(0) 2284288$

Fax +3717370922

\section{LITHUANIA}

Penki Kontinentai

A. Stulginskio 5, 2001 Vilnius

Tel +370 (5) 2664540

Fax +370 (5) 2664565

books@5ci.lt

www.books.lt

\section{NORWAY}

Akademika A/S

Postboks 84 Blindern, 0314 Oslo

Tel +4722853030 Fax +4722 853080

bloken@sio.uio.no

www.akademika.no

\section{ROMANIA}

Euromedia s.r.I.

Str Dionisie Lupu nr 65, 70184 Bucuresti

Tel + 4016140664

$\mathrm{Fax}+4013129646$

\section{SWEDEN}

Fritzes

Kundservice, 10647 Stockholm

Tel +46 (0)8 6909190

$\mathrm{Fax}+46(0) 86909191$

order.fritzes@nj.se

www.fritzes.se
THE NETHERLANDS

De Lindeboom Internationale Publicaties

M.A. de Ruyterstraat $20 \mathrm{~A}$,

NL-7482 BZ Haaksbergen

Tel +31 (0)53 5740004,

Fax +31 (0)535729296

books@delindeboom.com

www.delindeboom.com

\section{UNITED KINGDOM}

The Stationery Office

P.O. Box 276, London SW8 5DT

Tel +448706005522

Fax +44 8706005533

customer.services@tso.co.uk www.tso.co.uk/bookshop

USA

Bernan

4611-F Assembly Drive,

Lanham MD 20706-4391

Tel +1 (301) 4597666

Fax +1 (301) 4590056

query@bernan.com

www.bernan.com

\section{ÅLAND}

Lisco bok- och pappershandel

Skarpansvägen 25, Box 8 ,

22101 Mariehamn

Tel +358 (0)1817 177

Fax +358 (0)18 19771

info@lisco.fi 